$$
\text { DOE/CH/10324- T/8 }
$$

\title{
Spent Fuel and High-Level Radioactive Waste Transportation Report
}

November 1990

Prepared for the U.S. Department of Energy

Under Cooperative Agreement

DE-FCO2-87CH10324

by the

Southern States Energy Board

3091 Governors Lakes Drive, Suite 400

Norcross, Georgia 30071

(404) 242-7712 


\section{Note:}

This report has been prepared for the U.S. Department of Energy by the Southern States Energy Board under Cooperative Agreement DE-FC02$87 \mathrm{CH} 10324$. First released in November 1989, this report is updated annually and updates are released at the end of the calendar year and sent to parties on the Board's mailing list for high-level radioactive waste publications. If you read this report and it is later than January 1992, please contact Messrs. Mike Martinez or Alex Thrower at (404) 242-7712 to receive an update.

This report was prepared as an account of work sponsored by an agency of the United States Government. Neither the United States nor any agency thereof, nor any of their employees, nor any of their contractors, subcontractors, or their employees, makes any warranty, expressed or implied, or assumes any legal liability or responsibility for the accuracy, completeness, or usefulness of any information, apparatus, product, or process disclosed, or represents that its use would not infringe any privately owned right. Reference herein to any specific commercial product, process, or service by trade name, trademark, manufacturer, or otherwise, does not necessarify constitute or imply its endorsement, recommendation, or favor by the United States Government or any agency thereof. The view and opinions of authors expressed herein do not necessarily state or reflect those of the United States Government or any agency thereof.

The Southern States Energy Board (SSEB) is a public, non-profit organization created by an interstate compact. The States of Alabama, Arkansas, Florida, Georgia, Kentucky, Louisiana, Maryland, Mississippi, Missouri, North Carolina, Oklahoma, South Carolina, Tennessee, Texas, Virginia, West Virginia and the Commonwealth of Puerto Rico are members of the Board. The activities of the Board are funded by state support payments by the member states.

For more than two decades, the Southern States Energy Board has served the South with research, technical staff support, policy development and information services. SSEB's purpose is to improve the economy of the South and to contribute to the individual and community well-being of the people of the southern region. The Board assists its members in the creation of programs in energy, science and technology, environment and related areas of interest. SSEB provides a scientific and technical expertise on energy and environmental quality matters of state officials and the general public. 


\section{ABOUT SSEB}

In 1990 the Southern States Energy Board celebrates its 30th year of service to the southern region of the United States. SSEB, a public non-profit interstate compact agency, comprises 16 southern and border states and the commonwealth of Puerto Rico. The Board provides technical staff support, policy and program development and implementation and information services encompassing all areas of energy and environmental quality.

The states of Alabama, Arkansas, Florida, Georgia, Kentucky, Louisiana, Maryland, Mississippi, Missouri, North Carolina, Oklahoma, South Carolina, Tennessee, Texas, Virginia, West Virginia and the commonwealth of Puerto Rico are members of the Board. Any state contiguous to a member state is also eligible for membership in the Southern States Energy Compact.

Each member state is represented on the Board by three members, the governor and a legislator from both the state House and Senate. A federal representative is appointed by the President of the United States.

Created by state law and with the consent of Congress, SSEB has been granted a broad mandate to contribute to the economic and community well-being of the citizens of the southern region. This mandate is exercised through the creation of programs in the fields of energy, science and technology, environmental quality and related areas of concern. SSEB serves its members directly by providing timely assistance designed to lead to the development of effective energy and environmental policies.

The Board provides policy-making support and technical expertise on energy and environmental quality matters to government, industry and the general public. SSEB represents its members before governmental agencies at all levels and maintains a continuing liaison with other regional and national organizations.

In establishing SSEB more than a quarter of a century ago, the southern states recognized that the development of energy and environmental resources was and would continue to be a crucial factor in the attainment of a balanced and thriving economy. The founding states believed that the optimum benefits to be derived from energy use and management of the environment transcend state lines and require mutual cooperation. SSEB originated as the instrument for implementing this policy. 


\section{PREFACE}

This publication is intended to provide its readers with an introduction to the issues surrounding the subject of transportation of spent nuclear fuel and high-level radioactive waste, especially as those issues impact the southern region of the United States. It was originally issued by SSEB in July 1987 as the Spent Nuclear Fuel and High-Level Radioactive Waste Transportation Primer, a document patterned on work performed by the Western Interstate Energy Board and designed as a "comprehensive overview of the issues." This work differs from that earlier effort in that it is designed for the educated layman with little or no background in nuclear waste issues. In addition, this document is not a comprehensive examination of nuclear waste issues but should instead serve as a general introduction to the subject.

Owing to changes in the nuclear waste management system, program activities by the U.S. Department of Energy and other federal agencies and developing technologies, much of this information is dated quickly. While this report uses the most recent data available, readers should keep in mind that some of the material is subject to rapid change. SSEB plans periodic updates in the future to account for changes in the program. Replacement pages will be supplied to all parties in receipt of this publication provided they remain on the SSEB mailing list.

Spent Fuel and High-Level Radioactive Waste Transportation Report was prepared pursuant to Cooperative Agreement DE-FC02-87CH10324 between the U.S. Department of Energy and the Southern States Energy Board. The cooperative agreement directs SSEB to work with DOE's Office of Civilian Radioactive Waste Management, specifically the Chicago Operations Office, in exploring issues associated with the transportation of commercial spent nuclear fuel and high-level radioactive waste under provisions of the Nuclear Waste Policy Act of 1982 and the act's 1987 amendments. The nature of this work has been to assess the impact of these issues on the southern states and to identify and resolve transportation concerns, thus fostering a better public understanding of federal transportation activities. Presumably, this report will also advance public understanding of nuclear waste issues. 


\section{EXECUTIVE SUMMARY}

The United States has generated over 20,000 metric tons of uranium (MTU) spent nuclear fuel since the 1950 s, when the civilian nuclear industry was in its infancy. Since nuclear power has been, and continues to be, a significant energy source in this country, the problem of efficient, cost-effective and, above all, safe disposal of nuclear wastes is an issue that must be addressed. In particular, the transportation of nuclear wastes poses a number of questions that must be answered before waste can be adequately handled, transported or disposed of in a geologic repository.

In passing the Nuclear Waste Policy Act (NWPA) and the act's 1987 amendments (NWPAA), Congress sought to address definitively the problems of nuclear waste disposal. The NWPA and the NWPAA, administered by several federal agencies, including the U.S. Department of Energy (DOE), the Nuclear Regulatory Commission (NRC), the U.S. Department of Transportation (DOT), the Federal Emergency Management Agency (FEMA) and the Interstate Commerce Commission (ICC), provide for the development and construction of a geologic repository to dispose of wastes permanently. The NWPA and the NWPAA also contain provisions for the possible development of a monitored retrievable storage (MRS) facility for temporary storage of nuclear wastes.

The Office of Civilian Radioactive Waste Management (OCRWM) was created within DOE to oversee the geologic repository program for the disposal of civilian radioactive wastes. Within OCRWM, the Office of Systems Integration and Regulations (OSIR) establishes policies and procedures for implementing the transportation program and coordinates activities among ard between DOE, other federal agencies and states, local governments and Indian tribes. Several "operations offices" handle specific aspects of the program. The Chicago Operations Office, located in Argonne, Illinois, serves as the lead field office for institutional activities and transportation, economic and systems analyses, development of a Transportation Operations System and systems integration work for transportation. The Idaho Operations Office in Iclaho Falls, Idaho, is responsible for transportation program technology developments such as the design, fabrication and testing of prototype casks for shippirgg wastes. Oak Ridge National Laboratory in Oak Ridge. Tennessee, is operated in large part by a DOE contractor working with the department on the development and implementation of a transportation operations system. 
These offices and others within the federal government provide for government and public input and participation within the nuclear waste management system. For example, states, local governments and Indian tribes participate in the program through a series of discussions and meetings highlighting program goals and accomplishments. As DOE and other agencies meet major milestones, they brief Congress, state, tribal and local leaders on the status of the program. In addition, periodic regular meetings and workshops are held so that parties affected by the program will be educated about nuclear waste management. Publications such as the OCRWM Bulletin provide public information on program activities.

A number of rules and regulations have been promulgated concerning shipments and routing of spent fuel and high-level waste and these rules are administered by the agencies mentioned above. DOE is required by the NWPA to take title to, transport and dispose of commercially generated high-level waste, i.e., highly radioactive material containing fission products, traces of uranium and plutonium and other transuranic, or heavier than uranium, elements resulting from the chemical reprocessing of spent nuclear fuel. The NRC, meanwhile, is charged with responsibility for safety regulations, safeguard regulations and advance notification to state governors prior to shipments of spent fuel and other nuclear waste. The NRC maintains an active enforcement and inspection program. DOT, on the other hand, regulates the transportation of hazardous materials, including radioactive materials, in interstate commerce by land, air and on navigable waters. FEMA is responsible for establishing federal policies for, and coordinating, all civil emergency planning, management, mitigation and assistance functions of federal executive agencies. The Interstate Commerce Commission regulates the economic aspects of radioactive materials transportation for land shipments by, among other things, overseeing shipping costs.

As part of its responsibility for handling nuclear wastes, DOE, in an effort to assess the costs and risks associated with modes of transporting nuclear wastes, initiated a study aimed at ultimately reducing radiation exposure levels "as low as reasonably achievable." Based on historic shipments of spent fuel and high-level waste, DOE concluded in part that the highest system dose reduction occurs in systems where there is "...increased cask capacity, such as overweight truck casks and advanced design casks, increased end shielding on casks and 
use of remote handling at the repository." Many of the department's efforts have been, and are, aimed at developing a transportation system that incorporates these features.

In addition to planning for the actual shipments of spent fuel and high-level waste, DOE and the other responsible federal agencies have authority for routing of such materials. The goal of the federal government's highway routing regulations is to reduce risk "by reducing the amount of time radioactive material is in transit." To achieve this goal, DOT has developed a system pursuant to the Hazardous Materials Transportation Act and routing regulations, commonly called by Docket HM-164, governing the highway routing of nuclear wastes and other radioactive materials. The process also allows for states to designate "preferred" or "alternative" routes either to supplement or provide alternatives to the interstate highway system, which is generally the route chosen for transport. DOT uses the HIGHWAY routing model for much of its planning. Railroad routing issues, which are not governed by a defined set of rules such as HM-164, are often decided through the use of the INTERLINE routing model, among other tools.

Since responsibility for many routing issues is divided among and between state, tribal, local and federal sources, routing regulations are often a source of tension. The HMTA preempts inconsistent state or local laws. The HMTA has a process for obtaining a DOT determination of the consistency of a given state or local law with the HMTA or implementing regulations. This determination is termed an "inconsistency ruling." Through the inconsistency ruling, the Hazardous Materials Transportation Act is examined to determine if inconsistencies exist between state and federal requirements. DOT's Office of Hazardous Materials Transportation considers whether compliance with both state or local requirements and the HMTA, or regulations under the HMTA, is possible as well as the extent to which the state or local requirement, is an obstacle to the accomplishment and execution of the HMTA and its attendant regulations. Occasionally, if an unfavorable ruling results, the challenging authority will file suit in a federal court to determine if the state or local rule should be preempted.

The types of waste considered for transportation within the national nuclear waste management system described above include commercial spent fuel and high-level radioactive waste, or HLW. The former consists of irradiated fuel discharged from a commercial nuclear reactor or special fuels from test or research reactors. HLW, on the other hand, is generated during reprocessing of defense production reactor fuels and commercial spent fuel in an effort to recover usable uranium or plutonium. 
Spent fuel is usually stored at the reactor site where it was generated in a storage pool under forty feet of water. Owing to serious storage limitations, however, nuclear utilities have had to explore a number of options for storing spent fuel. A reactor site can, for example, improve its storage capacity by implementing one or more strategies such as: expanding and increasing the efficiency of available storage capacity (e.g., re-racking); rearranging the fuel rods in a more compact array (i.e., rod consolidation); using transshipments of spent fuel between existing pools; or adding spent fuel dry cask technology. Federal interim storage during an emergency is also a possibility.

HLW containing significant amounts of transuranic, or heavier than uranium, waste is stored on-site at ten facilities: the Hanford Reservation in Washington; Lawrence Livermore National Laboratory in California; the Nevada Test Site; Idaho National Engineering Laboratory; the Rocky Flats plant in Golden, Colorado; Los Alamos National Laboratory in New Mexico; Argonne National Laboratory in Chicago; the Mound facility in Ohio; Oak Ridge National Laboratory in Tennessee; and the Savannah River plant in South Carolina. These transuranics are part of the federal government's nuclear weapons program.

Spent fuel and HLW are transported and stored in several types of heavily shielded casks to protect the public and transportation workers from dangerous levels of radiation. Much of DOE's effort has been aimed at producing the most cost-effective and safest cask possible. The NWPA requires the development of a geologic repository program that, in turn, will result in more shipments of nuclear wastes than has been experienced to date. Consequently, a larger fleet of truck and rail transport casks is required. DOE and the other federal agencies involved in the national nuclear waste management system are committed to developing casks sufficient to handle the increased demand.

A cask, whether used for transportation or disposal, is designed in a similar fashion. Each cask contains a gamma shield, a neutron shield, a heat transfer surface, a lid, a cavity and a basket of boron or stainless steel. The actual configurations and capacities vary, depending upon specific cask requirements such as weight restrictions, transportation mode and material transported.

Casks are regulated by several agencies. All casks used in transporting and disposing of spent fuel to federal facilities are the responsibility of OCRWM, although DOT governs shipments and NRC certifies the shipping casks. To meet the various regulations administered by these agencies, the casks must undergo 
a series of intensive tests, including a mechanical drop test, a thermal test and a water immersion test. The goal is to subject casks to a series of tests in order to demonstrate compliance with regulatory requirements.

In testing for real-world accident conditions, DOE has performed transportation risk and cost analyses pursuant to NWPA requirements. One method for performing these studies was to use computer models and codes such as RADTRAN III. The RADTRAN III model calculates the radiological risks associated with radioactive materials transportation by considering two major modules: the incident free transport module in which doses resulting from normal transport are calculated, and the accident module, which calculates consequences and probabilities of accidents. Other computer models used in risk analyses include the HIGHWAY and INTERLINE models, mentioned previously.

Several studies have been performed by DOE to compare various individual and transported material risks with spent fuel shipments. Work is ongoing in this area. In March 1987, for example, DOE announced the development of the TRANSNET system "to speed transfer of transportation risk and systems analysis technology to qualified users by permitting access to the most comprehensive and up-to-date transportation risk models and associated databases." TRANSNET makes other systems available to users in calculating factors such as historical accident/incident data and shipping costs.

While DOE is committed to protecting public health and safety in its nuclear waste transportation program, the department also realizes that costs play a major role in planning. Accordingly, in DOE's Mission Plan for the Civilian Radioactive Waste Management Program, the department noted its intention to include transportation cost projections in its environmental assessments for possible repository sites. DOE made certain assumptions in its cost assessments, providing for a repository-only and a repository-MRS system as they relate to the proposed repository in Yucca Mountain. Nevada. In conjunction with these cost-risk assessments, DOE has used the TRICAM model to compare alternative nuclear waste management scenarios.

Although DOE and other federal agencies are careful to plan for the various condingencies and risks inherent in transporting nuclear wastes to ensure that a significant radiological release does not occur, emergency response in the event of a radiological release is also a valuable part of the department's planning efforts. FEMA has developed a document especially useful in this area. Entitled Guidance for Developing State and Local Radiological Emergency Response Plans and Preparedness for Transportation Accidents, the report is better known 
as FEMA-REP-5. FEMA-REP-5 was produced to assist state and local governments in preparing for and responding to high-level radioactive materials transportation accidents. The federal government's role is outlined as a supporting role for state, tribal and local governments as they take the lead in emergency response activities.

The federal government's role in this area has evolved through a series of federal statutes, appropriations authorizations and executive orders. In 44 CFR 351. "Radiological Emergency Planning and Preparedness," the various federal agencies are assigned responsibilities for emergency response. In addition, the regulation establishes the Federal Radiological Preparedness Coordinating Committee (FRPCC) to assist FEMA by providing policy direction for federal assistance to state, tribal and local governments on radiological emergency planning and preparedness activities. One of FRPCC's subcommittees developed the Federal Radiological Emergency Response Plan (FRERP) to consolidate federal response for the wide range of potential peacetime radiological emergencies. Each of the 12 federal agencies involved in emergency response activities is directed to prepare emergency response plans to carry out their respective roles under the FRERP.

Also, under \$180(c) of the Nuclear Waste Policy Amendments Act of 1987 , DOE "...shall provide technical assistance and funds to States for training for public safety officials of appropriate units of local government and Indian tribes...." The training will cover emergency response situations as well as the procedures for routine safe transportation of high-level radioactive waste and will be supported by the Nuclear Waste Fund.

FEMA-REP-5, meanwhile, goes on to outline the role of regional groups, states and local governments in implementing emergency response plans. In the South, for example, the Southern States Energy Board (SSEB) is given authority for the formulation and administration of measurc.: designed to promote safety in any matter related to the development, use or disposal of nuclear energy, materials, products, installations or wastes. The Board is further empowered to enter into supplementary agreements in this area. One such agreement is the Southern Mutual Radiation Assisiance Plan, created in 1973. The plan provides a mechanism for cooperation of radiological emergency assistance capabilities among and between the southern states. Other agreements such as the Civil Defense and Disaster Compact provide mutual aid among and between states in the event of a radiological release or other radiation-related emergency. 
FEMA-REP-5 discusses the requirement that shippers of radioactive materials package containers pursuant to DOT and NRC packaging standards and supply shipping papers with information sufficient to identify the materials involved in a transportation accident. The shipper must provide a list of persons to contact should an accident occur.

Funds for emergency response activities are derived from several sources. Some states, through permit and fee systems for generators of radioactive waste, have funded their emergency response activities. Still others have assessed fees on the nuclear power industry whether or not a specific utility generated the wastes involved in the accident. On the federal level, money from the Nuclear Waste Fund can be used for emergency response activities. Section 180(c) of the NWPAA is another potential source of funding for the nuclear waste management system's public safety and emergency response activities.

When the nuclear power industry was in its infancy, Congress recognized the need to establish a liability system to handle claims in the event of a nuclear incident or occurrence. Consequently, the Price-Anderson Act was passed in 1957 as an insurance and indemnity system for radiological incidents. In 1988, the act was amended to raise the liability ceiling for claims to over $\$ 7$ billion.

Price-Anderson provides for a two-pronged system of insurance and indemnity, depending on the type and size of the facility in question and the circumstances surrounding, among other things, a transportation accident. The act also establishes a framework for handling claims in conjunction with the Federal Tort Claims Act (FTCA) and state liability provisions.

In 1988 the act was changed to provide for, among other things: a presidential commission on catastrophic nuclear accidents; a civil penalty of up to $\$ 100,000$ for any indemnified party who knowingly violates the act; allowances for the NRC to borrow funds necessary for the payment of claims when awards exceed the amount of retrospective premiurn insurance available in a given year; and a 15-year extension, as opposed to the 10-year extension granted to the act in previous years.

Through the comprehensive system described in these pages, officials propose to safely generate, transport, handle and dispose of radioactive wastes within the national nuclear waste management system. 


\section{Chapter 1.0}

\section{The Nuclear Waste Policy Act and the Role of Transportation}

\subsection{Implementation of the Nuclear Waste Policy Act and Amendments}

The Nuclear Waste Policy Act of 1982 (NWPA), ${ }^{1}$ signed into law by President Reagan on January 7, 1983, represents a significant milestone in the nation's effort to effectively manage nuclear waste. The act serves as a statutory framework for the siting, construction and operation of the nation's geologic repository program, mentioned below, to dispose of high-level radioactive waste. The strength of the NWPA, unlike earlier federal programs, is that it sets forth a step-by-step statutory direction for cradle-to-the-grave handling of wastes. Never before had the national nuclear waste management system been given such a detailed plan for waste handling and disposal. ${ }^{2}$

Since the mid-1950s, when the U.S. civilian nuclear industry was in its infancy, electric utilities have generated over 20,000 metric tons of uranium (MTU) spent nuclear fuel. ${ }^{3}$ The Congress, in its NWPA findings, recognized that: "[f]ederal efforts during the past 30 years to devise a permanent resolution to the problems of civilian radioacive waste disposal have not been adequate." ${ }^{4}$ Thus, the NWPA was, and is, an attempt to provide guidance for all parties involved in licensing, constructing and operating a geologic repository or other facility for waste disposal. ${ }^{5}$

In outlining the plan for an integrated waste disposal system, the NWPA authorizes: 1. protection of public health and safety, along with environmental acceptability; 2 . acceptance of title to the waste starting no later than January 31,$1998 ; 3$. a repository for permanent disposal of spent fuel and high-level waste; 4 . safe transportation of waste to the repository; 5 . provisions for limited interim storage of spent fuel for utilities, as required by the Nuclear Regulatory Commission (NRC); 6. encouragement to nuclear facilities to use existing storage facilities at reactor sites effectively until waste is accepted for disposal; 7. involvement of the state and Indian tribes and full and open public participation; and 8. full cost recovery, with costs borne equitably by the waste generators. ${ }^{6}$

In December 1987 Congress passed, and President Reagan signed, the Nuclear Waste Policy Amendments Act of 1987 (NWPAA). ${ }^{7}$ Among other things, the amendments act provided that: Yucca Mountain. Nevada, be the site characterized for the proposed geologic repository; a nuclear waste technical 
review board, composed of 11 National Academy of Science members appointed by the President to evaluate the technical and scientific validity of the DOE secre activities, be established: a nuclear waste negotiator be empowered to seek a state or tribe willing to accept a monitored retrievable storage (MRS) facility or a repository and, if such a willingness is determined, to negotiate terms and conditions; a single MRS is authorized; an MRS review commission, composed of three members, is established to evaluate the advantages and disadvantages of bringing an MRS facility on line; NRC regulations and certification procedures are to be followed for cask development, and DOE is to provide technical assistance and funding to train public safety officials on nuclear waste transportation. ${ }^{8}$

\subsection{Federa: Agency Responsibility for the Transportation of Spent Fuel and High-Level Waste}

A number of federal agencies are responsible for the transportation of spent fuel and high-level waste within the nation's nuclear waste management system. A brief discussion of those agencies and their powers follows.

\subsubsection{The U.S. Department of Energy}

The U.S. Department of Energy (DOE) was formed in 1977 when the Atomic Energy Commission (AEC, 1946-1974) and the Energy Research and Development Administration (ERDA, 1974-1977) were consolidated. ${ }^{9}$ Among its other powers and duties, DOE has general responsibility for implementing federal policies on high-level radioactive waste as well as planning and coordinating a national low-level waste management and disposal system. ${ }^{10}$ DOE's Office of Civilian Radioactive Waste Management (OCRWM) is responsible for the development and construction of a geologic repository for the management and disposal of spent fuel and high-level radioactive waste generated by commercial nuclear reactors in the United States." ${ }^{11}$

The NWPA, in $\$ 10143$ and $\S 10194$ (d), requires DOE to accept title to commercial high-level radioactive waste and transport and dispose of such waste. $^{12}$ Additionally, DOE is empowered to: arrange for and provide casks necessary to transport waste ${ }^{13}$ make arrangements for shipping wastes; ${ }^{14}$ assess the accident potential and make recommendations concerning the shipment of 
wastes: ${ }^{15}$ maintain data on radiological monitoring: ${ }^{16}$ and provide information, assistance and telecommunication support to other federal agencies for emergency response. ${ }^{17}$

\subsubsection{The Nuclear Regulatory Commission}

The Nuclear Regulatory Commission (NRC) is an independent regulatory agency established in 1974 to develop and enforce regulations to protect the public health and safety from all commercial nuclear activities. ${ }^{18}$ Specifically, pursuant to provisions found in the Atomic Energy Act of 1954, as amended, the NRC is authorized to regulate the transportation of all nuclear material in the fuel cycle in three major categories: safety regulation through packaging requirements; protection of spent fuel shipments, including route approval, from acts of sabotage; and advance notification to governors and to other appropriate parties. ${ }^{19}$

The NRC generally coordinates its transportation functions with the U.S. Department of Transportation, mentioned below, through a memorandum of understanding (MOU) adopted by the two agencies in 1979. Pursuant to this MOU, the NRC regulates those who possess and use radioactive materials as well as the design, construction, use and maintenance of shipping containers for radioactive materials exceeding certain quantity and radioactivity limits. ${ }^{20}$ DOT, on the other hand, regulates carriers of radioactive materials and the conditions of transport such as routing, handling and storage, vehicle requirements and driver requirements. ${ }^{21}$

\subsubsection{The U.S. Department of Transportation}

The U.S. Department of Transportation (DOT) regulates hazardous materials, including radioactive materials, transportation in interstate commerce by land, air and on navigable waters. ${ }^{22}$ DOT regulations apply to the shipment of all privately-owned radioactive materials. Labeling, classification and marking of all radioactive waste packages also fall within DOT's purview. ${ }^{23}$

The Office of Hazardous Materials Transportation within DOT implements provisions of the Hazardous Materials Transportation Act (HMTA) by promulgating regulations on the coordination and control of domestic and international shipments of hazardous materials. HMTA regulations governing radioactive materials include provisions on: national safety regulation for the transportation of radioactive materials; routing regulations requiring the use of interstate 
highways where possible, except when states have designated alternative routes; and regulatory criteria and procedures for inconsistency and non-preemption rulings. ${ }^{24}$ Other DOT offices, such as the Federal Railroad Administration (FRA) and the Federal Highway Administration (FHA), among other things, ensure compliance and enforce provisions regarding rallroad and highway shipments of radioactive materials, respectively. ${ }^{25}$

\subsubsection{The Federal Emergency Management Agency}

The Federal Emergency Management Agency (FEMA) is responsible for establishing policies for, as well as coordinating, civil emergency management, planning and interaction among and between federal executive agencies charged with emergency response functions in the event of a radioactive materials transportation incident. ${ }^{26}$ Established pursuant to Executive Order 12148 (July 20, 1979), FEMA coordinates federal and state participation in developing emergency response plans and assumes responsibility for coordinating the development of the interim Federal Radiological Emergency Response Plan (49 Fed. Reg. 46542). The plan is designed to coordinate federal support of state and local governments, upon request, in responding to a radioactive materials transportation incident. ${ }^{27}$

FEMA has formed the Federal Radiological Preparedness Coordinating Committee (FRPCC) to assist states and local agencies in testing radiological emergency response plans. FRPCC's subcommittee on Transportation Accidents, composed of DOE, NRC, FEMA and other agency representatives, has produced a document, Guidance for Developing State and Local Radiological Emergency Response Plans and Preparedness for Transportation Accidents to provide guidance and support for state and local government planning. ${ }^{28}$

\subsubsection{The Interstate Commerce Commission}

The Interstate Commerce Commission (ICC) regulates the economic aspects associated with the transportation of radioactive materials by issuing operating authorities to carriers and by monitoring and approving freight rates. ${ }^{29}$ The ICC formerly regulated the safety aspects of radioactive materials shipments but those functions were transferred to DOT when the transportation department was created in April 1967..$^{30}$ 


\subsubsection{Program Responsibilities}

To carry out the national nuclear waste management objectives, the NWPA created the Office of Civilian Radioactive Waste Management (OCRWM) to coordinate NWPA program activities. ${ }^{31}$ The Office of Systems Integration and Regulations (OSIR) within OCRWM establishes strategies, policies and procedures for implementing the transportation program and coordinates sctivities among and between DOE, other federal agencies and states and Indian tribes. In an effort to accomplish these goals, OSIR has assigned responsibilities for various parts of the project to several DOE operations offices throughout the country. ${ }^{32}$

The Chicago Operations Office, located in Argonne, Illinois, serves as the lead field office for institutional activities and transportation, economic and systems analyses, development of the operation system and integration of program activities. National and regional groups as well as transportation-related professional groups and other contractors work with Chicago Operations to study transportation issues and work toward a timely and effective resolution to many of the transportation issues and problems mentioned within these pages. Chicago also supports environmental impact assessments for repository transportation and develops and maintains tools (e.g., models and databases) for policy analysis. ${ }^{33}$

Currently, the Oak Ridge National Laboratory (ORNL) is the national laboratory through which the Chicago Operations Office carries out the work related to transportation operations activities. At ORNL, a staff of ORNL and subcontractors supports the Chicago Operations Office by performing studies and activities related to transportation operations. This group of ORNL and subcontractor staff is sometimes referred to as the transportation operations project office (TOPO).

The Idaho Operations Office, located in Idaho Falls, Idaho, is responsible for transportation program technology developments such as the design, fabrication and testing of prototype casks for shipping wastes. Once the casks have been designed and tested, a team of outside experts verifies the designs and, assuming that certain criteria, discussed in Chapter 4.0, are met, the NRC certifies the designs. ${ }^{34}$

\subsubsection{Geologic Repository Program}

As a part of the effort to effectively manage the nation's nuclear waste, the NWPAA authorizes evaluating the suitability of siting a permanent geological 
repository for spent nuclear fuel and high-level waste. The site chosen for evaluation is the Yucca Mountain site on the edge of the Nevada Test Range in southwestern Nevada. ${ }^{35}$ Preliminary studies now taking place there. If the site proves to be suitable for the repository, DOE estimates that the facility will take seven years to construct and will be ready to accept waste by $2010 .^{36}$

Plans for the Yucca Mountain site call for the waste to be emplaced in a mine excavated in volcanic tuff 1,050 feet below the surface of the earth. The rock where the waste will be emplaced is part of a formation at least 6,500 feet thick. The water table at the site is 2,500 feet below the surface. ${ }^{37}$ These factors result in a flow rate of ground water from the proposed repository area to the water table of at least 10,000 years. Geochemical and mechanical processes will cause many radionuclides found :. waste to take even longer to travel that distance. ${ }^{38}$

The repository will consist of a surface complex to receive the wastes by rail and road and prepare it for disposal. The mine will cover 1,380 acres out of a potential 2,095 that appear to be suitable for waste emplacement. Waste in specially designed casks will be emplaced in boreholes drilled in the floor of the mine $^{39}$ The waste emplacement phase of the repository will last 26 years. The waste will be fully recoverable for an additional 24 years. During the entire 50 -year period, tests will be conducted to assure that the facility is performing as expected. If no problems are encountered, the site will then be backfilled and sealed. ${ }^{40}$

\subsubsection{Monitored Retrievable Storage}

The NWPAA authorizes DOE to site, construct and operate a Monitored Retrievable Storage (MRS) facility subject to certain restrictions linking construction of the MRS to constuction of a permanent repository. These linkages include prohibiting operation of the MRS before construction permits for the repository are issued or if the work on the repository is suspended. The act also limits the amount of spent fuel to be stored at the MRS to 10,000 MTU prior to the opening of the repository and 15,000 MTU when the repository is accepting waste. ${ }^{41}$ The act also authorizes the creation of a commission to study the relative advantages of an MRS over continued at-reactor storage to assess the need for an MRS. ${ }^{42}$

The Monitored Retrievable Storage Review Commission's report was released on November 1, 1989. In preparing its report, the commission conducted public hearings, studied and evaluated interim storage options, contracted studies by independent consultants and reviewed previous studies conducted by DOE and 
the state of Tennessee, as well as visited and studied several foreign country's storage facilities and reviewed their waste management programs. Based on this work, the commission presented a number of recommendations that, if adopted, would radically alter DOE's current program. ${ }^{43}$

The commission's most significant recommendation is that the MRS program be abolished and in its place DOE construct two much smaller facilities. The first would be a Federal Emergency Storage (FES) facility with a capacity of 2,000 MTU funded by the NWF. The second would be a User Funded Interim Storage Facility (UFIS) paid for by user fees assessed against those utilities using the facility. Both facilities would have relaxed linkages to the repository. ${ }^{44}$

The first facility recommended by the commission is the FES. As its name implies, its primary purpose would be the emergency storage of spent fuel. The commission contemplated two situations where such a facility might be necessary. The first would be in the event of a major accident at a nuclear generating site. Spent fuel from the reactor's holding pools would be shipped to the FES to allow the pools to be used for contaminated material from the event. A second use for the FES would be the storage of spent fuel from reactors that would otherwise have to shut down before their operating licenses expired because of a lack of on-site storage capacity. Since its emergency function would benefit all utilities operating nuclear plants, the FES would receive its funding through the NWF. Utilities that used the site to store their excess waste would be required to pay a user fee. ${ }^{45}$

The second facility recommended, the UFIS, would serve a slightly different function. The UFIS, a 5,000 MTU facility, would enable utilities to make a decision on the storage of their spent fuel that would allow them to weigh the benefits and drawbacks of off-site storage. By making the facility user-financed, rather than paid out of the NWF, the utilities would be able to decide which option best suits their needs (continued onsite storage or shipping the waste to the UFIS). ${ }^{46}$

Since the combined capacity of the recommended sites (7,000 MTU) would be less than the NWPAA's limit for the MRS $(10,000$ MTU before the opening of the repository, 15,000 when the repository begins accepting waste) the commission intends that on-site MRS storage predominate and that off-site storage be funded by utilities that make a decision based on their particular situation and involving economic factors (UFIS) or those situations that are truly emergencies. This, the commission contends, would prevent either facility from becoming a de facto repository. ${ }^{47}$ An MRS as envisioned in the NWPAA, on the other hand, is funded by the NWF, a tax based on the electricity generated by nuclear power plants. Once a plant stops generating electricity, it also stops 
generating money into the NWF. ${ }^{48}$ If the waste is in an MRS, the fear has been expressed that the utilities and DOE will lose interest in the waste and not be compelled to push for siting of the repository. ${ }^{49}$ The NWPAA addressed these fears by instituting statutory linkages between an MRS and a repository. The commission addressed these concerns by limiting the capacity of the UFIS to about six percent of the waste fuel that will be generated by the nuclear power industry. ${ }^{50}$

In a third recommendation, the commission suggested that Congress should reconsider the interim storage program by the year 2000. Such a review would enable Congress to incorporate technical, political and social developments into the program and assess the two facilities suggested by the commission. ${ }^{51}$

These recommendations were based on a series of findings by the commission about the current program. Paramount among these was the conclusion that the opening date of the repository would slip beyond 2003, as was targeted at the time the commission released its report. ${ }^{52}$ This prediction turned out to be prophetic as not long after the report was released the target date was pushed back to $2010 . .^{53}$

Assuming that the repository would indeed be delayed, the commission concluded that an unlinked MRS would not cost significantly more than the no-MRS option because of the expense of storing fuel at shut-down plants. ${ }^{54}$ If some kind of off-site storage is not established for the fuel from these plants, the utilities will incur a significant expense in storage of the fuels at the shut-down plants. Decommissioning will also be delayed. There is further concern that the skeleton crews that would remain to operate and watch the spent fuels would perform fuel-handling functions so infrequently that safety could be compromised. In a central facility there would be more fuel handling, a larger staff, and presumably greater competence. ${ }^{55}$

The commission also examined the transportation effects between the MRS and the no-MRS options. They concluded that regardless of the interim storage option chosen, the transportation risks would be minimal. Therefore, transportation issues should not bear on the decision of whether an interim storage facility should be built. ${ }^{56}$

In response to the commission's report, DOE agreed that an interim storage facility was needed, but contended that an MRS was still in the best interests of the nuclear waste management program. Currently, DOE plans to work with the Congress to modify the current linkages to allow an MRS to open sooner and store more waste than currently allowed by the NWPAA. DOE believes that such a 
program would increase public confidence in the nuclear waste management program. They fully support the appointment of the Nuclear Waste Negotiator authorized by the NWPAA to find a volunteer site for the MRS and an expedited opening of the facility, possibly as early as $1998 .{ }^{57}$

The state of Tennessee differs with DOE and the commission on the need for off-site storage. ${ }^{58}$ Tennessee contends that the most cost-effective and safe approach to the nuclear waste problem is an "integrated no-MRS" system. This system would utilize dual purpose casks to store spent fuel at the repository and nuclear power plants. These same casks would be used to ship the waste, by rail, to the repository. Tennessee urges DOE to consider seriously and research such an option and asks that DOE open the repository as soon as possible. ${ }^{59}$

\subsection{Transportation and Storage of Spent Fuel and High-Level Waste}

The transportation of spent fuel and highly radioactive waste is an integral part of the national nuclear waste management system. A number of utilities are expected to exhaust their existing spent fuel storage capacity prior to the completion of the geologic repository. ${ }^{60}$ To solve the problem of scarce storage capacity at reactor sites, several utilities are transshipping spent fuel from crowded facilities to facilities with greater storage capacity. Assuming that a federal facility is constructed, utilities are then expected to begin regular shipments to this facility in addition to transshipping. Consequently, it appears likely that the shipment of radioactive materials on the nation's highways, which already occurs to some degree, will increase in the future. ${ }^{61}$

Much of the transportation "system" for spent fuel is already in place but many of the procedures are still developing. Typically, the process runs or will run as follows: when spent fuel is designated for disposal, DOE will take title, i.e., legal responsibility, for the fuel. DOE service contractors will transport the waste to a federal storage facility, either an MRS, a repository or both. Contractors must demonstrate to DOE's satisfaction that they fully comply with all DOE, DOT, NRC and state requirements governing spent fuel shipments. Drivers must complete certain training and pass tests on operating procedures and routing criteria. Periodic training and reevaluation of drivers must occur every two years. ${ }^{62}$

The first step in truck transportation of spent fuel and radioactive waste is to deliver an empty shipping cask to a power plant site and unload it from the 
truck. The cask is then moved into the water pool where discharged spent fuel is temporarily stored. Using several special hoists, plant workers load the spent fuel into the shipping cask where it is placed onto the truck for transport. ${ }^{63}$

Before the casks leave tise plant site, radiation and contamination surveys are conducted to ensure that the casks are within allowable heat and radiation levels. Casks are also attached to a truck trailer and may be enclosed in a protective metal barrier to prevent accidental or unauthorized entry into the cask. Placards are also affixed to the truck cab and trailer to identify the materials being transported. Assuming that casks meet all federal requirements, the shipper then issues a certificate to the carrier stating that the casks are in compliance. ${ }^{64} \mathrm{An}$ examination is also conducted by federal and state officials to verify that the cask, the vehicle and all supporting equipment meet safety requirements. ${ }^{65}$

Once the truck is ready for the highway, certain rules and regulations promulgated by DOT must be observed. For example, trucks must follow "preferred" routes, i.e., generally interstate highways, using bypasses and beltways around cities when available. The driver must carry with him a written route plan that describes the origin and destination points, the selected route, planned stops, estimated departure and arrival times, telephone numbers for emergency response officials in each state and other information necessary to ensure shipment safety. ${ }^{66}$

Spent fuel shippers are required by the NRC to notify the governor or his or her designated alternate either by mail, seven days prior to shipment through the state, or four days prior to shipment if delivered by messenger service when spent fuel shipments are traveling through the state. ${ }^{67}$ Specific routes are not released to the public for security reasons. ${ }^{68}$ In some instances, security personnel may be required to accompany shipments through states or part of states. An on-board communications system and a "vehicle immobilization capability" are also available. ${ }^{69}$

When spent fuel and high-level radioactive materials are stored in either a repository or an MRS facility, the general procedures for storage and disposal are similar, although there are some differences. When, for example, spent fuel is stored in an MRS facility, the canister of fuel rods is transferred to a storage field and placed in a storage cask. When fuel is ready to be placed in a repository, the canister is placed inside another container, called an overpack, and the overpack is sealed. At that time, the waste package, if it has been originally placed in an MRS, is then transported to the repository. ${ }^{70}$ 
In either case, once the waste package reaches its final resting place, a transport vehicle receives the waste. A hole is drilled into the floor of the repository and the package is placed in the hole. Material may be packed around the waste package. A cap or plug is fitted into the hole and the hole is filled to the floor level with plugging material. ${ }^{71}$

\subsection{Government and Public Input and Participation}

DOE allows for input and participation in nuclear waste program activities by local, state and tribal jurisdictions as well as members of the general public. Indeed, the department has long considered public information an integral part of public acceptance of the nuclear waste management program.

\subsubsection{State, Local and Tribal Activities}

State, local and tribal groups are called upon to participate in DOE's nuclear waste management program in a number of ways. The NWPA calls for a comprehensive outreach and involvement plan so that all voices can be heard and all opinions considered. The goals of the program are to: notify affected parties of DOE's planned activities and solicit their comments; consult and cooperate with states and affected Indian tribes; assess the effects of program activities on states, localities and Indian tribes at frequent intervals; and provide for a substantial commitment by DOE to avoid, mitigate or compensate for any negative impacts that may occur. ${ }^{72}$

To accomplish these goals, DOE officials have held, and will hold, discussions with officials in states selected to host a storage or disposal facility prior to commencement of site characterization efforts. The department is concerned that state questions or problems be identified and addressed early in the program so that public outreach and participation can effectively meet the needs of all affected parties. $^{73}$

As DOE meets major milestones, officials brief Congress, state, tribal and local officials on the status of the program. In addition, meetings and workshops are held periodically so that parties affected by the program will be educated about nuclear waste management. ${ }^{74}$ 
Formal hearings are also a part of DOI's outreach program. Issues such as siting guidelines, environmental assessments, site-characterization plans and environmental impact statements are discussed and released for public comment. The department works with states, tribes and localities to establish convenient times and locations for hearings. Comments received through hearings and a formal written comment process will be considered as a particular document is prepared. In some cases, a "comment-response document" may be issued to address a series of concerns expressed by affected parties. ${ }^{75}$

DOE has also made plans to assist various parties financially in participating in the program. Groups such as the National Conference of State Legislatures, the National Congress of American Indians, the National Governors' Association, the Southern States Energy Board. The Midwest Council of State Governments and the Western Interstate Energy Board have entered into agreements with DOE to engage in a variety of activities such as: studies and strategic planning exercises; task forces to study specific issues; transportation-related studies; education of siate leaders and administrators; and bringing together state groups or representatives to discuss program activities. ${ }^{76}$

Additionally, to ensure that states and affected Indian tribes are actively involved in the entire nuclear waste management program, a formal consultation-and-cooperation $(\mathrm{C} \& \mathrm{C})$ process for the repository or MRS host states, was established in \$117(c) of the NWPA. A C\&C agreement will help to establish a working relationship among and between states, tribes and DOE as the program progresses. The agreement process will help "...provide for an orderly process and timely schedule for [s] tate review and evaluation, including identification in the agreement of key events, milestones, and decision points in the activities of the [s]ecretary at the potential repository site." ${ }^{.77}$.

\subsubsection{Public Participation}

In addition to the affected states, localities and tribes, members of the public are also invited to participate in the program. Indeed, DOE, in anticipation of public concern over the transportation and disposal of nuclear waste, has developed a number of initiatives to inform the public. These initiatives include: maintaining an efficient system for responding to information requests and other correspondence concerning nuclear waste in general and transportation matters in specific; conducting meetings and briefings for interested civic groups and other public assemblies to exchange information; developing educational resources concerning nuclear waste transportation and establishing an effective mechanism 
for dissemination; ensuring that adequate, objective transportation information is included in community information offices; and using the OCRWM Bulletin and other resources to impart news and information on the program to interested members of the public. ${ }^{78}$ 


\section{Notes for Chapter 1.0}

${ }^{1}$ Nuclear Waste Policy Act (NWPA) of 1982, 42 USC \$10101, et seq. (1983).

${ }^{2}$ Mission Plan for the Civilian Radioactive Waste Management Program, U.S. Department of Energy, June 1985, [DOE/RW-0005], pp. 4-7.

${ }^{3}$ MRS System Study Report, U.S. Department of Energy, June 1989 [DOE/RW-0235], Appendix B, p.6.

${ }^{4} 42$ USC $\$ 10131(\mathrm{a})(3)$.

${ }^{5}$ Managing the Nation's Nuclear Waste: Implementation of the Nuclear Waste Policy Act of 1982, p. 1.

${ }^{6}$ Managing the Nation's Nuclear Waste: Overview-Nuclear Waste Policy Act, U.S. Department of Energy, October 1985, [DOE/RW-0053], p. 1.

${ }^{7}$ Nuclear Waste Policy Amendments Act of 1987, Pub. L. No. 100-203, 101 Stat. 1330-227 (Title 5, Subtitle A, $\$ 5001$ et. seq., 1987).

${ }^{8}$ State Legislative Report: Nuclear Waste Policy Amendments Act of 1987. National Conference of State Legislatures, May 1988, pp. 1-2.

${ }^{9}$ The Nuclear Waste Primer: A Handbook for Citizens, The League of Women Voters Education Fund, Nick Lyons Books, 1985, pp. 4-5.

${ }^{10}$ Mission Plan for the Civilian Radioactive Waste Management Program, p. 3.

${ }^{11}$ Ibid., p. 145.

${ }^{12} 42$ USC $\S \S 10143$ and 10194(d). See also: 42 USC $\$ 10142$.

${ }^{13} 42$ USC $\$ 10221($ a)(8). See also: Managing the Nation's Nuclear Waste: Overview-Nuclear Waste Policy Act, pp. 2-3.

${ }^{14} 42$ USC $\$ 10175$, et seq.

${ }^{15}$ Ibid.

${ }^{16} 42$ USC $\S 10191$, et seq.

${ }^{17} 42$ USC $\S 10196$, et seq.

${ }^{18}$ The Nuclear Waste Primer: A Handbook for Citizens, p. 5.

${ }^{19}$ Transportation Institutional Plan, U.S. Department of Energy, August 1986, [DOE/RW-0094], p.23. See also: The Nuclear Waste Primer: A Handbook for Citizens, pp. 5-6.

${ }^{20}$ Spent Nuclear Fuel and High-Level Radioactive Waste Transportation Primer, Western Interstate Energy Board, June 1985, pp. 3-2.3 - 3-2.9. See also: 49 CFR Part 106, et seq. 
${ }^{21}$ Ibid.

${ }^{22}$ Ibid. See also: The Nuclear Waste Primer: A Handbook for Citizens, p. 6.

${ }^{23}$ Ibid.

${ }^{24}$ Spent Nuclear Fuel and High-Level Radioactive Waste Transportation Primer, pp. 3-2.5 - 3-2.9.

${ }^{25}$ Ibid.

${ }^{26}$ Ibid., pp. 3-2.9 - 3-2.10. See also: Transportation Institutional Plan, pp. B-8 - B-9.

${ }^{27}$ Ibid.

${ }^{28}$ Transportation Institutional Plan, p. B-9.

${ }^{29}$ Spent Nuclear Fuel and High-Level Radioactive Waste Transportation Primer, p. 3-2.10.

${ }^{30} \mathrm{Ibid}$. See also: Transportation Institutional Plan, pp. B-7 - B-8.

${ }^{31} 42$ USC \$10224. See also: Mission Plan for the Civilian Radioactive Waste Management Program. p. 145.

${ }^{32}$ Ibid., p. 147.

${ }^{33}$ Managing the Nation's Nuclear Waste: A Guide to OCRWM Transportation Program Responsibilities, U.S. Department of Energy, February 1986, [DOE/RW-0148], p. 1.

${ }^{34}$ Ibid.

${ }^{35} 42$ U.S.C. $\$ 10172$.

${ }^{36}$ Report to Congress on Reassessment of the Civilian Radioactive Waste Management Program. U.S. Department of Energy, November 1989 [DOE/RW-0247], p. 10.

${ }^{37}$ Site Characterization Plan Overview, Yucca Mountain Site, Nevada Research and Development Area, Nevada, U.S. Department of Energy, December 1988 [DOE/RW-0198], p. 15.

${ }^{38}$ Ibid., p. 86.

${ }^{39}$ Ibid., p. 42.

${ }^{40}$ Ibid., p. 44.

${ }^{41} 42$ U.S.C. $\$ 10168$.

${ }^{42} 42$ U.S.C. $\$ 10163$. 
${ }^{43}$ Nuclear Waste: Is There a Need for Federal Interim Storage, Report of the Monitored Retrievable Storage Review Commission. Monitored Retrievable Storage Review Commission, November 1, 1989, p.xiii. (Hereafter MRS Commission Report).

${ }^{44}$ Ibid., pi. 101-103.

${ }^{45}$ Ibid.

${ }^{46}$ Ibud.

${ }^{47}$ Ibid.

${ }^{48}$ The fee is a 1.0 mill per kilowatt-hour of electricity generated by civilian nuclear powe: plants, and a one-time fee for waste generated before the tax took effect. 42 U.S.C. \$1C222.

49"A Systems Evaluation of the High-Level Waste Management System Based on Integraticn of Dual Purpose Casks into the System as an Alternative to DOE's roposid Monitored Retrievable Storage Facility as an Integral Part of the System Final Report," I'oskins, Raymond E., June 1989, p. I-15, cited by MRS Commission Report, p. 95.

${ }^{50}$ MRS Commission Report, p. 103.

${ }^{51}$ Ibid.

${ }^{52}$ Ibid., p. 99.

${ }^{53}$ Report to Congress on Reassessment of the Civilian Radioactive Waste Management Program, U.S. Department of Energy, November 1989 [DOE/RW-0247], p. 11. (Hereafter Civilian Program Report).

${ }^{54} \mathrm{By} 2015$, a large number of nuclear plants will have reached the end of their operating lives. Without off-site storage, the spent fuel will have to remain on site until the repository is ready to accept it. MRS Commission Report, pp. 6?-70.

${ }^{55}$ Ibid., citing "MRS Systems Study Task G Report," Pacific Northwest Laboratory, PNL-6876, April 1989, p. 3.19.

${ }^{55}$ Ibid., p. 57.

${ }^{57}$ Civilian Program Report, pp. 17-18.

${ }^{58}$ Tennessee's interest in the MRS stems from it being chosen by DOE under the NWPA as the host site for the MRS. This decision was revoked by the NWPAA (42 U.S.C. \$10162). MRS System Study Report, U.S. Department of Energy, June 1989 [DOE/RW-0235], p. 1. 
${ }^{59}$ Tennessee's Position on the MRS: Final Comments to the Monitored Retrievable Storage Review Commission, State of Tennessee, July 1989, Reprinted in Southern States Energy Board Advisory Committee on Radioactive Materials Transportation, Final Agenda and Briefing Book, Southern States Energy Board, November 1989, pp. 53-69.

${ }^{60}$ Transportation Institutional Plan, pp. 3-4.

${ }^{61}$ Ibid. See also: Transporting Spent Nuclear Fuel: An Overview, U.S. Department of Energy, March 1986, [DOE/RW-0065], p. 9.

${ }^{62}$ Transporting Spent Nuclear Fuel: An Overview, pp. 9-10.

${ }^{63}$ Ibid.

${ }^{64}$ Ibid., p. 10.

${ }^{65}$ Ibid.

${ }^{66}$ Ibid.

${ }^{67}$ Ibid.

${ }^{68}$ Ibid.

${ }^{69}$ Ibid.

${ }^{70}$ Managing the Nation's Nuclear Waste: The Mlustrated Mechanics of Nuclear Waste Disposal, U.S. Department of Energy, October 1985. [DOE/RW-0054], pp. 2-3. See also: Office of Civilian Radioactive Waste Management: Annual Report to Congress, U.S. Department of Energy, March 1986, [DOE/RW-0004/2], pp. 18-21.

${ }^{71}$ Ibid.

${ }^{72} 42$ U.S.C. \$10195. See also: Managing the Nation's Nuclear Waste: Opportunities for Participation in the OCRWM Transportation Program. U.S. Department of Energy, April 1987, [DOE/RW-0171], pp. 1-2.

${ }^{73}$ Ibid. See also: Mission Plan for the Civilian Radioactive Waste Management Program, pp. 129-137.

\footnotetext{
${ }^{74}$ Ibid.

${ }^{75}$ Ibid.

${ }^{76}$ Ibid.

${ }^{77} 42$ USC \$10137.

${ }^{78}$ Ibid.
} 


\section{Chapter 2.0}

\section{Shipments and Routing of Spent Fuel and High-Level Waste}

\subsection{Shipments of Spent Tuel and High-Level Waste}

Although relatively little high-level waste and spent nuclear fuel is currently being shipped over the nation's highways and rail systems, the future promises to bring a vast increase in shipments. If DOE's plan for a delinked MRS is approved, shipments of spent fuel could start as early as 1998. A regulatory framework has already been established by DOE, DOT, NRC, FEMA and ICC. For purposes of understanding that framework, it is helpful to bear in mind that the Nuclear Waste Policy Act of 1982 defines the types of wastes--primarily high-level radioactive waste and spent fuel--that will be slated for disposal at a repository. ${ }^{1}$

\subsubsection{Federal Shipping Regulations, Requirements and Safeguards}

Responsibilities of federal agencies concerning the shipment of spent fuel and high-level waste are in certain instances unique to a specific agency and in other instances are overlapping between agencies. While the agencies discussed in Chapter 1.0 are also involved in spent fuel shipments, in some cases their roles are somewhat different with respect to fixed nuclear facilities on one hand and shipments on the other. The following is a summary of those agency responsibilities for shipments:

\subsubsection{U.S. Department of Energy}

As indicated in chapter 1.0, DOE is required by the NWPA to take title to, transport and dispose of commercially generated high-level radioactive waste and spent fuel pursuant to a contract executed by owners or generators of such waste. To introduce uniformity into contractual relationships between the federal government and operators of nuclear power facilities, DOE issued on April 18, 1983, a standard contract for waste disposal. ${ }^{2}$ The terms of that contract, coupled with the requirements of the NWPA, mandate that DOE must arrange for and provide all casks necessary for waste transportation; must make all arrangements for waste shipment; and must transport the spent fuel and wastes subject to licensing requirements and regulations by the NRC and DOT. All costs related 
to shipping and disposing of spent fuel and high-level radioactive wastes are to be borne by the owners and generators of the waste, primarily through fees paid into the NWPA-mandated Nuclear Waste Fund. ${ }^{3}$

Concerning DOE's responsibilities for the design, development and testing of packaging used for waste shipping. DOT has permitted DOE to certify the packaging in accordance with standards set by the NRC. Despite DOE's authority to certify its own packaging, the department and NRC in 1983 issued a procedural agreement declaring the department's plans to use packaging specifically approved by the NRC to be in accord with the NWPA. ${ }^{4}$

Additional DOE responsibilities relate to the department's authority to regulate contractors transporting radioactive materials (in the exercise of which authority DOE generally follows the safety regulations and packaging design standards set by the NRC and DOT), and its role in the initiation and coordination of federal assistance pursuant to the Federal Radiological Emergency Response Plan (as discussed in chapter 6.0). Furthermore, DOE conducts workshops throughout the nation to assist handlers, shippers, carriers and enforcement authorities in interpreting current transportation regulations.

\subsubsection{Nuclear Regulatory Commission}

The Nuclear Regulatory Commission is concerned, pursuant to the Atomic Energy Act of 1954, with the transportation of all nuclear material in the nuclear fuel cycle, including the transportation of spent fuel. The field of NRC regulations includes safety regulations, safeguard regulations and required advance notification to state governors prior to shipments of spent fuel and other nuclear waste. To ensure its regulations and control procedures are followed, the NRC maintains an active enforcement and inspection program keyed to inspection of a licensee's procedures and programs at its original shipping points.

The NRC's regulations generally are coordinated with DOT, as reflected and formalized in a 1979 "Memorandum of Understanding." The agreement provided for DOT regulation of carriers of radioactive material and the conditions of transport (e.g., routing, handling and storage, and vehicle and driver requirements), while vesting in the NRC authority for the regulation of persons who possess and use radioactive materials as well as for the design, construction, use and maintenance of shipping containers for materials exceeding certain quantity and radioactive limits and for special transport safeguard controls to protect against acts of sabotage. 
The potential for public danger arising from the sabotage of a spent fuel (as opposed to a highly radioactive waste) shipment prompted the NRC in 1980 to adopt safeguard requirements calling for a "physical protection system" for all spent fuel shipments, use of armed escorts in densely-populated areas, prior to notification of such shipments to appropriate state governors, and the use of an NRC-approved route. ${ }^{5}$ In 1984 , the NRC proposed to relax the regulations somewhat for shipments of fuel out of the reactor for 150 days or more, but no final regulations have been adopted and the fate of the proposal remains uncertain. ${ }^{6}$

In addition to the notification requirement prior to spent fuel shipments, the NRC also requires advance notification to a state's governor (or designee) of other nuclear waste shipments in Type B packaging. ${ }^{\text {? }}$

\subsubsection{U.S. Department of Transportation}

The Department of Transportation regulates the transportation of hazardous materials (including radioactive material) in interstate commerce by land, air and on navigable waters. DOT regulations apply to shippers and carriers where shippers are responsible for packaging, marking and labeling goods to meet the regulatory requirements for delivery to a carrier responsible for actual transport. Some companies act as a shipper's agent and complete transportation arrangements with a carrier on behalf of the shipper. Carriers are responsible for handling shipments, placarding vehicles in accord with DOT regulations and exercising due care in transporting the goods to a consignee.

Congress has provided DOT with several sources of authority to regulate the safe transportation of spent fuel and high-level radioactive waste shipments. Using the Hazardous Materials Transportation Act of 1974, the Rail Safety Act of 1974 and the Dangerous Cargoes Act, to name but a few, DOT has established a regulatory structure designed to protect life and property while simultaneously allowing hazardous materials to move through interstate commerce relatively unimpeded.

DOT shipper, carrier and transportation requirements are all found in Title 49 of the Code of Federal Regulations. Shipper requirements for marking, labeling, shipping papers, and shipper's certification may be found at \$\$172.300-172.310, 172.400-172.403, 172.200-172.203 and 172.204, respectively. Carrier requirements generally are found at 49 CFR Parts 300 and 399, although additional rules for highway carriers are also found in Parts 172 , 
173 and 177. Handling rules are specified at 49 CFR \$177.842; placarding rules at $\$ \$ 172.519$ and 172.556 and in Appendix B to Part 172; routing requirements in \$177.825; and driver certification of training requirements at \$177.825(d).

DOT regulations found at $49 \mathrm{CFR}$ also attempt to minimize the risk of exposure by providing radiation emission levels for waste packaging (\$173.441); external contamination limits for packaging (\$\$173.443 and 177.843); and handling procedures including regulation of the distances between workers and radioactive material (\$177.842).

DOT has established a National Response Center in Washington, D.C., to provide emergency response information, collect information on hazardous materials transportation accidents and notify specific state and local safety officials regarding major accidents. In addition, computerized records of traffic accidents involving hazardous waste (including carriers' identification, record of previous violations, etc.) are maintained at DOTs Cambridge, Massachusetts, office. The department also has prepared a comprehensive training program for responding to radioactive material transportation accidents. The training program, entitled "Handling Radioactive Materials Transportation Emergencies," is directed to "first-on-the-scene" emergency service personnel such as local fire, police and ambulance organizations.

\subsubsection{Federal Emergency Management Agency}

FEMA is responsible for establishing federal policies for, and coordinating, all civil emergency planning, management, mitigation and assistance functions of federal executive agencies. Additionally, FEMA is responsible for coordinating federal and state emergency response plans, as discussed in chapter 6.0. ${ }^{8}$

\subsubsection{Interstate Commerce Commission}

ICC jurisdiction is limited to the regulation of the economic aspects of radioactive materials transportation (for land shipments). The commission issues operating authorities to carriers as well as controls shipping costs (freight rates). 


\subsubsection{Transportation Shipping Modes}

DOE's Transportation Institutional Plan recognizes a number of different modes that might be used for the transportation of spent fuel and highly radioactive wastes. Specifically, the plan considers "legal weight trucks," "overweight trucks," "regular rail," "heavyweight rail" and "tug-barge/motor vehicles."

To assess the costs and risks associated with different modes of transportation, and combinations of such modes, DOE initiated a study named ALARA, an acronym from "as low as reasonably achievable," which represented the department's goal to reduce radiation exposures to levels as far below federal dose limits as is practicable. In 1988, the department released its report, Analysis of Radiation Doses from Operation of Postulated Commercial Spent Fuel Transportation Systems (DOE-CH/TPO-001), which concluded, in part, that the alternatives developed with the highest system dose reduction were: "(1) those with increased cask capacity, such as overweight truck casks and advanced design casks, (2) increased end shielding on casks and (3) use of remote handling at the repository." 10

\subsubsection{Historic Shipments of Spent Fuel and High-Level Waste}

From July 16,1979 , to September 1,1987 , there were 1,122 commercial and special/test spent fuel shipments in the United States totalling 883.576 metric tons. ${ }^{11}$ While many special test shipments have taken place since 1979 , the bulk of the shipments has involved commercial spent fuel. NRC receives its spent fuels shipping information under 10 CFR 73.37, which requires the commission's licensees to obtain advance approval of routes used for truck shipments of spent fuel.

Between 1979 and 1987 there were 386 spent fuel shipments in southern states totalling approximately 159.8 metric tons. This accounts for 34.4 and 18.1 percent of United States shipments and quantities, respectively. The majority of the southern shipments (315) and quantities (158.9 metric tons) took place within the region. The most significant shipments involved the transfer of 106.7 metric tons of commercial spent fuel in 114 shipments from Duke Power's Oconee I, II and III site near Seneca. South Carolina, to the utility's McGuire I and II site at Cornelius, North Carolina. ${ }^{12}$ 
In addition to NRC's listing of spent fuel shipments, DOT requires the post-notification of highway route-controlled quantity shipments of radioactive materials. Following the department's HM-164 final rulemaking (Fed. Reg., January 19, 1981), all shippers of specified quantities of radioactive materials were required to submit to DOT a shipment route plan and other information within 90 days of the shipment. Effective February 1, 1982 (49 CFR 173.22), the rules also mandated a more appropriate criteria for identifying the types of radioactive materials requiring post-notification. After July 1,1983 , the criteria replaced the use of "large quantity" with "highway route-controlled quantity" based on the $\mathrm{A} 1-\mathrm{A} 2$ radionuclide classification system. ${ }^{13}$

The radioactive shipment information is stored in the Radioactive Materials Routing Report (RAMRT) data base and is controlled by DOTs Office of Hazardous Materials Transportation. The RAMRT data originate from three sources: NRC's Office of Nuclear Material Safety and Safeguards, Division of Safeguards; the Office of Defense Waste and By-products Management, Division of Operations and Traffic of DOE; and NRC-licensed shippers. The report is available to states and the public, on request, in a computer printout format.

\subsection{Routing of Spent Fuel and High-Level Waste}

\subsubsection{Federal Routing Regulations and Requirements for Highway and Rail Shipments}

The goal of the federal government's highway routing regulations for spent fuel and high-level nuclear waste is to reduce risk "by reducing the amount of time radioactive material is in transi:."."14 Since interstate highways generally provide the fastest means for crossing the country, and generally have lower accident rates than other routes, they are the federal government's routing choice. $^{15}$

Three basic routing concepts for shippers are detailed in HM-164, the DOT final rule governing highway routing of radioactive materials, for devising a highway routing system. First, uniform and consistent route selection rules, which are also practical and enhance safety, must be used. Also, route selection should be based on a valid measure of reduced public risk. The overall risk of a route is dependent upon various factors such as accident rates, travel duration, traffic patterns, population density, road conditions, driver training and time of travel. Finally, routing decisions should carefully consider local views since 
"routing is a site-specific activity unlike other transportation controls, such as marking and packaging": ${ }^{16}$ however, routing regulations and final route selection should balance local and national interests. For rail transit, no federal routing regulation s exist; indeed, fewer alternative routes exist, track conditions limit the number of acceptable routes and rail lines generally are privately owned and maintained. ${ }^{17}$

\subsubsection{DOT Rules: The Hazardous Materials Transportation Act and HM-164}

The Hazardous Materials Transportation Act ${ }^{18}$ gives the federal government the power to preempt state requirements inconsistent with the act. ${ }^{19}$ For a state requirement to be preeminent, it must afford greater protection to the public and not place an unreasonable burden on commerce.

The federal government acknowledges that nuclear waste shipment routing is a key concern of state, local and tribal officials; consequently, states are allowed to designate alternative highway routes for spent fuel shipments so that their concerns can be adequately considered. For a route to become an acceptable alternative, the state must demonstrate that the proposed alternative is as safe as the routes specified by the federal government. Therefore, HMTA-preferred routes include interstate highways, as well as beltways around major cities, and/or state designated alternative routes. Carriers are allowed to leave these preferred routes only to pick-up, deliver or trimsfer a "large-quantity package of radioactive materials"; ${ }^{20}$ to obtain necessary iest, fuel and vehicle repairs; or to avoid emergency conditions that might make travel on a designated route unsafe. ${ }^{21}$

HM-164 provides explicit guidance on routing regulations requiring that trucks follow the most direct interstate route and avold large cities when an interstate bypass or beltway is available. Also, HM-164 requires that state governors receive timely notification prior to spent fuel transportation into their state.

\subsubsection{Alternative Route Selection}

DOT encourages states to examine their highway system and designate "preferred" or "alternative" routes for spent fuel transportation either to supplement or provide alternatives to the interstate system. Allowing states to designate alternative routes allows for local input into routing decisions. States are required to choose routes presenting the lowest possible risk to the public--i.e., 
a route or routes that minimize possible radiological impacts from shipments. Selection is made either pursuant to DOE's Guidelines for Selecting Preferred Routes for Large Quantity Shipments of Radioactive Materials or by using "an equivalent routing analysis that adequately considers overall risk to the public." 22 Substantive consultation with affected localities, states and tribes must be included in the analyses so that all potential impacts are considered. Routes must be registered with the U.S. Department of Transportation. ${ }^{23}$

If the federal government accepts a state's alternative route selections, residents and landowners along the newly designated route(s) may be able to apply to have those routes changed again. This situation could conceivably create "a virtual veto on the movement of irradiated fuel on all routes." 24 To avoid this unfortunate occurrence, the federal government has stressed cask safety and the low risk of an accident resulting in a radiological release. ${ }^{25}$

\subsubsection{Methodology for Selecting Routes}

DOT guidelines indicate that state selection of preferred highway routes for nuclear waste shipments is not the only routing analysis method avallable; federal regulations allow states "considerable flexdbility in carrying out the routing function." Any state must use a method that "adequately considers overall risk to the public." 26 States must also meet the requirements that they "solicit and consider input from other jurisdictions which are likely to be impacted by a routing decision. ${ }^{27}$ This consultation with affected local governments and adjoining states allows for consideration of all impacts of an alternative route and the route's continuity. Alternative routes designated by one state must meet another state's designations at each state's boundaries. The method of public participation is left up to the individual state, but states are encouraged to provide public notice of their proposed alternative routes and hold hearings if needed. States are also encouraged to provide time for comments. All alternative routes must be filed with the U.S. Department of Transportation at the conclusion of the designation process. ${ }^{28}$

A state must follow six general steps in selecting an alternative route. First, routes possibly available for shipping wastes between points must be determined. Also, a list of route comparison factors, including primary and secondary factors, must be developed. Route comparison factors for each potential route must be evaluated and the resulting analysis should provide for each primary comparison 
factor and, if deemed necessary, secondary factors. Next, the route that best minimizes the risks associated with waste transportation should be selected as the "preferred" route. The entire route selection process should be documented. ${ }^{29}$

\subsubsection{Southern State Routing Agencies and Advance Notification Agencies}

According to 49 CFR $\$ 171.8$, a state routing agency is an entity authorized to use the state legal process to impose routing requirements, enforceable by state agencies, on carriers of radioactive materials. Consequently, the selection, establishment and authority of a state routing agency is determined by state legislative action and/or executive branch decision. In most southern states the legislature has enacted measures that identify and require a specific state agency to promulgate regulations, rules and policies regarding the transportation of radioactive material into, within or through the state. The state agencies may be required to develop regulations for a variety of transportation issues including routing, hazardous materials definitions, permits, advance notification, escorts and bonding requirements, among others. ${ }^{30}$

The NRC requires advance notification to governors or their designees concerning the transportation of high-level radioactive materials and spent fuel shipments. The prenotification for spent nuclear reactor fuel shipments is addressed in 10 CFR Part 73 and the advance notification of large quantity radioactive waste shipments in 10 CFR Part 71 . In the South, all governors have designated a state agency and contact for receiving prenotification information. The state contact listing is updated annually in the Federal Register on or about June $30 .{ }^{31}$

The state agencies responsible for routing and advance notification in the South fall into seven general departmental categories including health, public safety, transportation, public service, state police/highway patrol, emergency management and nuclear waste. Only in Texas is the prenotification of spent fuel and large quantity shipments divided between two separate agencies. ${ }^{32}$ 


\subsubsection{Avallable Routing Models}

\subsubsection{FHGHWAY Routing Model}

Developed in October 1983, the HIGHWAY routing model is a computerized road atlas that includes more than 19,000 highway segments, 13,000 intersections and descriptions of over 240,000 miles of roadway in the continental United States. ${ }^{33}$ The data base includes a complete description of the interstate highway system, all U.S. highways (except those parallel to an interstate), most principal state highways and many county and local roads. The descriptive data on each highway segment include: highway designations, distance between endpoints, estimated driving speed, possible toll charges and whether the roadway is state approved for transporting spent fuel. With respect to spent fuel transportation, the model now includes commercial nuclear power plant locations and proposed waste management sites as identified by DOE. ${ }^{34}$

The HIGHWAY model will produce routes sensitive to distance, driving time and other criteria. The shortest route between two points may be either the shortest distance or the shortest travel time. The model incorporates a standard time and distance value that calculates routes similar to those chosen by common carriers. The number of drivers (one or two) may even be used to change shipment time based on assumed driving and rest-stop time. ${ }^{35}$

Additional route criteria can also be factored into the model to include or exclude any geologic or populated area of more than 100,000 people, highway intersections or roadway segments. As mentioned earlier, the calculated routes will use "preferred routes" to the greatest extent possible. Finally, state and local legislative restrictions may be incorporated into the model in projecting alternative routes. These restrictions are sometimes preempted by the HMTA. ${ }^{36}$

\subsubsection{INTERLINE Routing Model}

The INTERLINE routing model was developed in November 1983 by ORNL to produce potential rail route networks for transporting radioactive materials. The current system includes some 17,000 links and nearly all the mainlines, branchlines and rall spurs in the United States except industrial spur lines. ${ }^{37}$ The nation's rall system consists of many independent companies, which makes judging potential routes far more complicated than selecting highway routes. ${ }^{38}$ 
While the model identifies the shortest distance route, the system is designed

to reflect the corporate and operational structure unique to the railroad industry. ${ }^{39}$ For example, railroads will usually attempt to maximize a shipment's distance traveled on their system, particularly the first rail carrier to handle the shipment. The model uses a standard multiplier to compensate for this advantage. The model also will automatically minimize the number of tranfers from one railroad company to another. INTERLINE incorporates a weighting factor to make a model use the most heavlly traveled mainlines except in the vicinity of the origin or destination where specific branch lines are required. Like the HIGHWAY model, the rail data base can restrict specific rall links should there be any state or local legislation prohibiting or impeding rail shipment through an area. Currently, however, the lack of such legislation allows spent fuel shipments to take place just as though it is any other general freight. ${ }^{40}$

\subsection{State and Local Government Transportation Restrictions}

Regulations governing nuclear materials transportation are sometimes a source of tension between states/localities and the federal government as these entities enact statutes and ordinances to control the movement of materials on the roads and highways. To test the validity of these measures, the state or local governments may obtain advisory rulings from DOT through an inconsistency ruling or non-preemption determination in lieu of litigation between the federal government and the state/local parties. Alternatively, the validity of the measure may be tested in court.

\subsubsection{Federal Inconsistency Rulings}

A state and/or local government that passes legisluidion on radioactive materials transportation, or any person directly affected by the legislation, may obtain an advisory administrative ruling on whether the act is inconsistent with the Hazardous Materials Transportation Act (HMTA) ${ }^{41}$ or regulations issued under the act. A party adversely affected by a state or local rule need not seek an advisory agency ruling before challenging the rule in a court of law.

Once an advisory administrative ruling is requested, the HMTA is examined to determine if inconsistencies exist between state and federal requirements. In reaching its decision, the DOT's Office of Hazardous Materials Transportation considers the following factors: whether compliance with both the state or local 
requirements and the HMTA, or regulations issued under the HMTA, is possible; and the extent to which the state or local requirement is an obstacle to the accomplishment and execution of the HMTA and its regulations. ${ }^{42}$

DOT's first inconsistency ruling, or IR-1, concerned New York City's health code restrictions on radioactive materials requiring a certificate of "emergency transport" for each shipment of radioactive material traveling through the city. In this ruling, the city ordinance effectively banning shipments of radioactive materials in or through the city was ruled consistent with the HMTA. The final rule was challenged and initially ruled invalid in City of New York v. U.S. Department of Transportation. ${ }^{43}$ That decision was subsequently reversed on appeal. The rule was found to be rationally related to the goal of promoting acceptable levels of highway safety in the transportation of radioactive material expressed in the HMTA. ${ }^{44}$

IR-2 addressed the validity of Rhode Island's restrictions on the transportation of bulk flammable gas (i.e., liquid propane and natural gas) by highway. The rules required compliance with certain operating and equipment requirements. Certain rules and regulations on communications capabilities required under state and local ordinances were held consistent with the HMTA and associated regulations. But requirements on written notification to state agencies of accidents, illuminated rear bumper signs, shank-type locks on trailers, permit requirements for each shipment and prohibitions on travel during rush hour were found inconsistent. These rulings were affirmed on appeal and in court. See: National Tank Truck Carriers, Inc. v. Burke, 535 F. Supp. 509 (D.R.I. 1982), affd 698 F.2d 559 (1st Cir. 1983).

IR-3 involved restrictions imposed by the city of Boston on the routing, time of day and other hazardous materials transportation requirements. DOT concluded that city regulations concerning the immediate reporting of accidents to local officials, requiring the use of major roads except for pickups and deliveries, assessing penalties for violations of valid local regulations, requiring the use of headlights, specifying separation distances between vehicles and adopting federal and state motor carrier safety regulations were consistent. However, city regulations requiring: marking vehicles to identify products, written accident reports, restricting travel during the a.m. rush hours and restricting the use of certain streets were ruled inconsistent. On appeal, the routing restrictions inconsistency finding was rescinded. ${ }^{45}$ 
IR-4 involved a Washington state statutory provision affecting the color of shipping papers for hazardous materials being transported wholly within the state. DOT ruled that state law requiring intrastate shipments of hazardous materials carried by motor vehicles to be accompanied by red or red-colored shipping papers was inconsistent witi the HMTA, claiming that the state scheme would obstrur. a nationally uniform regulatory system of shipping papers. ${ }^{46}$

IR-5 addressed the New York City fire department's regulations concerning the transportation of hazardous gases. In National Tank Truck Carriers, Inc. v. City of New York, ${ }^{47}$ the court found several requirements consistent: rush hour curfews limited to the city; permits that $\mathrm{cn} \cdot \mathrm{l} d \mathrm{~d}$ be obtained over the telephone; and routing restrictions, which prohibited transport through the city unless no practics: alternative route existed. Meanwhile, in examining the city's definitions of such hazardous gases, DOT found the definitions differed from those found in the HIMTA and thus were inconaistent. ${ }^{48}$

IR-6 involved the city of Covington, Kentucky's attempt to require advance notification of any shipments of hazardous material hauled within the city. The ordinance failed to specify how and when such notification should be given or what information should be provided. In its ruling, DOT found the ordinance extended the scope of the regulated hazardous materials to a range of materials not subject to the HMTA and, therefore, the ordinance was deemed inconsistent. ${ }^{49}$

DOT issued its seventh through fifteenth inconsistency rulings following application by the Nuclear Assurance Corporation (NAC) for rulings declaring certain state and local transportation restrictions inconsistent with federal law and, therefore, preempted. NAC claimed that the restrictions were keeping them from carrying nuclear waste from Ontario, Canada, to a reprocessing facility at the Savannah River Plant in South Carolina, along a route preferred for safety and financial reasons. ${ }^{50}$

TR-7 addressed an order from the governor of New York suspending shipments of spent nuclear fuel on two non-interstate highway routes. DOT ruled that the governor's action was consistent with the HMTA because it required compliance with federal regulations requiring use of the interstate highway system. ${ }^{51}$

IR-8 concerned Michigan's use of meesures such as confidentiality standards, inspection requirements (relating to valid regulations), incorporation of federal regulations and notification of shipment schedule changes and concluded that such measures were consistent with the HMTA. However, state regulaticins concerning the definitions of RAM, application for approval of 
shipments and the criteria for acceptance (including container testing and certification requirements) different from the federal regulations, written notification of approvals and notifications of delays and emergency plan implementation were found to be inconsistent with the HMTA. ${ }^{52}$

IR-9 addressed the governor of Vermont's letter advising that shipments of spent nuclear fuel would not be permitted in the state until federal agencies established a national policy on nuclear waste transportation. DOT found the restriction not to be a state "requirement" and thus not subject to an inconsistency ruling. ${ }^{53}$

IR-10 was issued in response to the New York State Thruway Authority's regulations prohibiting the transportation of radioactive materials under its procedures, which generally approved of shipments of low-level radioactive materials and disapproved shipments of highway route controlled quantities. DOT found these procedures to be inconsistent with the HMTA. ${ }^{54}$

IR-11 addressed the Ogdensberg (NY) Bridge and Port Authority's regulations. DOT found that the regulations specifying international bridge crossing times, requiring escort, compensation thereof, and evidence of unquantified "proper" insurance and incorporating county requirements were inconsistent as applied to non-highway route controlled quantities. ${ }^{55}$

IR-12 concerned St. Lawrence County's (NY) laws regulating transportation on non-interstate highways. As applied to non-highway route controlled quantities, the county law was consistent in its non-regulatory and non-obligation policy statement. However, the county laws were inconsistent in its permit requirements and hazardous waste definitions. ${ }^{56}$

IR-13 addressed the Thousand Island (NY) Bridge Authority's regulations regarding permit, fee and escort requirements as applied to vehicles carrying highway route controlled quantities of RAM over interstate highway systems bridge were inconsistent. ${ }^{57}$

IR-14 involved a Jefferson County (NY) ordinance regulating transportation of highway route controlled quantities in certain area, including interstate highways. DOT found the ordinance consistent insofar as it contained front and rear escort requirements identical to NRC standards, but inconsistent in requiring 24 hour pre-notification, limiting transport to May-October period and prohibiting holiday and inclement weather shipments. ${ }^{58}$ 
IR-15 again dealt with Vermont's transportation regulations. DOT found that the state regulations covering highway, rall and water transport of irradiated reactor fuel and nuclear waste were consistent as to statement of intent, information requirements, confidentiality standards and inspection requirements. However, the regulations were inconsistent as applied to federally-regulated highway route controlled quantities, application and criteria for shipment approval, Vermont's written notice of approval, notice requirements for changes in schedule and monitoring of shipments by state officials. ${ }^{59}$

IR-16 concerned an ordinance established by the City of Tucson (AZ) that created regulations differing significantly from federal regulations and prohibiting certain transportation within or through the city. The regulations also spoke to the issue of prenotification. DOT found the ordinance inconsistent with the HMTA. $^{60}$

IR-17 addressed the Illinois statutory fee on spent fuel transportation through the state. DOT found the $\$ 1,000$ per cask fee for funding inspection and emergency response programs to be consistent with federal regulations. ${ }^{61}$

IR-18 held that Prince George's County, Maryland regulations covering the statement of intent, findings and some definitions of radioactive materials transportation were consistent with the HMTA; however, other, broader definitions and penalties, permits, advance notice, information, time, routing, escort and bonding requirements were held inconsistent. ${ }^{62}$

IR-19 addressed the state of Nevada's regulations regarding railroad-related loading, unloading, transfer and storage of radioactive and other hazardous materials. The DOT found that state regulations containing burdensome and discretionary permitting systems were inconsistent with the HMTA. ${ }^{63}$

IR-20 involved regulations of the Triborough Bridge and Tunnel Authority (NY) governing shipments of explosives and other hazardous material. DOT ruled that the regulations effectively prohibiting the transport of the explosives and hazardous material and any unfettered ban on transportation was inconsistent. However, traffic controls, inspections, separation distances and requirements to comply with lawful orders were consistent. ${ }^{64}$

IR-2 1 concerned a Connecticut statute and regulations regarding radioactive materials transportation permitting information, documentation, certification, time restrictions, routing, escort requirements and related definitions. DOT found the regulations to be inconsistent with the HMTA. ${ }^{65}$ 
IR-22 addressed the New York City fire department's directives concerning tank truck carriages of hazardous liquids and gases. DOT ruled that city regulations regarding cargo containment systems, equipment and related areas were inconsistent because they involved exclusively federal areas and caused delays. ${ }^{66}$

IR-23 involved New York City time and routing restrictions. DOT decided that city routing and time restrictions on through-traffic hazardous material transportation were inconsistent since there was no indication that public safety was threatened. ${ }^{67}$

IR-24, decided on May 31, 1988, is the latest DOT inconsistency ruling as of the time of this writing. The ruling concerns the city of San Antonio's regulation regarding placarding of small quantities of explosives. DOT ruled that the city regulation adopting vague explosives-placarding requirements of the 1979 fire code was inconsistent since placarding is exclusively a federal prerogative. ${ }^{68}$

IR-25 questions whether \$I of Ordinance 88-378 of the City of Maryland Heights, Missouri, is inconsistent with the HMTA and the Hazardous Materials Regulations (HMR) and, therefore, is preempted to that extent under section 112(a) of the HMTA (49 App. U.S.C. 1811 (a)).

Section I of the ordinance states that: "No person shall haul sewage, sludge, human excrement, special, hazardous or infectious wastes without providing a bond in the amount of one thousand dollars $(\$ 1,000.00)$ per vehicle for each vehicle, hauling or to haul sewage, sludge, human excrement, special, hazardous or infectious waste."

Since bonding, insurance and indemnity requirements for hazardous material transportation are exclusively federal, the absence of such a requirement in the HMR reflects the OHMT's belief that it is not needed and is inconsistent with the HMR. ${ }^{69}$

IR-26, Docket IRA-42 - Sections $100.00-100.11$ of Title 13, Chapter 1 of the California Administrative Code are inconsistent with the HMTA and the HMR. In relevant part, these regulations provide that out of state drivers transporting hazardous material or waste must receive specified training applicable to the type of material transported. The rules also require that out of state drivers carry either an employer indicating such training or a California non-resident special drivers certificate authorizing transport of hazardous materials. In addition, these regulations include detailed training requirements for drivers hauling hazardous 
waste, hazardous material and bulk liquid loads. These regulations are inconsistent with the HMR to the extent that they apply to operators of motor vehicles transporting hazardous material who are domiciled in another state. ${ }^{70}$

IR-27, Docket IRA-44, refers to DOE's application for an inconsistency ruling on Colorado Public Utilities Commission Regulations for the Safe Transportation of Nuclear Materials by Motor Vehicle (CPUC NT Regulations). CPUC NT regulations, providing for annual and single trip permit fees, are inconsistent with the HMTA and HMR to the extent that they support an inconsistent permit system and discriminate against radioactive materials as compared to other hazardous materials. ${ }^{71}$

IR-28, Docket IRA-45, determined that the city of San Jose, California's ordinance regarding hazardous materials storage was inconsistent as applied to transportation (including storage, loading and incidental unloading) with respect to hazardous materials definition, permitting, information and documentation, storage, unloading, loading, and certain incident reporting requirements; and related civil penalty provisions. However, most of the reporting requirements of the ordinance and the related civil penalties were deemed consistent. ${ }^{72}$

IR-29, Docket IRA-48, addressed Maine's statutes and regulations on hazardous materials transportation permits and fees. The fees were inconsistent insofar as they were based on the SARA Title III list of hazardous substances instead of HMR's Hazardous Materials Table. ${ }^{73}$

IR-30, Docket IRA-47, addressed transportation provisions of Oakland. California's Nuclear Free Zone Act. The ordinance provisions addressing radioactive materials transport were found to be inconsistent in all respects. The ordinance called for a forty-five day prenotification to the city for all shipments of radioactive material, routing and mode requirements for shippers, special placarding, complete prohibition on the transportation and related activities for some classes of materials, information requirements, and inspection and fee provisions. ${ }^{74}$ 


\section{Notes for Chapter 2.0}

${ }^{1}$ Report to Congress on Reassessment of the Civilian Radioactive Waste Management Program. U.S. Department of Energy, November 1989 [DOE/RW-0247] pp.vii-x. See also: 42 USC \$10131 et seq.

${ }^{2} 48$ Fed. Reg. 16590.

${ }^{3} 42$ USC $\$ 10222$.

${ }^{4} 49$ CFR §173.7(d); 48 Fed. Reg. 51875.

${ }^{5} 10$ CFR $\$ 73.37$.

${ }^{6} 49$ Fed. Reg. 23867.

${ }^{7} 10$ CFR $\$ 71.97$.

${ }^{8}$ Executive Order 12148 [July 20, 1979].

${ }^{9}$ Transportation Institutional Plan, U.S. Department of Energy, August 1986, [DOE/RW-0094], pp. A-88 - A-90.

${ }^{10}$ Ibid., pp. A-91 - A-92; OCRWM Bulletin, August 1988, p. 4.

${ }^{11}$ Public Information Circular for Shipments of Irradiated Reactor Fuel NRC Office of Nuclear Material Safety and Safeguards, April 1988, [NUREG-0725 rev. 6], p. 6.

${ }^{12}$ Ibid.

${ }^{13}$ Charles E. Sell and Bradford W. Welles, An Assessment of the U.S. Department of Transportation's Radioactive Materials Routing Report, International Energy Associates, January 1986, p. 2.

${ }^{14}$ Have Waste, Will Travel: An Examination of the Implications of High-Level Nuclear Waste Transportation, Natural Hazard Research. The University of Colorado, July 1987, [Working Paper \#59], p. 58.

${ }^{15}$ Ibid.

${ }^{16} 46$ Fed. Reg. 5299 (1984).

${ }^{17}$ Ibid., pp. 58-60.

${ }^{18} 49$ U.S.C. App. $\$ 1801$, et seq.

${ }^{19}$ Ibid.

${ }^{20}$ Hazardous Materials Transportation Act/HM-164. See also: Have Waste, Will Travel, pp. 58-60. (A final rule has been issued for pickup and delivery of radioactive materials setting out a formula for routing, 55FR 19210 [to be codified at 49 CFR §177.825], May 8, 1990).

${ }^{21}$ Ibid. 
${ }^{22}$ Lessons Learned by Southern States in Designating Alternative Routes (Draft), Southern States Energy Board, May 1989, p. 1. See also: Guidelines for Selecting Preferred Routes for Large Quantity Shipments of Radioactive Materials, U.S. Department of Transportation, June 1981 [DOT RSPA/MTB-81].

${ }^{23}$ Guidelines for Selecting Preferred Routes for Large Quantity Shipments of Radioactive Materials, p.1.

${ }^{24}$ Have Waste, Will Travel, p. 60.

${ }^{25}$ See Chapter 4.0, "Transportation and Storage Casks," for more information on cask specifications and the likelihood, or lack thereof, of a radiological release.

${ }^{26}$ Guidelines for Selecting Preferred Routes for Large Quantity Shipments of Radioactive Materials, p.1.

${ }^{27}$ Ibid.

${ }^{28}$ Ibid.

${ }^{29}$ Ibid.

${ }^{30} 49$ CFR $\$ 171.8$.

${ }^{31}$ Ibid., p. 4.

${ }^{32}$ Ibid.

${ }^{33}$ Spent Nuclear Fuel and High-Level Radioactive Waste Transportation Primer, Southern States Energy Board, July 1987, p. 2-24.

${ }^{34}$ Ibid. See also: HHGWWY, a Transportation Routing Model: Program Description and Revised Users' Manual, Oak Ridge National Laboratory, October 1983, [ORNL/TM-8758].

${ }^{35}$ Ibid.

${ }^{36}$ Ibid.

${ }^{37}$ Ibid., p. 2-28. See also: INTERLINE, a Railroad Routing Model: Program Description and User's Manual, Oak Ridge National Laboratory, November 1985, [ORNL/TM-8944].

${ }^{38}$ Ibid.

${ }^{39}$ Ibid.

${ }^{40}$ Ibid.

${ }^{41} 49$ App. U.S.C. 1801 , et seq.

${ }^{42}$ Spent Nuclear Fuel and High-Level Radioactive Waste Transportation Primer, p. 5-3.

${ }^{43} 715$ F.2d 732 (2d Cir. 1983), cert. denied, 465 U.S. 1055 (1984). 
${ }^{44}$ Inconsistency Ruling No. 1 (1978). Index to Preemption of State and Local Laws and Regulations under the Hazardous Materials Transportation Act, Research and Special Programs Administration, June 5, 1989, p.26. See also: Inconsistency Ruling, IR-1, 43 Fed. Reg. 16954 (1978).

${ }^{45}$ Inconsistency Ruling, IR-3, 46 Fed. Reg. 18918 (1979).

${ }^{46}$ Inconsistency Ruling, IR-4, 47 Fed. Reg. 1231 (1981).

${ }^{47} 535$ F. Supp. 509 (D.R.I. 1982), affd 698 F.2d. 559 (1st Cir. 1983).

${ }^{48}$ Inconsistency Ruling, IR-5, 47 Fed. Reg. 51991 (1982).

${ }^{49}$ Inconsistency Ruling, IR-6, 48 Fed. Reg. 760 (1982).

${ }^{50}$ Index to Preemption of State and Local Laws and Regulations under the Hazardous Materials Transportation Act, Research and Special Programs Administration, June 5, 1989, p.26.

${ }^{51}$ Inconsistency Ruling, IR-7, 49 Fed. Reg. 46635 (1983).

${ }^{52}$ Inconsistency Ruling, IR-8, 49 Fed. Reg. 46637 (1984).

${ }^{53}$ Inconsistency Ruling, IR-9, 49 Fed. Reg. 46644 (1984).

${ }^{54}$ Inconsistency Ruling, IR-10, 49 Fed. Reg. 46645 (1984).

${ }^{55}$ Inconsistency Ruling, IR-11, 49 Fed. Reg. 46647 (1984).

${ }^{56}$ Inconsistency Ruling, IR-12, 49 Fed. Reg. 46650 (1984).

${ }^{57}$ Inconsistency Ruling, IR-13, 49 Fed. Reg. 46653 (1984).

${ }^{58}$ Inconsistency Ruling, IR-14, 49 Fed. Reg. 46656 (1984).

${ }^{59}$ Inconsistency Ruling, IR-15, 49 Fed. Reg. 4660 (1984).

${ }^{60}$ Inconsistency Ruling, IR-16, 50 Fed. Reg. 20872 (1985).

${ }^{61}$ Inconsistency Ruling, IR-17, 51 Fed. Reg. 20926 (1986).

${ }^{62}$ Inconsistency Ruling, IIR-18, 52 Fed. Reg. 200 (1987).

${ }^{63}$ Inconsistency Ruling, IR-19, 52 Fed. Reg. 24404 (1987).

${ }^{64}$ Inconsistency Ruling, IR-20, 52 Fed. Reg. 24396 (1987).

${ }^{65}$ Inconsistency Ruling, IR-21, 52 Fed. Reg. 37072 (1987).

${ }^{66}$ Inconsistency Ruling, IR-22, 52 Fed. Reg. 46574 (1987).

${ }^{67}$ Inconsistency Ruling, IR-23, 53 Fed. Reg. 16840 (1988).

${ }^{68}$ Inconsistency Ruling, IR-24, 53 Fed. Reg. 19848 (1988).

${ }^{69}$ Inconsistency Ruling, IR-25, 54 Fed. Reg. 16308 (1989).

${ }^{70}$ Inconsistency Ruling, IR-26, 54 Fed. Reg. 16314 (1989).

${ }^{71}$ Inconsistency Ruling, IR-27, 54 Fed. Reg. 16326 (1989).

${ }^{72}$ Inconsistency Ruling, IR-28, 55 Fed. Reg. 8884 (1990). 
${ }^{73}$ Inconsistency Ruling, IR-29, 55 Fed. Reg. 9304 (1990).

${ }^{74}$ Inconsistency Ruling, IR-30, 55 Fed. Reg. 9676 (1990). 


\section{Chapter 3.0}

\section{Characteristics of Spent Fuel and High-Level Waste}

\subsection{Spent Fuel}

Under the NWPAA, two types of waste can be disposed of at the proposed repository: spent fuel from nuclear reactors and high-level radioactive waste (HLW) from the reprocessing of fuel. ${ }^{1}$

Spent fuel consists of irradiated fuel rods and assemblies discharged from commercial, test and research reactors. Since 1972, when commercial reprocessing ceased in this country, these wastes have been stored at the individual nuclear plant sites. ${ }^{2}$ Spent fuel is highly radioactive and great care must be taken in handling it. $^{3}$

HLW is produced as the waste products from the reprocessing of nuclear fuels, either from further reactor use of for weapons purposes. However, the vast majority of this waste is a result of defense activities. ${ }^{4}$ Although lower in radioactivity than spent fuel, much HLW is in liquid, sludge, or particulate form that must be rendered chemically inert and solidified prior to disposal. ${ }^{5}$

A third type of waste that will be disposed of at a separate facility is transuranic (TRU) waste. ${ }^{6}$ TRU wastes are those contaminated with heavier than uranium compounds and consist mainly of by-products and contaminated materials from defense activities, and fuel processing and fabrication. ${ }^{7}$ They are of lower activity and generate little or no heat, but contain isotopes with half-lives of more than twenty years. ${ }^{8}$

\subsubsection{Nuclear Fuel Cycle}

The production of spent fuel represents the final stage in the nuclear fuel cycle. The cycle begins with the mining of uranium ore, generally in the western United States. ${ }^{9}$ Once the uranium ore has been mined, it is then crushed, ground and chemically refined to produce a uranium compound known as yellowcake. The yellowcake is then taken to a conversion facility where it is converted to uranium hexafluoride $\left(\mathrm{UF}_{6}\right) \cdot{ }^{10}{ }^{10}$ The $\mathrm{UF}_{6}$ gas is enriched in the isotope uranium-235 by the gaseous diffusion process to obtain the desired fissile content. ${ }^{11}$ Chemical conversion of the enriched $U_{6}$ changes its form from a gas to solid uranium 
dioxdde $\left(\mathrm{UO}_{2}\right)$. The $\mathrm{UO}_{2}$ is then formed into ceramic pellets and encapsulated in a helium atmosphere within a zircalloy tube at a fuel fabrication facility to form fuel rods. ${ }^{12}$ Figure $3-1$ is a schematic of a typical fuel rod assembly. Five fabrication facilities are located in the U.S., with three in the South. ${ }^{13}$

Fuel rods in typical commercial reactors range from 10.5 to 13 feet in length and are slightly over .5 inches in diameter. ${ }^{14}$ The rods are combined at the fabrication facility into a square unit known as a fuel assembly. Each assembly can contain from forty-nine to two hundred and sixty-four rods. Figure 3-2 illustrates a typical fuel rod assembly. The number of rods in the assembly is dictated by the type of reactor design involved.

Two basic types of commercial reactor designs exist in the U.S. ${ }^{15}$ : pressurized water reactors (PWR) ${ }^{16}$ and bolling water reactors (BWR). ${ }^{17}$ Currently, PWR fuel assemblies come in fuel rod arrays of $14 \times 14,15 \times 15,16 \times 16$ and $17 \times 17 .^{18}$ An average $17 \times 17$ PWR fuel assembly is made up of two hundred and sixty four rods and weighs approximately one-half ton. ${ }^{19}$ The BWR fuel arrays have evolved from $6 \times 6$ and $7 \times 7$ arrays to a new type of fuel assembly featuring a $9 \times 9$ array of fuel rods. This evolution occurred owing to developing technologies. ${ }^{20}$ A typical $8 \times 8 \mathrm{BWR}$ fuel assembly has sixty four rods and weighs approximately one quarter ton. $^{21}$

The variety of fuel assembly arrays is significant since their relative sizes (including dimension and length) will directly affect the capacity to store and transport such fuel owing to the limited capacity of the transport and storage casks. In addition, the level of radioactivity and heat generated will vary depending upon the configuration of the array and the type of reactor, i.e., PWR or BWR.

Throughout the nuclear fuel cycle, from mining to fuel assembly, the level of radioactivity is very low. However, once the fuel assemblies in the core of the reactor are allowed to undergo a self-sustaining nuclear fission reaction generating heat, the level of radioactivity increases significantly. In time, the assembly's capacity to maintain a controlled reaction and generate an adequate amount of heat for electric power generation is diminished to the point where it must be removed from the reactor, stored in a protected environment and replaced with fresh fuel. ${ }^{22}$

Even after a fuel rod is spent it contains a higher concentration of $\mathrm{U}^{235}$ than natural uranium (1.4 percent rather than the .7 percent in natural uranium). Fuel rods can thus be reprocessed to produce new fuel. Some commercial reprocessing was done at West Valley, New York from 1966-1972. A combination 
Figure 3-1

Schematic of a Typical Westinghouse Fuel Rod

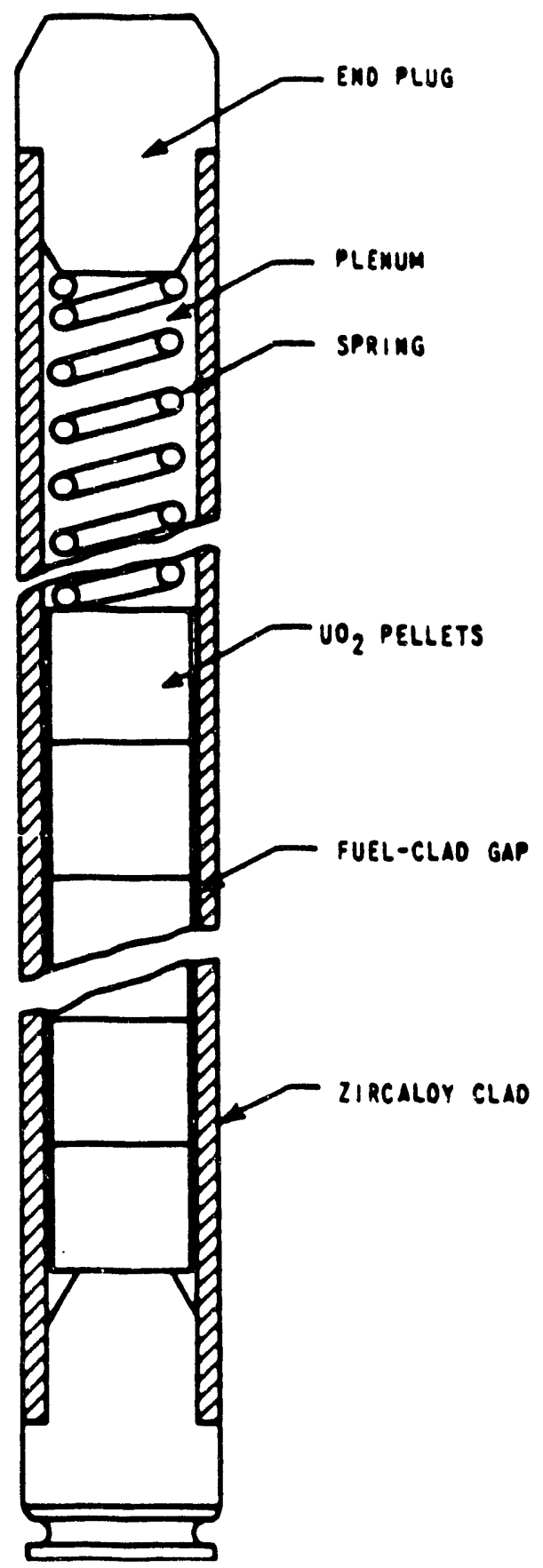

Source: J.W. Poddy, etal. Physical and Decay Characteristics of Commercial LWR Spent Fuel. Oak Ridge National Laboratory, Oak Ridge, Tennessee, January 1986, (ORNL/TM-9591), p. 2-13.

53 
Figure 3-2

Schematic of a Fuel Assembly from Arkansas Nuclear One

ORNL OWG 85-987
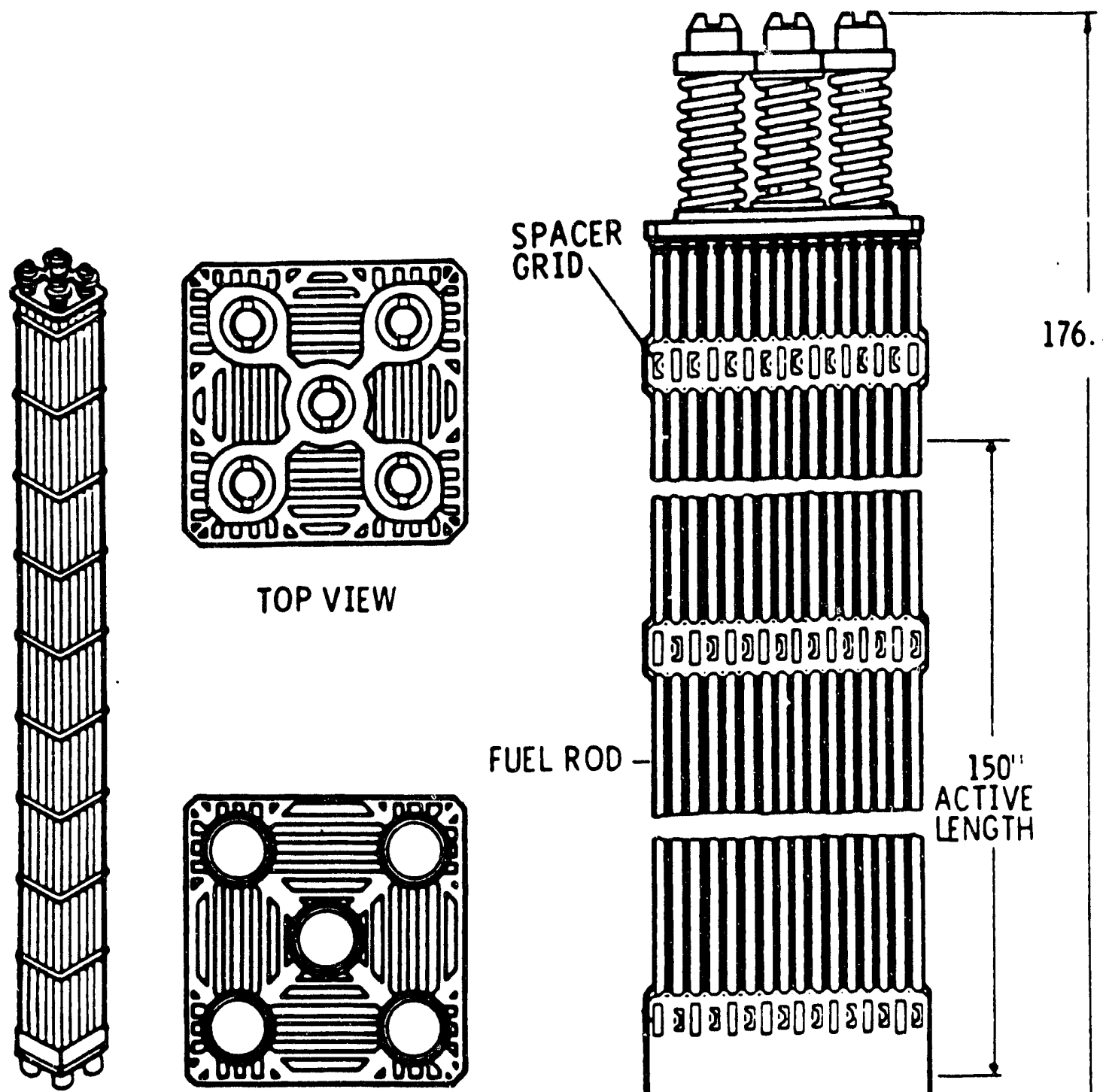

TOP VIEW
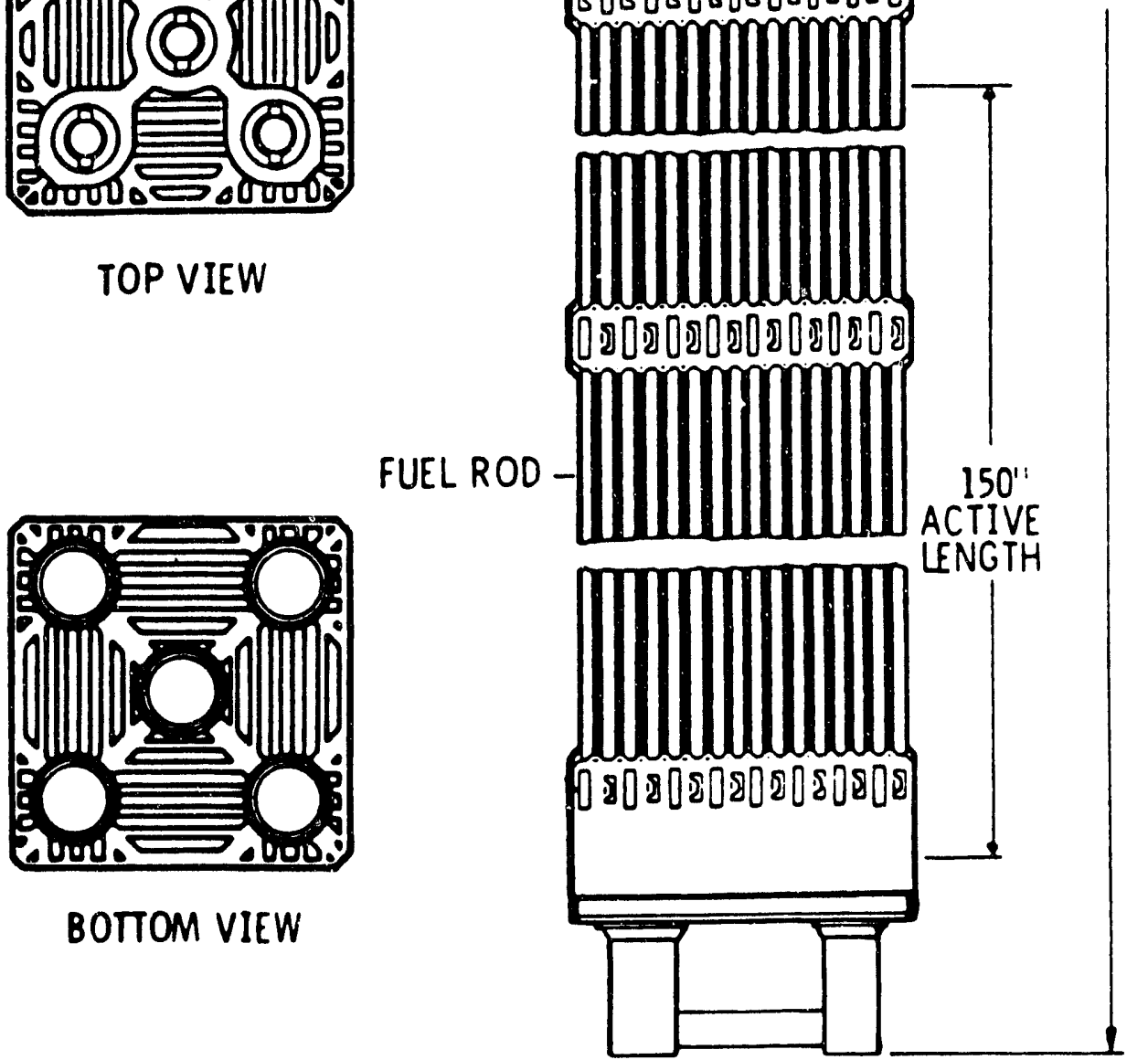

Source: J.W. Roddy, etal., Physical and Decay Charactenstics of Commerclal LWR Spent Fuel. Oak Ridge National Laboratory, Oak Ridge, Tennessee, January 1986, (ORNLTM-9591), p. 2-19. 
of political and economic factors has prevented any commercial reprocessing from being undertaken since. Fuel from military reactors, however, is currently being reprocessed for both weapons and use in navel reactors.

\subsubsection{Production of Commercial Spent Fuel}

Spent fuel is the irradiated or "burned" fuel no longer useful in sustaining a nuclear chain reaction; it must therefore be replaced. Once every 12 to 24 months, the reactor is shut down for fuel replacement. ${ }^{23}$ Approximately one-third of the hot and highly radioactive reactor fuel (50 to 220 fuel assemblies) is removed from the reactor by an overhead crane. The spent fuel is then stored and replaced with fresh uranium fuel. Table 3-1 provides the current spent fuel inventory in the U.S. ${ }^{24}$

Table 3-1

Spent Fuel Inventory Reconciliation (as of December 31, 1988)

\begin{tabular}{lrrrrrrr} 
& \multicolumn{3}{c}{ Assemblies(a) } & \multicolumn{3}{c}{ MTIHM } \\
\multicolumn{1}{c}{ Status of Fuel } & BWR & PWR & Total & BWR & PWR & Total \\
& & & & & & \\
At Reactor Sites & 37,209 & 25,541 & 62,750 & 6,756 & 10,85013 & 17,607 \\
At Morris, Illinois & 2,835 & 352 & 3,187 & 432 & 3 & 565 \\
At West Valley, New York(b) & 85 & 40 & 125 & 11 & 15 & 26 \\
Reprocessed at West Valley & 6 & 100 & 106 & 1 & 45 & 46 \\
\multicolumn{1}{c}{ Total Fuel Discharged } & 35,147 & 23,434 & 58,581 & 6,295 & 9,847 & 16,142
\end{tabular}

(a) Some of these are fuel bearing components that may contain more or less fuel than an intact assembly.

(b) All of the fuel stored at West Valley, New York belongs to DOE. Commercial fuel that was not reprocessed was returned to the utility that generated it.

Source: Spent Fuel Storage Requirements, U.S. Department of Energy, Richland Operations Office, October 1988, [DOE/RL-86-5], p. 3-13. 


\subsubsection{Storace of Commercial Spent Fuel}

After the spent fuel sssemblies are removed from the reactor, they are transferred under water to a forty foot deep temporary storage pool near the reactor. ${ }^{25}$ The assemblies are lowered into storage racks that must be kept separated to provent the spent fuel assemblies from undergoing a spontaneous chain reaction. Pool storage allows the spent fuel to decay, thereby reducing the level of radioactivity and thermal power. ${ }^{26}$

Pool capacity originally depended on shipping spent fuel to a reprocessing plant or an off-site location, such as an interim or permanent storage facility. ${ }^{27}$ Since no reprocessing plants or permanent storage facilities are currently in operation, limited at-reactor storage space is an increasing problem.

Currently, nearly all commercially produced spent fuel is stored in on-site reactor cooling pools. Material not stored on-site is stored at the Midwest Fuel Recovery Plant in Morris, Illinois. ${ }^{28}$ The West Valley facility is being decommissioned; the remaining stored spent fuel will be transported back to the original reactors. The only fuel remaining at the site is owned by DOE. ${ }^{29}$

Table 3-2

Projected Cumulative Storage Requirements--Maximum AR Capacity, Assemblies

\begin{tabular}{|c|c|c|c|c|c|c|c|c|c|c|c|c|c|}
\hline Pool & & 1989 & 1990 & 1991 & 1992 & 1993 & 1994 & 1995 & 1996 & $\{997$ & 1998 & 1999 & 2000 \\
\hline Oconee 1\&2(b) & PWR & 0 & 0 & 7 & 111 & 163 & 215 & 267 & 319 & 417 & 417 & 510 & 555 \\
\hline Crystal Rur 3 & PWR & 7 & 7 & 7 & 84 & 84 & 84 & 153 & 153 & 153 & 218 & 218 & 218 \\
\hline Robinson 2 & PWH & 0 & 27 & 87 & 87 & 135 & 135 & 183 & 229 & 229 & 272 & 272 & 314 \\
\hline Brunswick : & BWR & 0 & 141 & 141 & 321 & 321 & 321 & 501 & 501 & 670 & 670 & 843 & 843 \\
\hline Cavert Clf 1ác & PWR & 0 & 0 & 0 & 0 & 89 & 181 & 181 & 274 & 360 & 447 & 529 & 613 \\
\hline Brunswisk 2 & PWR & 0 & 0 & 0 & 25 & 25 & 205 & 205 & 205 & 374 & 374 & 540 & 540 \\
\hline Ark Nuclear 1 & PWR & 0 & 0 & 0 & 0 & 0 & 0 & 0 & 0 & 17 & 17 & 71 & $\overline{71}$ \\
\hline Sequoyah i\&2 & PWR & 0 & 0 & 0 & 0 & 0 & 0 & 0 & 0 & 0 & 0 & 0 & 13 \\
\hline Oconne 3(b) & PWR & 0 & 0 & 4 & 4 & 56 & 108 & 108 & 156 & 156 & 203 & 203 & 249 \\
\hline
\end{tabular}

Source: U.S. Department of Eliargy, Cask Salely Moeting, Salt Lake City, Utah, February 6-7, 1986.

Limited storage space for spent fuel at most nuclear power plants has made facility shutdown a serious possibility. An estimated 10 southern reactors are expected to fill their storage pools to capacity by the year $2000 .^{30}$ Table 3-2 sets out the projected annual storage needs for select southern reactors up to the year 2000. This projection is based upon expected reactor spent fuel discharges and maximum use of current at-reactor capacity. 
Figure 3-3

Comparison of PWR Spent Fuel Racks
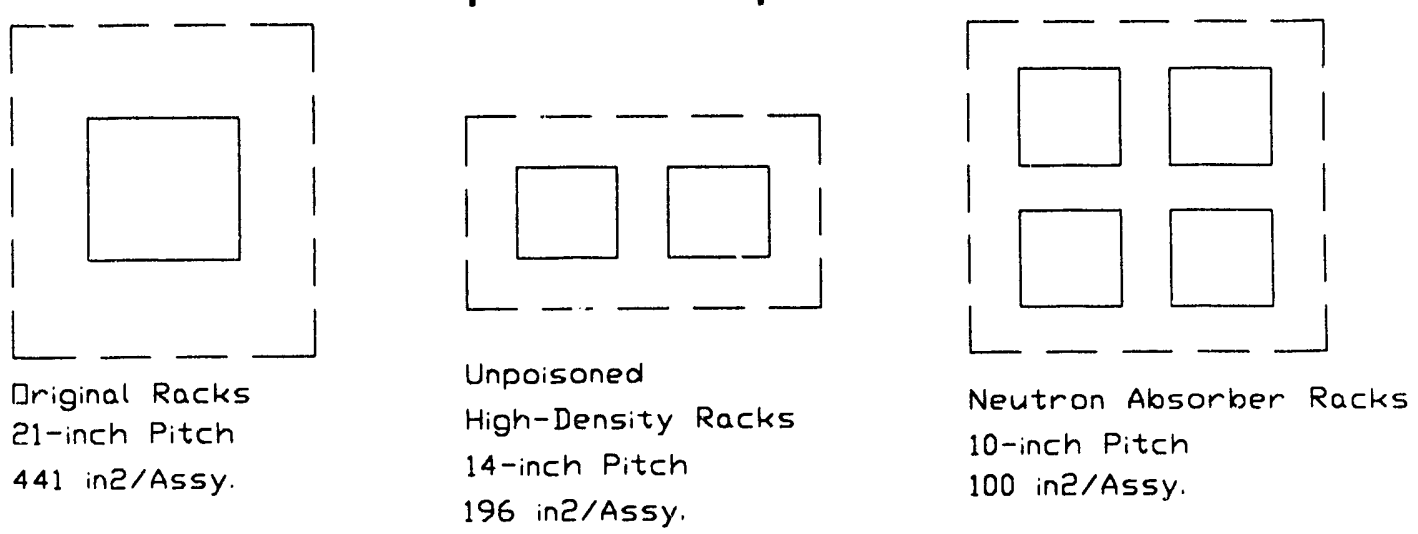

Source: U.S. Department of Energy, Cask Safety Meeting, Salt Lake City, Utah, February 6-7, 1986.

While storage pool capacity is a real and increasing problem, options exist for additional storage space for the spent fuel. A reactor site can improve its storag: capacity by implementation of one or a combination of the following strategies: expanding and increasing the efficiency of available storage pool capacity (e.g., re-racking); rearranging the fuel rods in a more compact array (rod consolidation); and using of transshipments of spent fuel between existing pools; or adding spent fuel dry cask technology. ${ }^{31}$

The expansion of existing storage pool capacity is a relatively simple and direct way to hold more spent fuel. The popular method of re-racking condenses the storage pool area where the spent fuel assemblies are placed. ${ }^{32}$ By replacing nonfuel storage racks with all fuel handling racks or using stainless steel or boron (neutron absorbing) racks, storage capacity can be improved substantially, as demonstrated in Figure 3-3. Re-racking is advantageous owing to its cost effectiveness. It has also been licensed by the NRC. ${ }^{33}$ The problem with re-racking (or double tiering the racks) is the potential structural and seismic constraints owing to size and strength limitations in the pool floor. ${ }^{34}$

Another method presently under consideration for expanding available pool space is rod consolidation. Rod consolidation involves the dismantling of a spent fuel assembly, separating the fuel rods from the hardware that holds them together, rearranging the rods in a more compact array and separately storing the nonfuel-bearing hardware.$^{35}$ Rod consolidation can double the density of fuel rods in a single canister, increasing the capacity of storage pools and providing a cost savings in spent fuel transportation costs. ${ }^{36}$ The most significant project demonstrating the feasibility of rod consolidation was performed in September 
1987, when Northeast Utility Services Company (NUSCO) successfully completed its in-pool consolidation demonstration at the Millstone 2 reactor near Waterford, Connecticut. $^{37}$

A dry consolidation pilot program was installed at the Idaho National Engineering Laboratory (INEL) in Idaho Falls. By the end of 1987, 48 assemblies were successfully consolidated. The data gathered was used to design prototype production scale equipment. Equipment delivery and cold (non-radioactive) testing is began at INEL in $1990 .^{38}$

Like re-racking, rod consolidation has its own limitations and uncertainties. Rod consolidation causes heavier weight loadings, thus creating possible seismic and structural load constraints. ${ }^{39}$ Also, consolidating fuel rods requires the handling, processing and disposal of assembly hardware as well as the fuel rods themselves. ${ }^{40}$

Another option is to transship the spent fuel. This can be accomplished either by transportation of storage casks or through interconnected pools, either off-site or on-site. ${ }^{41}$ By using this technique, the excess storage capacity of one facility can delay the need for additional storage at another. Before Duke's dry storage facility at Oconee became operational, shipments from Oconee to its facility at McGuire were common 175 assemblies were shipped in 1987 alone. ${ }^{42}$

Complications make transshipments somewhat unappealing. In some instances, off-site transshipments have been barred by state laws and local ordinances, not to mention a significant amount of public resistance. ${ }^{43}$ As for on-site transfers of spent fuel, the delayed final solution does nothing to change the long term storage requirements for a reactor. ${ }^{44}$

An additional option for improving a reactor site's storage capacity involves the use of dry storage technology. Dry storage can be provided in various forms, such as casks, modules, drywells or vaults, all located outside the pools. ${ }^{45}$ In the case of vaults and drywells, these concepts may be more appropriate for larger central storage use than for individual reactor storage owing to their size.

Dry storage provides a relatively simple and passive form of spent fuel storage. Perhaps more importantly, dry storage technology can be implemented at nearly any reactor site at a reasonable cost. All of the dry storage systems are designed to have low maintenance requirements and provide additional capacity as required ${ }^{46}$ Currently, the leading candidate for spent fuel dry storage is the metal storage cask, primarily because metal casks are the most modular and offer the most advanced technology. ${ }^{47}$ 
Dry cask storage test programs began in 1977 at the Nevada EMAD site and have since become part of extensive test and demonstration programs. In July 1986. Virginia Power become the first utility in the U.S. to receive an NRC license for dry storage at its Surry Plant. ${ }^{48}$ This facility became operational in $1987 . .^{49}$ The results obtained from the demonstration programs at the Surry facility will be complemented by reports from France and Great Britain. ${ }^{50}$ A second dry storage system, this one using horizontal concrete silos, is operating at Carolina Power \& Light's (CP\&L) H.B. Robinson plant. Duke Power also has a license for a similar system at its Oconee plant. ${ }^{51}$

Many factors should be considered when attempting to draw conclusions about which additional storage method utilities are likely to choose.$^{52}$ Currently, dry storage methods have an advantage in technical maturity and advanced technology, but the long run economics for many sites may ultimately favor consolidation or re-racking. ${ }^{53}$

The NWPA recognized the potential disruption of commercial nuclear power production from insufficient at-reactor storage. While $\$ 131$ of the act specifies that the owners and operators of the civilian nuclear power plants have the primary responsibility for interim storage of their spent fuel, $\$ 136$ of the act provides for Federal Interim Storage (FIS) for utilities that cannot provide adequate storage for their spent fuel and their operation is thereby threatened. ${ }^{54}$

The objective of the FIS program is to plan for and provide assurance of a federal capability to store (on an interim basis) limited quantities (up to 1900 metric tons) of spent fuel from utilities operating nuclear power plants in the U.S. ${ }^{55}$ This storage capability will be made available when a dire need exists (i.e., when, despite their best efforts, utilities are unable to meet their spent fuel storage needs) as determined by the NRC. ${ }^{56}$ Eligibility for such storage is to be determined by the NRC in response to an application by the owner of the reactor. ${ }^{57}$ The authority to enter into contracts for FIS expires on January $1,1990 .^{58}$ To date, no applications have been filed with the NRC seeking a determination of eligibility by a commercial reactor for FIS. $^{59}$

Current spent fuel inventories and storage projections indicate little, if any, immediate demand for federal interim storage. ${ }^{60}$ In fact, it is doubtful that an FIS system will ever be instituted at all. Since the funding for the FIS system would be completely recoverable from the commercial users, the potential cost should stimulate utilities to seek more immediate and less expensive on-site storage options. ${ }^{61}$ Also, the site selection process for an FIS could well turn out to be at least as difficult to resolve as a repository or MRS storage site selection. ${ }^{62}$ Should an FIS be needed, however, concern exists within the Department of Energy that 
the number of transportation casks (particularly legal weight truck casks) currently in use will be insufficient to carry the projected amount of FIS-destined spent fuel in the early 1990 's. ${ }^{63}$

Spent fuel from special research and test reactors is produced by commercial industries, universities and defense facilities. It is difficult to determine the amount of special/test fuel produced and stored since much of it undergoes reprocessing. Special/test fuel is currently transported to either the Savannah River Plant in South Carolina or the Idaho Chemical Processing Plant in Idaho. ${ }^{64}$

\subsection{High-Level Waste and Transuranics}

High-level waste (HLW) is highly radioactive waste generated by the reprocessing of spent reactor fuel and irradiated targets. ${ }^{65}$ HLW may contain significant amounts of transuranic (TRU) waste and fission products. The waste may be an acidic, highly radioactive and heat-producing liquid or a solid material derived from such liquid waste. Federal regulations require that any commercial HLW generated in the future be converted into solid form within five years. ${ }^{66}$

Currently, TRU waste is stored at ten locations: The Hanford Reservation in Washington; Lawrence Livermore National Laboratory in California; the Idaho National Engineering Laboratory; the Nevada Test Site; the Rocky Flats Plant in Colorado; Los Alamos National Laboratory in New Mexico; Argonne National Laboratory in Illinois; the Mound facility in Ohio; Oak Ridge National Laboratory in Tennessee; and the Savannah River Site in South Carolina. A small amount of commercial HLW was generated at the Nuclear Fuel Services Plant (NFS) near West Valley, New York from 1966 through 1972 and is currently stored there. ${ }^{67}$

Inventories of TRU waste and HLW are stored in tanks, bins and capsules. ${ }^{68}$ At SRS, the alkaline liquid, salt cake and sludge wastes are stored in high integrity carbon steel tanks. At INEL, the acid liquid and calcine waste are stored in double containment underground stainless steel tanks. HANF also processes some wastes into double-walled capsules stored in water basins. At NFS, the alkaline liquid and sludge waste is stored in an underground carbon steel tank. ${ }^{69}$

Officials at all of the TRU waste storage sites have plans to implement a processing plant to incorporate the waste into a stable solid medium (e.g., glass or ceramic pellets) for eventual disposal..$^{70}$ The volume of interim waste will be greatly reduced once all HLW and TRU waste is processed. Processing of wastes 
has started at WVDP. A glassification plant is expected to be operating at SRS in 1992, a vitrification plant is planned at Hanford by 1999, and a processing facility for ICPP is scheduled for early in the 21 th century. 


\section{Notes for Chapter 3.0}

${ }^{1} 42$ U.S.C. 10107

${ }^{2}$ Raymond H. Murry, Understanding Radioactive Waste. Third Edition, Battelle Memorial Institute, 1989, pp. 57-58.

${ }^{3}$ Ibid., p.67.

${ }^{4}$ Integrated Data Base for 1989: Spent Fuel and Radioactive Waste Inventories, Projections, and Characteristics, U.S. Department of Energy, Nov. 1989, [DOE/RW-0006, Rev. 5], p. 39-40.

${ }^{5}$ Ibid., p. 41.

${ }^{6} 10$ CFR $§ 60.135$

${ }^{7}$ Integrated Data Base, p. 81-82.

${ }^{8}$ Ibid., p.3.

${ }^{9}$ Understanding Radioactive Waste, p. 72.

${ }^{10} \mathrm{~A}$ PWR utilizes high pressure to transfer heat from a primary loop to a secondary loop containing the working fluid (i.e., the steam system). The steam produced in the secondary loop spins the turbine and then crosses heat exchangers where it is converted back to water. Spent Nuclear Fuel and High-Level Radioactive Waste Transportation Primer, Southern States Energy Board, p. 1-29.

${ }^{11} \mathrm{~A}$ BWR uses low pressure to boil water directly in the reactor itself. The steam then follows the same progress as a PWR system. Spent Nuclear Fuel and High-Level Radioactive Waste Transportation Primer, p. 1-29.

${ }^{12}$ Roddy, J.W., et al.; Physical and Decay Characteristics of Commercial LWR Spent Fuel, Oak Ridge National Laboratory. January, 1986 [ORNL/TM-9591], p.2-1.

${ }^{13}$ Ibid., p. 2-30.

${ }^{14}$ Ibid., p. 2-10.

${ }^{15}$ Ibid., p. 2-39.

${ }^{16}$ The storage pool acts to slow down the fast fission neutrons as well as dissipate the heat generated. Spent Nuclear Fuel and High-Level Radioactive Waste Transportation Primer, p. 1-6.

${ }^{17}$ Karl Stahkopf et al., "Geological Disposal of Nuclear Waste," EPRI Journal [May 1982], p.8. 
${ }^{18}$ Spent Nuclear Fuel and High-Level Radioactive Waste Transportation Primer, 1987, p. 1-6.

${ }^{19}$ The West Valley and Morris Plants were originally constructed to reprocess the spent fuel so as to recapture usable uranium and plutonium. Only the West Valley plant ever became operational for this purpose, starting in 1966 and closing in 1972 owing to the poor economics of commercial reprocessing. Both plants, however, still store a number of the original spent fuel assemblies sent there to be reprocessed. Spent Nuclear Fuel and High-Level Radioactive Waste Transportation Primer, p. 1-15.

${ }^{20}$ Spent Fuel Storage Requirements 1988, October 1989 [DOE/RL 89-30] p. 38.

${ }^{21}$ Annual Report to Congress, U.S. Department of Energy, Office of Civilian Radioactive Waste Management, August 1988 [DOE/RW-0189], p. 25-27.

${ }^{22}$ U.S. Department of Energy, Cask Safety Meeting, Salt Lake City, Utah, February 6-7, 1986.

${ }^{23}$ Understanding Radioactive Waste, p. 65.

${ }^{24}$ Final Version Dry Cask Storage Study, U.S. Department of Energy, Feb. 1989 [DOE/RW-0220], p. I-17.

${ }^{25}$ Understanding Radioactive Waste, p. 66.

${ }^{26}$ Annual Report to Congress, p. 27.

${ }^{27}$ Ibid.

${ }^{28}$ Final Version Dry Cask Storage Study, p. I-19.

${ }^{29}$ Annual Report to Congress, p. 27.

${ }^{30}$ Integrated Data Base, p. 181.

${ }^{31}$ Ibid.

${ }^{32}$ Ibid., p. 3.6.

${ }^{33}$ Final Version Dry Cask Storage Study, p. I-19.

34"Cooperative Demonstration Projects for Spent Nuclear Fuel," OCRWM Backgrounder, U.S. Department of Energy, Office of Civilian Radioactive Waste Management, Aprll 1987 [DOE/RW-0138], p. 2.

${ }^{35}$ R.W. Lambert, et. al., "Waste Management Storage: A Progress Report," Waste Management '86 Proceedings, March 1985, Tucson, Arizona. p. 359.

36" Cooperative Demonstration Projects for Spent Nuclear Fuel," p. 2.

${ }^{37}$ Annual Report to Congress, p. 27. 
${ }^{38}$ Telephone conversation between Judith Holm, DOE-Chicago and Alex Thower, Southern States Energy Board, November 13, 1990.

${ }^{39}$ Annual Report to Congress, Office of Civilian Radioactive Waste Management, U.S. Department of Energy, Dec. 1989 [DOE/RW-0216], p. 18.

${ }^{40}$ In particular, sites with additional storage requirements of between 100 and 350 MTHM may favor consolidation.

${ }^{41}$ Spent Fuel Starage Requirements 1989-2020, U.S. Department of Energy, U.S. Department of Energy, October 1989, [DOE/RL-89-30], p. 34.

${ }^{42}$ Telephone conversation between E.M. Geddie, Manager of Nuclear Operations at Duke Power and Alex Thower, Southern States Energy Board, November 11, 1990.

${ }^{43}$ Spent Fuel Storage Requirements 1989-2020, p. 34.

${ }^{44}$ Annual Report to Congress, p. 27.

${ }^{45}$ Ibid.

${ }^{46}$ Ibid.

${ }^{47}$ Ibid.

${ }^{48}$ Implementation Plan for Deployment of Federal Interim Storage Facilities for Commercial Spent Nuclear Fuel, Pacific Northwest Laboratory, January 1985. [DOE/RW-0019], p. 12.

${ }^{49}$ Ibid., p. 5.

${ }^{50}$ Ibid., p. 6.

${ }^{51}$ Telephone conversation between E.M. Geddie, Manager of Nuclear Operations at Duke Power and Alex Thower, Southern States Energy Board, November 11, 1990.

${ }^{52}$ Annual Report to Congress, p. 15.

${ }^{53}$ Ibid., p. 18.

${ }^{54}$ Integrated Data Base for 1988, p. 41.

${ }^{55}$ High Level and Transuranic Wastes, p. 3-4.

${ }^{56}$ Integrated Data Base for 1988, p. 22.

${ }^{57}$ Ibid., p. 41.

${ }^{58}$ Ibid., p. 46.

${ }^{57}$ Ibid.

${ }^{58}$ Ibid., p.46.

${ }^{59}$ Ibid.

${ }^{60}$ Integrated Data Base for 1988, p. 45. 
${ }^{61}$ Implementation Plan for Deployment of Federal Int:erim Storage Facilities for Commercial Spent Nuclear Fuel, p. 12.

${ }^{62}$ Ibid., p. 6.

${ }^{63}$ Ibid.

${ }^{64}$ High-Level and Transuranic Wastes: Background Information Document for Final Rule, U.S. Environmental Protection Agency, Office of Radiation Programs, August 1985. [EPA 520/1-85-023], p. 12.

${ }^{65}$ Integrated Data Base for 1989, p. 39.

${ }^{66}$ High-Level and Transuranic Wastes, pp. 3-4.

${ }^{67}$ Integrated Data Base for 1989, p. 44.

${ }^{68}$ Ibid., p. 39.

${ }^{69}$ Ibid., p. 44.

${ }^{70}$ Ibid. 


\section{Chapter 4.0}

\section{Transportation and Storage Casks}

\subsection{Spent Fuel Transportation and Storage Casks}

Spent fuel and high level waste is stored and transported in heavily shielded casks to protect the public and transportation workers from dangerous levels of radiation. Casks will generally weigh between 25 and 125 tons empty and consist of a stainless steel storage cylinder and massive steel shielding. The spent fuel cargo carried by the casks comprises only three percent of the cask's total weight.

The Nuclear Waste Policy Act (NWPA) requires an increase in the number of spent fuel shipments in the future; therefore, a larger fleet of truck and rail transport casks will probably be required. ${ }^{1}$ These additional casks must be developed and designed in accordance with regulations spelled out in the NWPA. Each cask design must meet the Department of Energy's (DOE's) requirements for system safety, efficiency and cost effectiveness before the design will be certified by the Nuclear Regulatory Commission (NRC). The certification period is five years, with an option for a five-year renewal. ${ }^{2}$

The transport cask is designed to protect against a release of radioactivity during shipment. ${ }^{3}$ Each cask is required to withstand a sequence of tests encompassing a range of severe accident conditions. ${ }^{4}$ Transport casks are rigorously tested owing to damage possibilities resulting from transportation accidents.

\subsubsection{Cask Design}

The basic design of a spent fuel cask is the same throughout the industry. Each cask consists of at least the following components: a gamma shield (6 to 8 inches of steel, lead or depleted uranium); a neutron shield (water or solid polymer); a heat transfer surface (stainless steel); a lid; a cavity; a basket (boron or stainless steel); an outer inner shell*; energy absorbers*; external impact limiters*; and vehicle tiedowns.*

*extra shielding, collision protection and tiedown equipment unique to transport casks. 
Casks are designed with 6 to 8 inch thick walls of shielding material that provide for heat dissipation and containment. The actual dimensions, configurations and capacities vary, depending entirely upon specific cask requirements (e.g., transport material, mode of transportation, weight restrictions, reactor facilities, etc.). ${ }^{5}$

OCRWM has awarded five contracts to develop a new generation of casks with larger capacity for shipping spent fuel from commercial reactors to the MRS or to the repository. Three contracts are for the development of rail/barge casks, and two for legal weight truck casks. ${ }^{6}$ Preliminary designs for the casks were scheduled by all contractors by December $1989 .{ }^{7}$ The casks are summarized in Table 4-1.

Another concept in cask design explored by cask designers and DOE is the dual purpose cask. The idea behind the dual purpose cask is to combine the uses of a storage cask and a transport cask, thereby eliminating the need for a separate cask for each task. ${ }^{8}$ Dual purpose casks are similar in concept, design and shape to metal storage-only casks. Ideally, this concept will allow for a substantial cost savings by increasing cask efficiency and reducing handling expenses. ${ }^{9}$ The option of loading spent fuel into a cask, storing it for a long period of time and shipping the fuel to DOE facility without unloading or transferring the spent fuel to a shipping cask is especially attractive because of the decrease in handling. ${ }^{10}$

Difficulties exist when a large storage cask is upgraded to meet transportation cask requirements. The storage casks will need modifications in the lid and sealing system, the spent fuel basket and the body of the cask. ${ }^{11}$ Materials with better structural properties may be required to meet the severe accident conditions pursuant to NRC regulations (e.g., stainless steel neutron absorbers to replace water neutron shields). ${ }^{12}$ Dual purpose casks have also proven to be too expensive to the utilities in the long run because of the large initial costs in purchasing casks. On the other hand, dual-purpose casks could be used in the federal waste management system with attendant cost savings provided they are made available by utilities on a timely basis. ${ }^{13}$ But the scenarios that would afford the cost savings are very narrow, and the limited savings would not nearly offset the added cost of the casks. ${ }^{14}$ Therefore, DOE has discontinued funding dual cask development effective January $1990 .{ }^{15}$ 


\subsubsection{Cask Regulatory Standards and Testing}

The performance standards, testing and certification requirements for spent fuel casks have been established by the NRC, ${ }^{16}$ the DOT ${ }^{17}$ and the International Atomic Energy Agency. ${ }^{18}$ To avoid possible conflicts and overlap in regulations, these agencies have agreed to divide their respective responsibilities. ${ }^{19}$ DOT, as discussed in chapter 1, has the responsibility for regulating the transportation of radioactive materials and for general labeling, handling, loading and unloading requirements. The NRC sets standards for packaging and regulating the shipments of spent fuel to and from reactor plants. ${ }^{20}$

Under the NWPA, all shipments of spent fuel to federal facilities (repository, MRS or research center) are the responsibility of the DOE's Office of Civilian Radioactive Waste Management, but these shipments must comply with the DOT and NRC regulations. ${ }^{21}$ In addition, the DOE is obligated under the NWPA to transport spent fuel shipments in NRC-certified shipping casks. ${ }^{22}$

The intent of the cask safety regulations is to protect the public from the risk of radioactive emissions. ${ }^{23}$ Quite often, merely complying with design requirements may not be enough to adequately ensure public safety. Performance testing criteria, which must be met before a cask can be certified, have been brought into question. ${ }^{24}$ The NRC requires that a "margin of safety" be factored into cask designs to ensure NRC certification and cask integrity.

To be awarded NRC certification, a cask must be able to withstand all normal conditions plus a series of hypothetical accident conditions without emitting more than a certain amount of radioactivity. The normal conditions of transport include: heat $\left(100^{\circ} \mathrm{F}\right)$; cold $\left(-40^{\circ} \mathrm{F}\right)$; reduced pressures; increased pressures; vibration; water spray; and free drop (one foot). ${ }^{25}$.

The hypothetical accident conditions for cask testing were developed from a National Academy of Sciences committee's recommendations on tests that would simulate damage to spent fuel casks in the most severe credible accidents. ${ }^{26} \mathrm{~A}$ description of the regulatory tests is as follows:

\section{Mechanical}

a) Eree Drop - Thirty foot drop of the spent fuel cask into a flat, horizontal, unyielding surface with the cask positioned so that its weakest point is struck and maximum damage expected. ${ }^{27}$ 
b) Puncture - A 40 inch free drop of the cask onto an essentially unyielding 6 inch diameter steel bar at least eight inches long; the bar must strike the cask at its most vulnerable spot and in a manner in which maximum damage expected. ${ }^{28}$

\section{Thermal}

c) Fire - After the mechanical tests are completed, the package is exposed for at least 30 minutes to temperatures of $1475^{\circ} \mathrm{F}^{29}$

\section{Water Immersion}

d) Immersion of the entire cask package under at least three feet of water for at least eight hours in a position where maximum leakage is expected; immersion of entire cask package under water pressure equal to immersion below at least 50 feet of water for at least eight hours. ${ }^{30}$

Physical safety testing is rarely performed on full scale models or actual casks. ${ }^{31}$ Testing is generally done on quarter scale models, cask component sections or through computerized modeling analysis. Testing on scale models has the advantage of providing physical performance data at a fraction of the cost of full-scale testing. ${ }^{32}$ Sophisticated software packages have been designed to ensure cask structural integrity without requiring the physical examination of the actual cask. ${ }^{33}$

\subsubsection{Existing Casks and Manufacturers}

Currently, 15 rail and truck shipping casks are in service in the United States. ${ }^{34}$ Most of these casks were designed to meet transportation needs identified prior to the enactment of the NWPA. A listing of these casks is included in table 4-1.

The actual manufacturing of the transport casks is not done by the designers. but is subcontracted out to different manufacturing firms in this country and abroad. Some of the countries that presently manufacture casks to be used in the U.S. include Japan, Spain, West Germany and France. 


\subsubsection{Cask Flandling Canabilities}

The cask handling capabilities of each commercial nuclear reactor will dictate the mode of transport used to ship the spent fuel shipments. Rail casks, for example, weigh considerably more than truck casks and therefore cannot be handled by all reactors with facilities limited by factors such as crane capacity, crane height and access to a rail line. ${ }^{35}$ If a reactor lacks adequate facilities to handle rail casks, the mode of transport is then limited to overweight or legal weight trucks. Table 4-2 identifies spent fuel shipping cask handling capabilities among southern commercial reactor facilities.

\subsubsection{Cask Development and Acquisition for NWPA Shipments}

Under the NWPA, the nur ber of spent fisel shipments will probably increase significantly in the future. The NWPA has also expanded the role of DOE in spent fuel transportation, placing DOE in the position of determining future transportation cask needs. To fulfill this role, the DOE will assist in the development of a new generation of transport casks to meet the added burden of NWPA requirements.

A two-phased transportation acquisition schedule has been established by DOE to support the development of the various casks necessary to ship spent fuel to storage or disposal facilities. As mandated by \$137(a)(2) of the NWPA, DOE is required to use the private sector to the maximum extent possible in all areas of its transportation system , including cask development. 


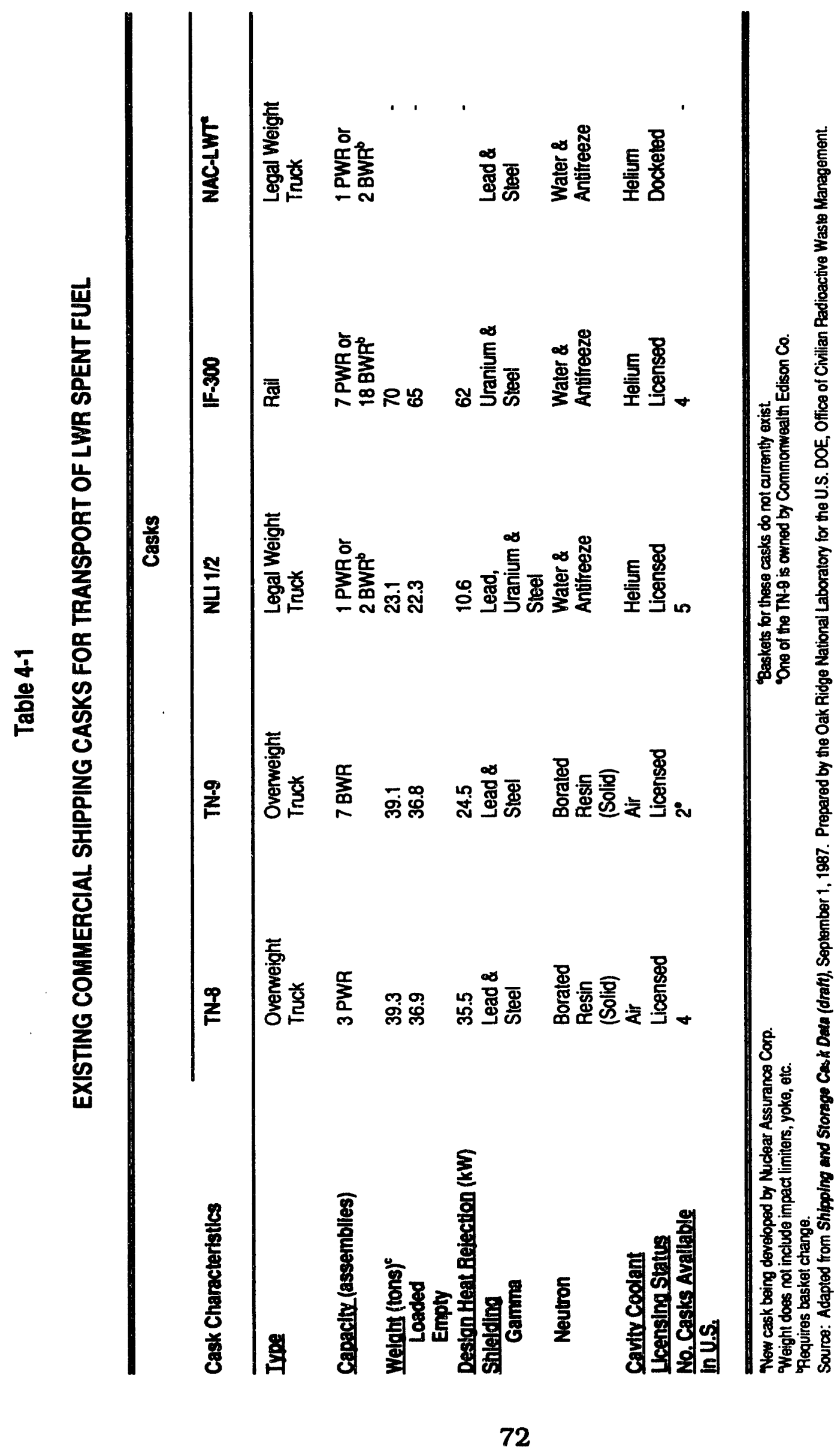


Table 4-2

In Plant Spent Fuel Shipping Cask Handling Capabilities of Southern Commercial Nuclear Power Plants'

\begin{tabular}{|c|c|c|c|c|c|c|c|c|}
\hline State & Plant nam $\theta^{2}$ & $\begin{array}{c}\text { Cask } \\
\text { Experience }\end{array}$ & $\begin{array}{l}\text { Prelerred } \\
\text { Cask }\end{array}$ & $\begin{array}{l}\text { Cask Crane } \\
\text { Capecity" }\end{array}$ & $\begin{array}{c}\text { Crane } \\
\text { Hoight" }\end{array}$ & Depth & $\begin{array}{c}\text { Storage Pool } \\
\text { Width }\end{array}$ & Length \\
\hline AL & $\begin{array}{l}\text { Bellebonte-1 (PWR) } \\
\text { Bellefonte-2 (PWR) } \\
\text { Browns Ferry-1 (BWR)" } \\
\text { Browns Ferry-2 (BWR)" } \\
\text { Browns Ferry-3 (BWR)" } \\
\text { Farloy-1 (PWR)* } \\
\text { Farloy-2 (PWR)" }\end{array}$ & & $\begin{array}{c}N L 10 / 24 \\
N L 10 / 24 \\
(6) \\
(6) \\
(6)\end{array}$ & $\begin{array}{l}150^{5} \\
150^{5} \\
106 \\
106 \\
106 \\
125 \\
125\end{array}$ & $\begin{array}{l}33 \\
33 \\
N / A \\
N / A \\
N / A \\
20.3 \\
20.3\end{array}$ & $\begin{array}{c}43 \\
43 \\
39 \\
39 \\
39 \\
40.8 \\
40.8 \\
\end{array}$ & $\begin{array}{c}12 \\
12 \\
8 \\
8 \\
8 \\
11 \\
11\end{array}$ & $\begin{array}{c}12 \\
12 \\
8 \\
8 \\
8 \\
13.3 \\
13.3 \\
\end{array}$ \\
\hline$A R$ & $\begin{array}{l}\text { Arkansas Nucl.-1 (PWR)" } \\
\text { Arkansas Nucl.-2 (PWR)* }\end{array}$ & & & $\begin{array}{l}100 \\
100\end{array}$ & $\begin{array}{l}29 \\
20\end{array}$ & $\begin{array}{l}43 \\
43 \\
\end{array}$ & $\begin{array}{l}9.5 \\
9.5 \\
\end{array}$ & $\begin{array}{l}10.2 \\
10.2\end{array}$ \\
\hline $\mathrm{FL}$ & $\begin{array}{l}\text { Crysta River-3 (PWR)* } \\
\text { St. Lucie-1 (PWR)* } \\
\text { St. Lucio-2 (PWR)" } \\
\text { Turkey Point-3 (PWR)* } \\
\text { Turkey Point-4 (PWR)" }\end{array}$ & $\begin{array}{c}\text { NAC-1 } \\
\text { NACWFSA, NLI/2 } \\
\text { NACWNSA, NLIV2 } \\
\end{array}$ & $\begin{array}{l}\text { Truck } \\
\text { Truck } \\
\text { Flaxible } \\
\text { LWT8 } \\
\text { LWT8 } \\
\end{array}$ & $\begin{array}{l}120 \\
105^{7} \\
105 \\
105 \\
105\end{array}$ & $\begin{array}{c}30.7 \\
46 \\
46.3 \\
9.4 \\
8.4 \\
\end{array}$ & $\begin{array}{c}43.7 \\
41.2 \\
41.2 \\
40 \\
40 \\
\end{array}$ & $\begin{array}{c}10 \\
10 \\
11.6 \\
9.8 \\
9.8 \\
\end{array}$ & $\begin{array}{c}10 \\
12 \\
12.5 \\
10.1 \\
10.1 \\
\end{array}$ \\
\hline GA & $\begin{array}{l}\text { Hatch-1 (BWA) } \\
\text { Hatch-2 (BWR)" } \\
\text { Vogtlo-1 (PWR) } \\
\text { Vogto-2 (PWR) }\end{array}$ & $\begin{array}{l}\text { IF-300 } \\
\text { IF-300 }\end{array}$ & $\begin{array}{l}125 \\
125 \\
125 \\
125\end{array}$ & $\begin{array}{l}28 \\
28 \\
40 \\
40\end{array}$ & $\begin{array}{c}39 \\
39 \\
46.4 \\
46.4\end{array}$ & $\begin{array}{c}12 \\
12 \\
13.4 \\
13.4 \\
\end{array}$ & $\begin{array}{c}14 \\
14 \\
13.4 \\
13.4\end{array}$ & \\
\hline LA & $\begin{array}{l}\text { River Bend-1 (BWR) } \\
\text { Walerford-3 (PWR) }\end{array}$ & (9) & $\begin{array}{r}125 \\
125^{10} \\
\end{array}$ & $\begin{array}{r}28 \\
29.5 \\
\end{array}$ & $\begin{array}{c}43 \\
45.5 \\
\end{array}$ & $\begin{array}{l}12 \\
12 \\
\end{array}$ & $\begin{array}{l}12 \\
13 \\
\end{array}$ & \\
\hline MD & $\begin{array}{l}\text { Calvert Clifts-1 (PWR) } \\
\text { Calvert Clifts-2 (PWR) }\end{array}$ & $\begin{array}{l}\text { NACNFSA, NLIV2 } \\
\text { NACNFS4, NLIV2 }\end{array}$ & $\begin{array}{l}\text { NLIV2 } \\
\text { NLIV2 }\end{array}$ & $\begin{array}{l}150 \\
150\end{array}$ & $\begin{array}{l}35 \\
35\end{array}$ & $\begin{array}{l}41 \\
41\end{array}$ & $\begin{array}{l}9 \\
9\end{array}$ & $\begin{array}{l}11 \\
11\end{array}$ \\
\hline MO & Callaway-1 (PWR) & & & 150 & 31.3 & 44.3 & 16 & 18 \\
\hline MS & Grand Gulf-1 (BWR)• & & & 150 & 38 & 49 & 16 & 16 \\
\hline$N C$ & $\begin{array}{l}\text { Brunswick-1 (BWR)" } \\
\text { Brunswick-2 (BWR) } \\
\text { Harris-1 (PWR) } \\
\text { MoGuire-1 (PWR) } \\
\text { MoGuire-2 (PWR) }\end{array}$ & $\begin{array}{c}\text { NACNFS4, NUIV2 } \\
\text { NACNFS4, NLIV2 } \\
\text { NUIV2 } \\
\text { NLIV2 }\end{array}$ & $\begin{array}{l}\text { IF-300 } \\
\text { IF-300 } \\
\text { IF-300 } \\
\text { Truck } \\
\text { Truck }\end{array}$ & $\begin{array}{l}125 \\
125 \\
150 \\
125 \\
125\end{array}$ & $\begin{array}{c}28.2 \\
28.2 \\
27 \\
26.2 \\
26.2\end{array}$ & $\begin{array}{c}38.8 \\
38.8 \\
35 \\
48.4 \\
48.4\end{array}$ & $\begin{array}{l}10.3 \\
10.3 \\
12 \\
9.1 \\
9.1\end{array}$ & $\begin{array}{c}10.3 \\
10.3 \\
12 \\
11.1 \\
11.1\end{array}$ \\
\hline sc & $\begin{array}{l}\text { Catawba-1 (PWR) } \\
\text { Catawba-2 (PWR) } \\
\text { Oconoe-1 (PWR)' } \\
\text { Ocone日-2 (PWR)' } \\
\text { Oconno-3 (PWR)' } \\
\text { Robinson-2 (PWR) } \\
\text { Summer-1 (PWR) } \\
\end{array}$ & $\begin{array}{l}\text { NAC-1, NLIV2 } \\
\text { NAC-1, NLIV2 } \\
\text { NAC-1, NLIV2 } \\
\text { IF-300 } \\
\end{array}$ & $\begin{array}{l}\text { Truck } \\
\text { NAC-1, NLIV2 } \\
\text { TN-8 } \\
\text { IF-300 } \\
\text { AL" }\end{array}$ & $\begin{array}{l}125 \\
125 \\
100 \\
100 \\
100 \\
125 \\
125 \\
\end{array}$ & $\begin{array}{c}32.4 \\
32.4 \\
23.7 \\
23.7 \\
23.8 \\
37 \\
31.5 \\
\end{array}$ & $\begin{array}{c}48.4 \\
48.4 \\
44 \\
44 \\
44 \\
40.7 \\
39 \\
\end{array}$ & $\begin{array}{l}9.1 \\
9.1 \\
7.1 \\
7.1 \\
7.2 \\
9 \\
13 \\
\end{array}$ & $\begin{array}{c}11.5 \\
11.5 \\
8.7 \\
8.7 \\
8.9 \\
9 \\
13 \\
\end{array}$ \\
\hline TN & $\begin{array}{l}\text { Sequoyah-1 (PWR) } \\
\text { Sequoyah-2 (PWR) } \\
\text { Wats Bar-1 (PWR) } \\
\text { Watts Bar-2 (PWR) }\end{array}$ & $\begin{array}{l}\text { Al" } \\
\text { Al" } \\
\text { (12) } \\
(12) \\
\end{array}$ & $\begin{array}{l}125 \\
125 \\
125 \\
125 \\
\end{array}$ & $\begin{array}{l}32.5 \\
32.5 \\
\text { NAA } \\
\text { NA }\end{array}$ & $\begin{array}{l}25 \\
25 \\
50 \\
50 \\
\end{array}$ & $\begin{array}{l}12 \\
12 \\
8.1 \\
8.1 \\
\end{array}$ & $\begin{array}{l}12 \\
12 \\
8.1 \\
8.1 \\
\end{array}$ & $\begin{array}{l}12 \\
12 \\
8.1 \\
8.1\end{array}$ \\
\hline$T X$ & $\begin{array}{l}\text { Commanche Peak-1 (PWR) } \\
\text { Commanche Peak-2 (PWR) } \\
\text { S. Texas Proj.-1 (PWR) } \\
\text { S. Texas Proj.-2 (PWR) }\end{array}$ & $\begin{array}{l}T N-12 \\
T N-12\end{array}$ & $\begin{array}{l}130 \\
130 \\
150 \\
150\end{array}$ & $\begin{array}{l}30 \\
30 \\
29 \\
29\end{array}$ & $\begin{array}{l}47 \\
47 \\
41 \\
41\end{array}$ & $\begin{array}{l}13 \\
13 \\
10 \\
10\end{array}$ & $\begin{array}{l}13 \\
13 \\
10 \\
10\end{array}$ & \\
\hline
\end{tabular}

Source: Adapled from Shipoing and Stonge Ceak Data (draft), Seplember 1, 1987. Propared by the Oak Ridge National Laboratory for the U.S. DOE, Office of Civilian Radioactive Wasto Management. 
Table 4-2 (continued)

In Plant Spent Fuel Shipping Cask Handling Capabilities

of Southern Commercial Nuclear Power Plants'

\begin{tabular}{|c|c|c|c|c|c|c|c|}
\hline Plant name $e^{2}$ & $\begin{array}{c}\text { Cask } \\
\text { Experience }\end{array}$ & $\begin{array}{l}\text { Prelented } \\
\text { Cask }\end{array}$ & $\begin{array}{c}\text { Cask Crane } \\
\text { Capecity" }\end{array}$ & $\begin{array}{l}\text { Crane } \\
\text { Height }\end{array}$ & Depth & $\begin{array}{l}\text { Storage Pool' } \\
\text { Width }\end{array}$ & Length \\
\hline North Anna-1 (PWR)" & & TNE & 125 & 20 & 45 & 12 & 12 \\
\hline North Anna-2 (PWR)" & & TN-8 & 125 & 20 & 45 & 12 & 12 \\
\hline Surry-1 (PWR) & $T N-8$ & TN-8 & 125 & 29 & 40.5 & 12 & 12 \\
\hline Surry-2 (PWR)" & TN-8 & $T N-8^{19}$ & 125 & 28 & 40.5 & 12 & 12 \\
\hline
\end{tabular}

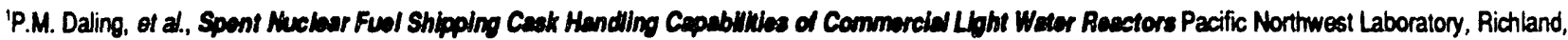
Washington, April 1984, Appendix A.

2Asterisk (") denotes operating plants.

'Cask crane capacity in tons.

"Cask crane height and storape pool in ieet.

Designed for 100-ton cask with 10 PWR fuol assembly capacity.

"67-1on cask analyzed for use.

'Cask crane specifications limited to 25-ton load.

Legal weight truck; plant license limits cask use to single assembly casks with 25-ton cask weight maximum.

'Facility based upon a cask 7 feet in diameter, 18 foet long and 100-bn maximum load weight with 18 fuel assemblies.

${ }^{10}$ Derated crane capacity to 70.5 tons.

"Assumed capable by plant porsonnel to handle all oxisting cask types.

${ }^{12}$ Designed for up to a 100 -ion rail or truck cask

'May be shipping TN-9 cask in near future.

Source: Adapted from Shipping and Storags Caak Duta (draft), Seplember 1, 1987. Prepared by the Oak Ridge National Laboratory for the U.S. DOE, Office of Civilian Radioactive Waste Management.

The second phase of the program will evaluate potential service contractors responsible for normal NWPA shipping operations. Considerations include fleet procurement; carriage arrangement; inspection; maintenance and repair services; training operations and security personnel. ${ }^{36}$ Although the private sector must be used to the maximum extent possible. DOE will provide technical assistance whenever necessary and supervise the entire quality assurance program. ${ }^{37}$ If the situation should arise that the private sector is unwilling or unable to provide spent fuel transportation at reasonable costs, DOE will use direct federal services to ensure that service arrangements and operational activities for the cask transportation system are maintained. ${ }^{38}$ 


\subsection{High-Level Waste Casks for NWPA Shipments}

The NWPA not only assigned DOE the task of establishing and operating a system for disposal of spent nuclear fuel, but it also required DOE to develop a system for disposing of both commercial and defense high-level waste (CHLW and DHLW).

\subsubsection{Cask Design}

Unlike commercial spent fuel, which is shipped in the form of fuel rod assemblies, CHLW and DHLW are liquid wastes or solids derived from liquid wastes that must be vitrified into stable, easy-to-handle canisters. These canisters are then fitted into a cask for transport to a repository or storage facility.

Current cask designs for transporting HLW include legal weight truck (a truck whose weight does not exceed the maximum allowable on the nation's highways) and rail casks. ${ }^{39}$ These casks are larger than the transport casks that carry spent fuel assemblies and contain heavier shielding. ${ }^{40}$

A CHLW cask, when constructed, will be 14 feet long and almost three feet wide, have almost 15 inches of gamma and neutron shielding and weigh almost 49,200 lbs. fully loaded. ${ }^{41}$ Each legal weight truck cask can carry one canister of CHLW. ${ }^{42}$ A CHLW rail cask is 14 feet long, over seven feet wide and weigh 167,200 lbs. fully loaded. ${ }^{43}$ Each CHLW rail cask can carry up to 12 canisters. ${ }^{44}$

The capacity and weight of the DHLW truck casks are similar to the CHLW truck casks. The DHLW casks have over 23 inches of gamma and neutron shielding and weigh 49,800 lbs. fully loaded..$^{45}$ Each CHLW truck cask can carry one canister. ${ }^{46}$ Rail DHLW casks, however, will be slightly shorter ( 13 feet), much wider ( 10 feet) and weigh more ( 187,000 lbs. fully loaded) than a CHLW cask. ${ }^{47}$ Each DHLW rail cask can transport up to five canisters. ${ }^{48}$ 


\section{Notes for Chapter $\mathbf{4 . 0}$}

${ }^{1}$ Lake H. Barrett, "Review and Status of the DOE Cask Acquisition Program," Journal of the Institute of Nuclear Materials Management, XV (April 1987): pp. 19-21.

${ }^{2}$ Transporting Spent Nuclear Fuel: An Overview, U.S. Department of Energy, Office of Civilian Radioactive Waste Management, March 1986 [DOE/RW-0065], p. 11.

${ }^{3}$ The League of Woman Voters Education Fund, The Nuclear Waste Primer (New York: Nick Lyons Books, 1985), p. 42.

${ }^{4}$ Ibid., p. 42.

${ }^{5}$ Transporting Spent Nuclear Fuel, p. 11.

${ }^{6}$ Annual Repart to Congress, U.S. Department of Energy, Office of Civilian Radioactive Waste Management, December 1989 [DOE/RW-0216], p. 13.

${ }^{7}$ Preliminary Design Report Executive Summary. Nuclear Packaging NUPAC 140B Cask, Nuclear Packaging, Inc., May 1990 [DOE/ID/12700-1 Ex. Sum]

${ }^{8}$ Final Version Dry Cask Storage Study, U.S. Department of Energy, Office of Civilian Radioactive Waste Management, February 1989 [DOE/RW-0220], p. I-49.

9"Storage and Transport Casks Combine to Bring Benefits," Nuclear Engineering International, December 1988.

${ }^{10}$ Final Version Dry Cask Storage Study, p. I-48.

${ }^{11}$ Ibid., p. I-49.

${ }^{12}$ Ibid.

${ }^{13}$ Ibid., p. II-26.

${ }^{14}$ Ibid., p. II-27.

${ }^{15}$ "FY HLW Budget at $\$ 500$ Million, No Fund for Dual Cask Work," The Radioactive Exchange (January 19, 1989), p. 1.

${ }^{16} 10$ CFR 71.

${ }^{17} 49$ CFR 173.

${ }^{18}$ Safety Series No. 6: International Atomic Energy Agency Standards: Regulations for the Safe Transport of Radioactive Materials, International Atomic Energy Agency, Vienna, Austria, 1979. 
${ }^{19} 44$ Fed. Reg. 38690, July 2, 1979. See also: The Nuclear Waste Primer, p. 41.

${ }^{20} 10$ CFR 71, 73.

${ }^{21}$ Ibid.

${ }^{22}$ Ibid.

${ }^{23}$ Transporting Spent Fuel, U.S. Nuclear Regulatory Commission, March 1987 (NUREG/BR-0111), p. 11.

${ }^{24}$ The Nuclear Waste Primer, p. 42.

${ }^{25} 10$ CFR 71.71.

${ }^{26}$ Transporting Spent Nuclear Fuel: An Overview, p. 13.

${ }^{27} 10$ CFR 71.73 (1).

${ }^{28} 10$ CFR 71.73 (2).

${ }^{29} 10$ CFR 71.73 (3).

${ }^{30} 10$ CFR 71.73 (4).

${ }^{31}$ The Nuclear Waste Primer, p. 42.

${ }^{32}$ Presentation by Mr. William Lake, DOE-Washington, "DOE Cask Development Program," Midwestern High-Level Radioactive Waste Committee Meeting, Minneapolis, Minnesota, November 15, 1990.

33"Shipping Cask Analysis System," Energy and Technology Review, June 1989, p. 42.

${ }^{34}$ Shipping and Storage Cask Data (draft), September 1, 1987. Prepared by the Oak ridge National Laboratory for the U.S. DOE, Office of Civilian Radioactive Waste Management.

${ }^{35}$ Spent Nuclear Fuel and High-Level Radioactive Waste Transportation Primer, Southern States Energy Board, July 1987, pp. 7-8.

${ }^{36}$ Transportation Business Plan, U.S. Department of Energy, Office of Civilian Radioactive Waste Management, January 1986, [DOE/RW-0046], p. 35.

${ }^{37}$ Ibid.

${ }^{38}$ Ibid., p. 42.

${ }^{39}$ A.W. Dennis et al., NNWSI Repository Operational Procedures for Receiving Packaging, Emplacing and Retrieving High-Level and Transuranic Waste, Sandia National Laboratories, 1984 [SAND83-1166], p. 3-1.

${ }^{40} \mathrm{Ibid}$.

${ }^{41}$ Ibid., pp. 3-11.

${ }^{42}$ Ibid. 
${ }^{43}$ Ibid., pp. 3-13.

${ }^{44}$ Ibid.

${ }^{45}$ Ibid., pp. 3-16.

${ }^{46}$ Ibid.

${ }^{47}$ Ibid., pp. 3-19.

${ }^{48}$ Ibid. 


\section{Chapter 5.0}

\section{Transportation Risk and Cost Analysis}

\subsection{Analysis of Risks Involved in Transporting Spent Fuel and High-Level Waste}

Provisions of the Nuclear Waste Policy Act of 1982 had the effect of requiring the Department of Energy to conduct analyses of the risks involved in transporting spent fuel and high-level waste. Although DOE had the benefit of some historical information regarding accidents and incidents involving radioactive wastes, it necessarily turned to the development of computer models and systems to permit useful and accurate risk assessments. Out of DOE's efforts came the creation of the RADTRAN, WASTES, HIGHWAY, INTERLINE and other computer programs to provide necessary data and to make the required computations and projections. Although DOE published its assessments in 1986, risk analysis efforts have continued and the basic programs and databases have been made available to authorized users through the TRANSNET network. The result of these efforts by DOE, together with related work performed by or for such agencies as NRC, has been to indicate that the likelihood of a serious threat from radioactive hazards arising out of a transportation accident is extremely slim, while the risk of sabotage occurring during such transportation is even more remote.

\subsubsection{NWPA Mandated Risk Analyses}

Any effort to develop a responsible system for the transportation of spent fuels and high-level wastes necessarily would involve attempts to determine and assess the risks inherent in that system. Recognizing that fact, the Nuclear Waste Policy Act of 1982 required, as a component of the environmental assessments mandated for each proposed characterization site, that consideration be given to "...the effects of the site characterization activities on the public health and safety and the environment."1 DOE, in its 1985 Mission Plan for the Civilian Radioactive Waste Management Program, pledged that "OCRWM will continually assess the effects of its transportation plans and activities on all affected parties" and noted that such assessments would include "generic analyses of the safety, environmental impacts, and costs of transportation for various storage and repository siting options." ${ }^{2}$ 
How then to assess the risks to safety of the transportation of spent fuels and HLW? Fortunately, experience with shipments of such fuels and wastes has resulted in relatively few transportation accidents, and none of those few has entailed the creation of any significant radiological hazard. ${ }^{3}$ Using in part the data available from those few accidents, though, NRC as early as 1977 attempted to quantify the radiological risk to the public from all shipments of radioactive material and, in its Final Environmental Statement on the Transportation of Radioactive Material by Air and Other Modes, concluded that, despite a presumption that releases of radioactive material could occur under certain severe accident circumstances, "the overall resulting radiological risk from transporting spent fuel under current regulations was calculated to be acceptable." ${ }^{4}$ The NRC performed a modal study in 1988 to determine radiological risks under certain real world accident conditions. Again, the radiological risks were found to be acceptable.

Pursuant to its responsibilities under NWPA and in addition to its other risk assessment efforts. DOE attempted to gain an even greater understanding of the lessons of actual transportation accidents by commissioning Sandia National Laboratories to study and analyze all accidents and incidents involving the transportation of radioactive material during the period 1971-1980. Sandia's 1985 report, authored by J.D. McClure and A. Tyron-Hopko and entitled, Radioactive Material (RAM) Transportation Accident/Incident Analysis, disclosed a total of 370 transporting and handling "accidents" during the period, as well as an additional 664 "reported incidents. ${ }^{15}$ The reported accidents involved a total of 1.198 radioactive material packages, only 10 of which were "Type B" packages (those designed to retain the integrity of containment and shielding when subjected to normal conditions of transport and hypothetical accident test conditions).$^{6}$ None of the Type $B$ package accidents resulted in a packaging failure, nor was there any release of their radioactive contents. ${ }^{7}$

Despite the valuable information gained through accident studies such as that conducted by Sandia, far more sophisticated assessments and analyses were required for purposes of the environmental assessments mandated by NWPA and DOE's commitment to ongoing risk studies and analyses. The number of variables necessary for consideration was truly staggering. Factors such as cask capacity, waste consolidation, use of dedicated trains, the amount of fission energy remaining in particular shipments of spent fuel, the physical form of the material, the fuel assembly design and the particular isotope involved, among many others, could have a substantial impact on the risks involved in any accident. ${ }^{8}$ 


\subsubsection{Computer Models and Codes}

To permit consideration of the multitude of variables pertinent to nuclear waste transportation risk assessments. DOE, in cooperation with Sandia National Laboratories, Battelle Pacific Northwest Laboratories and Oak Ridge National Laboratory, proceeded with the creation of a number of computer models and systems by which key variables could be computed or estimated and, ultimately, risks could be ascertained or projected. Underlying those efforts was a decision by DOE to make certain "simplifying assumptions," the most important of which was to create "unit-risk" factors to "represent the risk of transportation for a unit distance of travel in a defined population zone." The use and development of such unit-risk factors was described by M.M. Madsen and others in Sandia's 1983 report, RADTRAN II Users Guide (SAND82-2681), and, as suggested by the report's title, the computer model was known as RADTRAN. ${ }^{9}$

As described by J.W. Cashwell and K.S. Neuhauser of Sandia National Laboratories and E.A. Kern of the Los Alamos National Laboratory, the RADTRAN model, in its current form designated RADTRAN III: "calculates the radiological risks associated with the transport of radioactive materials. RADTRAN may be used alone for simple origin-destination calculations or can be used to generate radiological unit-risk factors (risk per shipment-kilometer). The units of risk are dose or radiological health effects, which include latent cancer fatalities and genetic effects." Further explaining RADTRAN, the authors noted:

The RADTRAN III code consists of two major modules: the incident free transport module in which doses resulting from normal transport are calculated, and the accident module which calculates consequences and probabilities of accidents. Included in the incident-free module are models describing:

- offlink dose, e.g., dose to persons within 800 meters of the transport link (highway, railway or waterway):

- dose to persons sharing the transport link (onlink dose), which includes three submodels describing doses to persons in (a) vehicles traveling in the opposite direction, (b) vehicles traveling in the same direction, and (c) passing/adjacent vehicles, respectively; 
- dose to members of the public at stops; and

- dose to drivers, rail crews, etc. (occupational dose).

Each of these calculations is performed separately for each shipment type and for each transport mode in each of three population density zones.

In the accident module of the code, the range of possible accidents can be divided into a maximum of 8 severity categories. The probability and consequences of accidents of each severity are specified for each important radionuclide in each shipment type for each transport mode in each population density zone. The accident probabilities are derived from historical data for each mode. The consequences are calculated from the parameters describing the package, such as the radionuclide inventory of the contents (source term data) and the behavior of the contents under the specified accident conditions (fraction of material released, fraction of released material in aerosol form, etc.), and by the meteorological and exposure models contained in the code.

RADTRAN III differs from its predecessors in several ways. Important changes include (a) improvements in the rail-stop model, (b) inclusion of an ingestion pathway model in the accident analysis module, and (c) inclusion of a submodule in the calculation of onlink doses that accounts more correctly for adjacent/passing vehicles. ${ }^{10}$

RADTRAN is currently being updated in modular form to take into account state-specific information. RADTRAN-IV is expected to be available in the 1991 calendar year. ${ }^{11}$

RADTRAN has been used in the program in several ways. It can be used to calculate the risks for transporting several shipments between an origin and destination. Alternatively, RADTRAN can be used to calculate unit risk factors.

Having isolated unit risk factors for relevant population zones through the use of RADTRAN, DOE's risk assessment efforts then required the determination and inclusion of three additional factors: "(1) the total distance per trip, (2) the fraction of travel in each of the population zones, and (3) the number of shipments that may occur."12 For purposes of determining distance factors, computer routing models for highway and rail shipments, designated, respectively, HIGHWAY and INTERLINE, were developed. Those modules permitted the computation of mileage 
factors such as the estimated highway and rail distances from southern reactor centroids and the Savannah River Plant to the proposed repository site at Yucca Mountain, Nevada, as presented in Table 5-1. ${ }^{13}$

Table 5-1
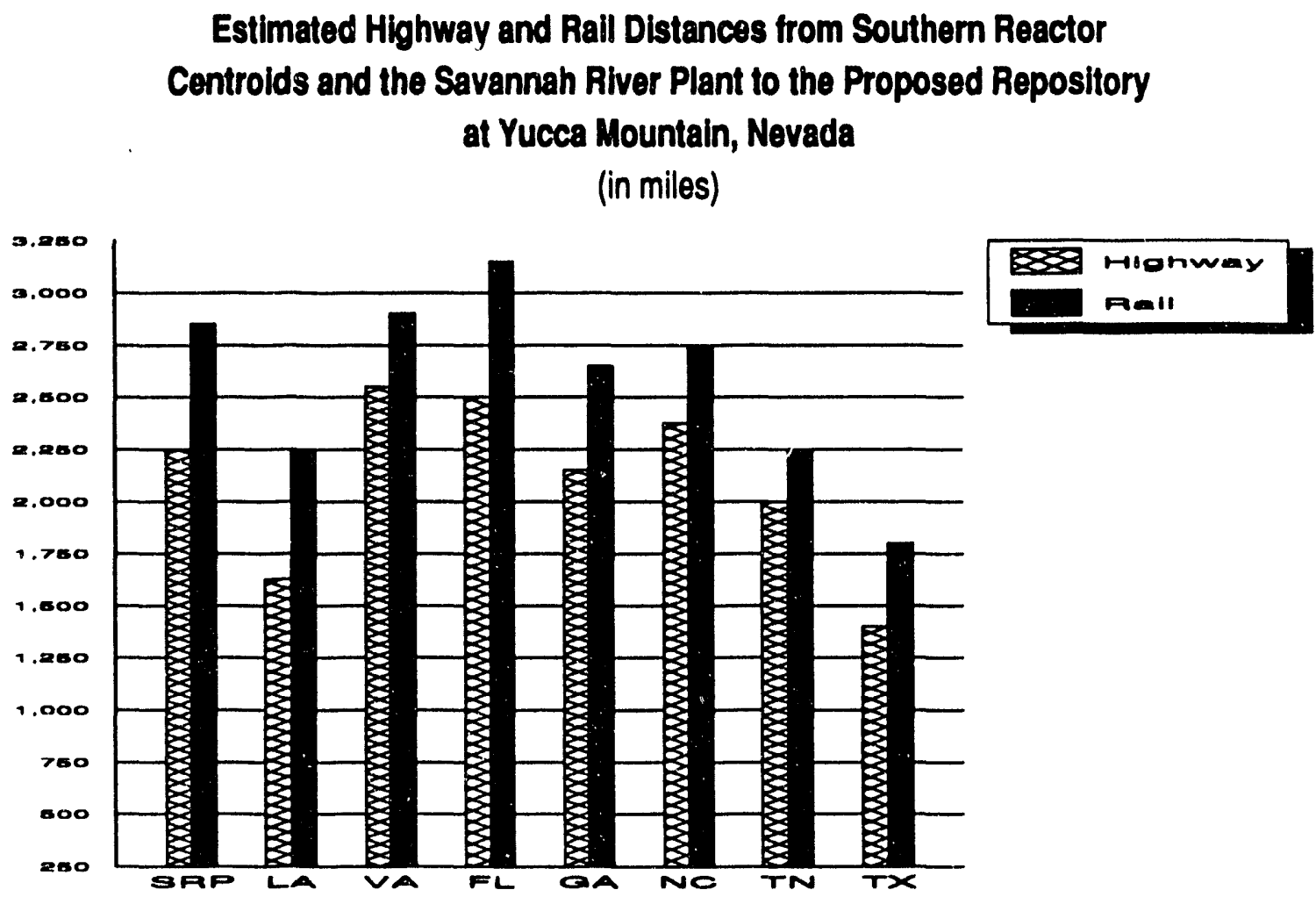

Source: J.W. Cashwell, et. al., A Prellminary Analysis of the Cost and Risk of Tranoporting Nuclear Waste to Potential Candidate Repottory Sites, SAND83-0867, Sandia National Laboratorles 1984, p.16.

As the answer to the question of potential numbers of shipments is a factor of the amount of spent fuel and HLW generated, the WASTES II computer model was developed at Battelle Pacific Northwest Laboratories "to model the generation of spent nuclear fuel, the buildup of spent fuel inventories within the system, and transportation requirements for the movement of wastes throughout the system." 14 Information derived from HIGHWAY and INTERLINE made possible the calculation of critical shipment and distance projections such as the estimated annual shipment through southern states and the United States, figures illustrated in Tables 5-2 and 5-3. 


\section{Table 5-2}

\section{Estimated Annual Shipment Miles through Southern States for Transporting Spent Fuel Directly from Nuclear Reactors (in thousand miles)}

\begin{tabular}{|c|c|c|c|c|c|c|}
\hline & $\begin{array}{l}\text { To the } \\
\text { repo } \\
\text { Yucca }\end{array}$ & & $\begin{array}{l}\text { To a pos } \\
\text { Site at }\end{array}$ & & $\begin{array}{l}\text { To Yucca } \\
\text { via an }\end{array}$ & \\
\hline & Bail & Inuck & Bail & Inuck & Bail & Inuck \\
\hline$A L$ & 0.4 & 2.9 & 5.6 & 15.4 & 5.6 & 15.4 \\
\hline AR & 1.4 & 102.6 & 5.9 & 0.0 & 5.9 & 0.0 \\
\hline $\mathrm{FL}$ & 0.0 & 41.1 & 0.0 & 44.4 & 0.0 & 44.4 \\
\hline $\mathrm{GA}$ & 9.4 & 53.4 & 7.2 & 43.8 & 7.2 & 43.8 \\
\hline KY & 12.7 & 0.0 & 26.1 & 18.2 & 30.5 & 18.2 \\
\hline LA & 1.3 & 0.0 & 0.6 & 0.0 & 0.6 & 0.0 \\
\hline$M D$ & 0.0 & 29.4 & 2.0 & 13.9 & 2.0 & 13.9 \\
\hline MS & 0.9 & 12.6 & 1.9 & 9.4 & 1.9 & 9.4 \\
\hline MO & 47.4 & 31.9 & 1.8 & 7.1 & 7.9 & 7.1 \\
\hline NC & 3.7 & 0.0 & 13.4 & 6.2 & 13.4 & 6.2 \\
\hline OK & 3.4 & 123.5 & 0.3 & 0.0 & 0.3 & 0.0 \\
\hline SC & 2.4 & 2.9 & 1.7 & 7.0 & 1.7 & 7.0 \\
\hline TN & 9.4 & 111.1 & 26.9 & 122.6 & 28.7 & 122.6 \\
\hline$T X$ & 6.3 & 63.7 & 3.9 & 0.0 & 3.9 & 0.0 \\
\hline VA & 1.6 & 16.9 & 7.3 & 145.2 & 7.3 & 145.2 \\
\hline WV & 1.2 & 7.5 & 0.2 & 6.2 & 0.2 & 6.2 \\
\hline
\end{tabular}

Source: Extracted Irom letter, D.S. Joy, Chemical Technology Division, Oak Ridge National Laboratory, February 3, 1986.

-Assumptions include rail preference from reactors; truck capacity 2 PWR or 5 BWR assemblies; rail cask capacity 14 PWR or 36 BWR assemblies.

-Assumptions include rail prelerence from reactors; truck cask capacity 2 PWR or 5 BWR assemblies; rail cask capacity 14 PWR or 36 BWR assemblies; western reactors ship directly to a repository. Table relies on MRS siting data compited prior to passage of the NWPAA of 1987 lor comparison purposes only.

×Assumptions include rail preierence from reactors; truck cask capacity 2 PWR or 5 BWR assemblies; reactor rail cask capacity 14 PWR or 36 BWR assemblies; MRS rail casks contain consolidated spent fuel with five casks per dedicated train shipment; western reactors ship directly to a repository. 
Table 5-3

\section{Comparisons of Annual Shipment Miles through Southern States and the United States for Transporting Spent Fuel \\ Directly from Nuclear Reactors \\ (in miles)}

(I)

To the Proposed Repository at Yucca Mountain, NV

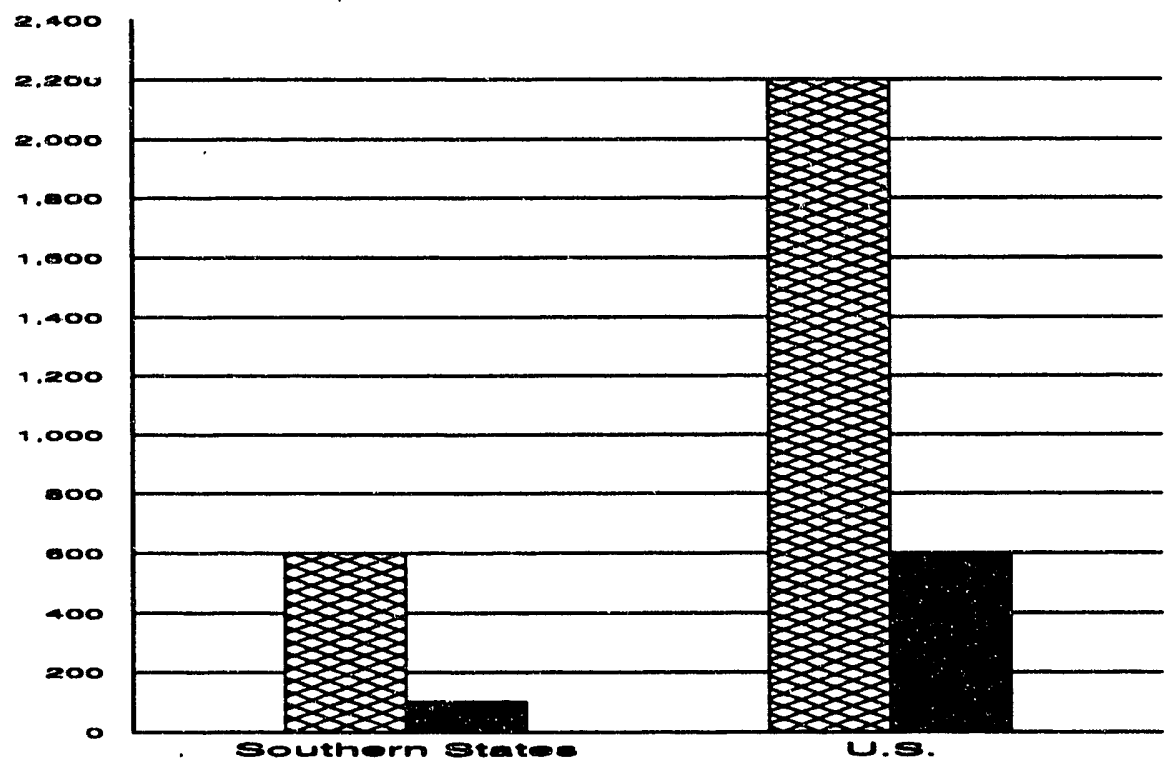

"Estimated total annual shipments: 262 by rail, 295 by truck

(II)

To a Possible MRS Site at Oak Ridge, TN
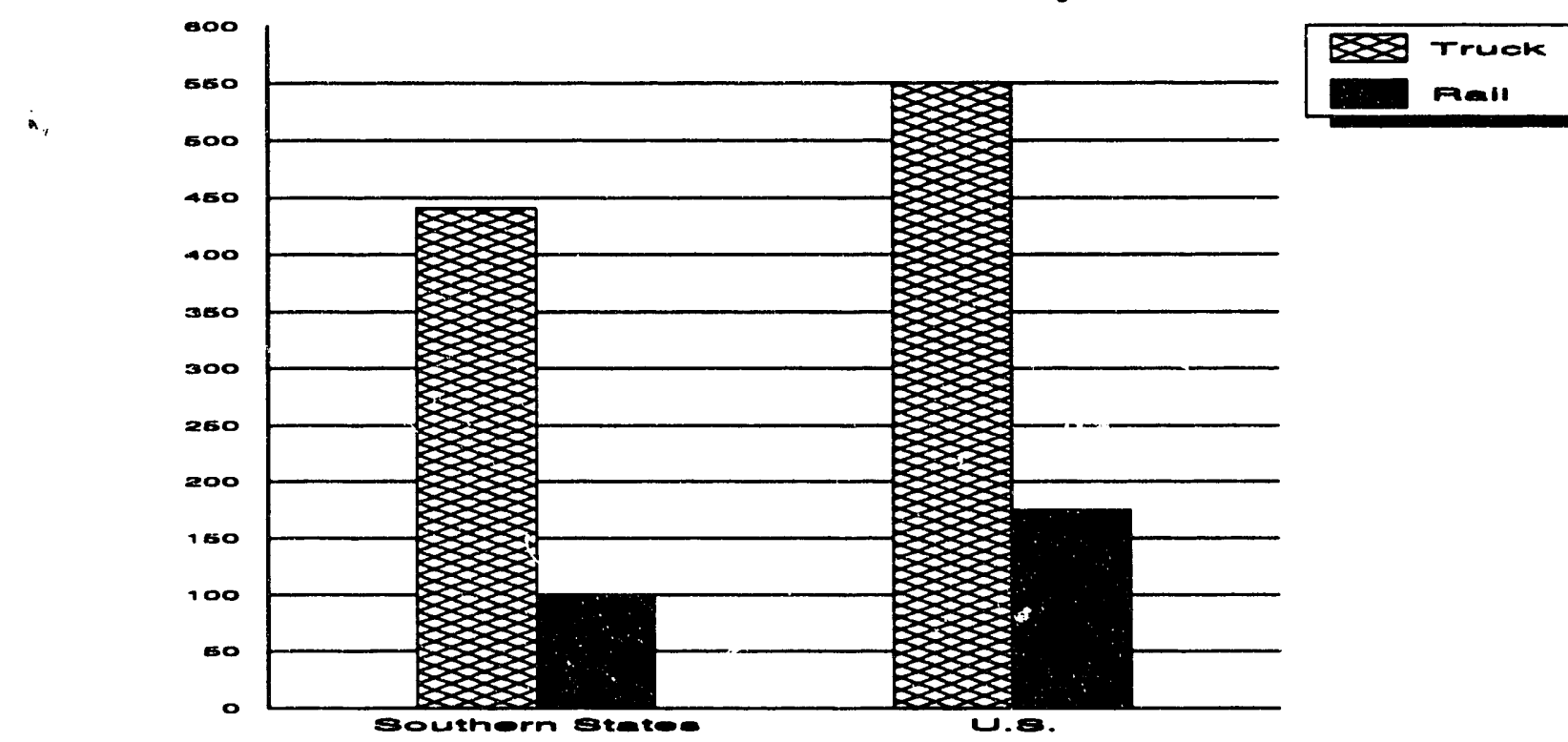

'Estimated total annual shipments: 217 by rail, 862 by truck Graph reiies on MRS siting data complied prior to passage of the NWPAM of 1987 for comparison purposes only. 
Table 5-3 (continued)

(III)

To Yucca Mountain via an MRS

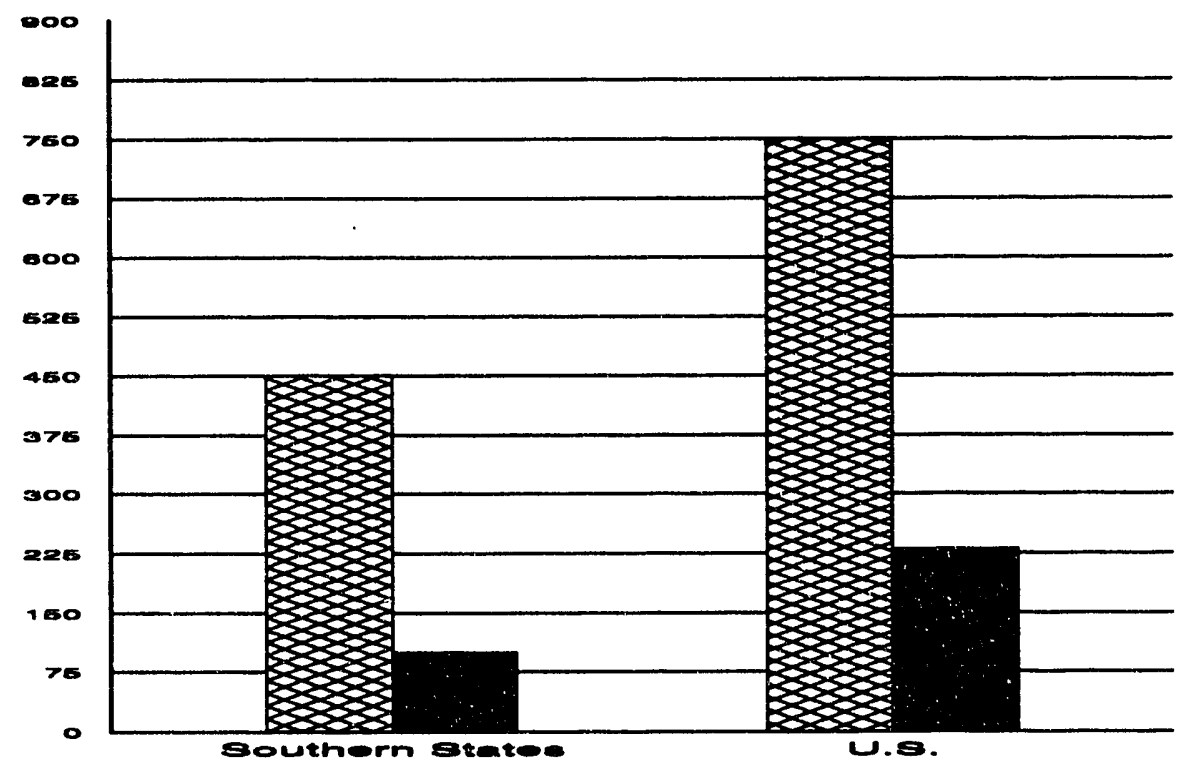

Estimated tobal shipments: 862 by truck including 201 from westem reactors to repository; 260 by rail, including 30 from westem reactors to repository and 22 from MRS. Graph relies on MRS siting data compilod prior to passage of the NWPAA of 1987 for comparison purposes only.

Source: Extracted from letter, D.S. Joy, Chemical Technology Division, Oak Ridgo National Laboratory, February 3, 1986

"-Southem States" includes Southem States Energy Board (SSEB) member states Alabama, Arkansas, Florida, Georgia, Kentucky, Louisiana, Maryland, Mississippi, Missouri, North Carolina, Oklahoma, South Carolina, Tennessee, Texas, Virginia, and West Virginia. Assumptions applicable in Table 6-2, are also applicable to this table. For specific totals, see SSEB, Spent Muclar Fual and High-Lovet Radionetive Waete Traneportation Primer, July 1987, pp.8-5 to 8-8.

\subsubsection{Calculations of Estimated Risk}

By combining unit-risk factors, percent travel in population zones, the number of shipments, and distance per waste shipment, DOE with the help of RADTRAN II, WASTES II, HIGHWAY, and INTERLINE was able, by the release in May 1986 of its environmental assessments for potential repository sites, to predict the total transportation risk for each potential location. The estimates of both radiological and non-radiological transportation risks for the proposed Yucca Mountain, Nevada, repcsitory are presented in Table 5-4 for both a repository-only system and a repository-MRS system. Risks are expressed in terms of fatalities and injuries, although there is an important distinction among the types of fatalities.

The latent cancer fatalities associated with the radiological risks are a predicted number of fatalities that might occur after a delayed period following exposure. The values in Table 5-4 include fat ${ }^{\prime}$ is related to an individual's exposure and consequent first and second geiıcration genetic effects. These 
numbers have their basis in statistical projection. In contrast, non-radiological fatalities are immediate and would be expected as a result of an equivalent amount of any cargo traveling the same distances.

Important factors to note in the risk analysis include the following:

- Total risks (fatalities) involved in transport are a function of distance traveled: the greater the total distance traveled by rail or truck, the greater the risk will be.

- The greatest radiological risk has been found to result from public exposure at transit stops when transported by truck. The length of time stopped, the number of people at stops and their distance from the cargo are all important risk factors.

- The radiological risks from normal transport are greater than the risks expected from accidents.

- In perspective, a Sandia report ${ }^{15}$ indicates that during the 26-year repository lifetime, 177,000 latent cancer fatalities might occur from natural background radiation nationally, while approximately 65,000 people might die from truck accidents and 32,000 from train accidents.

It is important to note that the risk analyses as used in DOE's environmental assessments are generic in nature. Certain route-specific information, such as terrain, weather conditions and the need for upgrading existing road and rail systems, has not been included in the evaluation.

\subsubsection{Risk Comparisons}

Many studies have been conducted that compare various individual and transported material risks with spent fuel shipments. An individual risk analysis was conducted in 1977 for NRC by Brookhaven National Laboratory, the report of which was entitled, Risk Comparisons for the Transportation of Spent Fuel from Nuclear Reactors (BNL 36390). A 1981 Pacific Northwest Laboratory report, Risks in U.S. Energy Material Transportation (PNL-SA-8545) compared energy 
products routinely shipped in the U.S. Both showed that the overall risk of transporting spent fuel is substantially lower in comparison with other risk activities, although it is not risk free.

\subsubsection{Ongoing Risk Analysis Efforts}

The work of risk analysis and assessment by no means ceased with the issuance of environmental assessments for proposed repository sites. DOE, NRC, their contracting laboratories, and other agencies continue the work on efforts to identify and minimize transportation risks. Pacific Northwest Laboratories, for example, issued in November 1987 its report, Analysis of Radiation Doses from Operation of Postulated Commercial Spent Fuel Transportation Systems. An NRC contractor, the Lawrence Livermore National Laboratory, published in February of the same year a report entitled, Shipping Container Response to Severe Highway and Railway Accident Conditions, which concluded that 99.43 percent of such highway accidents and 99.67 percent of railway accidents would entail no radiological significance. Of the remaining accidents, the study found that less than 0.001 percent of truck shipments and 0.012 percent of rail shipment accidents were estimated to be likely to cause a radiological hazard in excess of federal regulatory limits. ${ }^{16}$

In March 1987, DOE announced the development of the TRANSNET system "to speed transfer of transportation risk and systems analysis technology to qualified users by permitting access to the most comprehensive and up-to-date transportation risk models and associated databases." Pioneered by Sandia on behalf of DOE's Office of Defense Programs, TRANSNET makes accessible RADTRAN III, WASTES II, INTERSTAT (an automated modeling system that permits the user to assess the impacts of route-specific data on the choice of highway routes), FRTRATE (which estimates shipping costs, cask/package utilization and anticipated lease costs that may be incurred), TRANSIS (which allows input of historical accident/incident data), and StateGEN and StateNET (designed to assist states and other entities to better understand the impact of state and local data on route choices). ${ }^{17}$ 
Table 5-4

\section{Estimated Spent Fuel and FIW Transportation Risks for Proposed Yucca Mountain Repository over the Life of the Repository}

\begin{tabular}{|c|c|c|c|c|}
\hline \multirow[b]{2}{*}{ Mode/Risk Type } & \multicolumn{2}{|c|}{ Radiolodcal Risks } & \multicolumn{2}{|c|}{ Non-Radioloncal Risk } \\
\hline & $\begin{array}{c}\text { Repository } \\
\text { Only } \\
\text { System }\end{array}$ & $\begin{array}{c}\text { Repository - } \\
\text { MRS } \\
\text { Sustem }^{b}\end{array}$ & $\begin{array}{l}\text { Repository } \\
\text { Only } \\
\text { System }\end{array}$ & 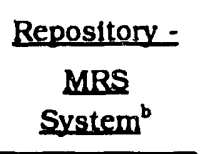 \\
\hline Truck transportation ${ }^{c}$ & & & & \\
\hline Normal occupational fatalities & 1.70 & 0.90 & 0.6 & 0.5 \\
\hline Normal non-occupational fatalities & 9.50 & 4.70 & 8.0 & 5.2 \\
\hline Accident non-occupational fatalities & 0.04 & 0.06 & 28.0 & 36.0 \\
\hline Accident occupational injuries & & & 16.0 & 230.0 \\
\hline Accident non-occupational injuries & & & 450.0 & 250.0 \\
\hline Total fatalities & 11.00 & 5.70 & 37.0 & 42.0 \\
\hline
\end{tabular}

Rail transportation ${ }^{\text {d }}$

\begin{tabular}{lcccr} 
Normal occupational fatalities & 0.10 & 0.10 & 0.2 & 0.4 \\
\hline Normal non-occupational fatalities & 0.10 & 0.1 & 0.2 & 1.7 \\
\hline Accident non-occupational fatalities & 0.02 & 0.05 & 2.6 & 25.0 \\
\hline Accident occupational injuries & & & 25.0 & 240.0 \\
\hline Accident non-occupational injuries & & & 5.1 & 49.0 \\
\hline Total fatalities & 0.30 & 0.30 & 3.0 & 27.0
\end{tabular}

Source: Environmental Acsessment: Dost Smith County Stte, Toxes, DOERW-0069, U.S. Department of Energy, Office of Civilian Radioactive Waste Management, 1986, pp.A.53 and A-58.

"Radiological fatalities include first- and second-generation genetic effects.

"Estimated risks of shipping (1) all spent fuel from reactors to an MRS facility, (2) consolidated spent fuel from the MRS facility to the repository, (3) secondary waste from the MRS facility to the repository and (4) high-fovel waste directly to the repository. All shipments from the MRS facility are assumed to bo in 100-10n casks.

'As respects a Repository - MRS System contemplates shipment by truck from reactors and HLW processing plants; shipment in dedicated trains from MPS lacility 10 repository.

'As respects a Repository - MRS System, the 100-ton cask carries ready-to-emplace disposal containers. 


\subsubsection{Cask Sabotage Risks}

Discussions of risk analysis in the event of cask sabotage are included in other chapters related to the regulation of transportation and cask issues. The sabotage studies cited therein have provided the basis for NRC transportation safeguard requirements and the commission's proposal to relax such regulatory rules.

An initial study conducted by Sandia National Laboratories (SAND77-1927) prompted issuance of NRC interim safeguard requirements in 1979, but contained risk estimates that were unavoidably subject to great uncertainties owing to lack of technical data. A later draft of the Sandia report was published by NRC as NUREG/CR-0743. Although this draft report predicted less serious consequences in the event of cask sabotage, a significant degree of uncertainty remained.

Additional risk analyses were sponsored by NRC and DOE and issued as final reports in 1982 and 1983, respectively. The NRC study, conducted by Battelle Columbus Laboratories (NUREG/CR-2472), and the DOE study, conducted by Sandia National Laboratories (SAND82-2365), contained average and significantly lower consequence values upon which NRC has based its recommended transportation safeguard requirements.

\subsection{Costs for Transporting Spent Fuel and High-Level Waste}

As noted at 5.1.1, DOE's Mission Plan for the Civilian Waste Management Program noted the department's intention to include transportation cost projections in its environmental assessments for possible repository sites. As such cost projections ultimately were presented in the final environmental assessments, the total cost of transport for each type of waste (spent fuel, high-level radioactive waste and transuranic waste) was defined as the sum of capital costs, maintenance costs and shipping charges. Transportation schedule requirements and shipment numbers used to derive cost estimates were calculated by use of WASTES II, which simulates the movement of nuclear waste from point of generation to inal destination.

Capital costs were defined as the cost of the transportation packaging and its trailer or railcar. These costs do not include facility requirements, such as highway or rail-line construction to the repository site or facility handling equipment requirements. Maintenance costs are directly proportional to the number of packages required per year. Based on estimates of state-of-the-art 
casks designed for waste transport to a repository (as opposed to casks currently in use), shipping costs were determined using shipping rates for given waste types and calculated shipment distances.

Notable assumptions used in cost determination include the following:

- $\quad$ All truck shipments were assumed to travel at an average speed of 35 miles per hour;

- $\quad$ Average rail speed was determined to vary from approximately $3 \mathrm{mph}$ for short hauls to approximately $12 \mathrm{mph}$ for cross-country shipments;

- Total loading plus unloading time for casks at the point of origin and at a repository was assumed to be five days for a rail package and three days for a truck package; and

- Transportation casks were assumed to be licensed with an estimated lifetime of 15 years, with casks being replaced once during the lifetime of the first repository.

Total transportation costs in 1985 dollars were estimated in the environmental assessments under a repository-only and a repository-MRS system and are shown in Table 5-5 as they related to the proposed repository at Yucca Mountain, Nevada. The total costs did not include costs of facility improvements, handling equipment and other equipment required to clean, load or unload the casks. Such costs were calculated in connection with repository facility costs.

As was the case with risk analysis, DOE's interest in cost analysis is a continuing one, the department's announced objective being to design a transportation system for spent nuclear fuel and HLW that is safe and cost-effective. 


\section{Estimated Spent Fuel/HLW Transportation Cost Summary for Propused Yucca Mountain Repository" \\ (in millions of 1985 dollars)}

\begin{tabular}{lcr} 
Mode/Cost & Bepositorr Only System & Bepositon - M \\
100\% Truck & & \\
Capital & $266 / 59$ & 379 \\
\hline Maintenance & $145 / 36$ & 227 \\
\hline Shipping & $876 / 157$ & 963 \\
\hline Total & $1296 / 152$ & 1569
\end{tabular}

$100 \%$ Rail

\begin{tabular}{ccc} 
Capital & $275 / 79$ & 367 \\
\hline Maintenance & $146 / 45$ & 222 \\
\hline Shipping & $604 / 196$ & 988 \\
\hline Total & $1024 / 320$ & 1576
\end{tabular}

Source: Environmentw Asecesement: Dew Smihh County, Toxas, DOERW-O069, U.S. Department of Energy, Office of Civilian Radioactive Wasto Management, 1986, pp.A-63, A-64, A-67, A-68.

"Costs summarized in this table are besed upon cask requirements as follows: 100\% truck, 236 for repository only system (161 for repository - MRS systems); $100 \%$ rail, 154(111); rail from MRS to repository, (86).

"Costs estimates do not include consolidated HLW and spent fuel shipped from MRS to repository. All shipments are in 100-bn casks.

For purposes of repository - MRS system, contemplates $100 \%$ truck \& MRS/rail from MRS \& repository.

To further that otjective, the department has developed a computer code to analyze the transportation system on the basis of lifetime risk and cost. As explained in the OCRWM Bulletin:

...The code, known as the Transportation Pisk and Cost Analysis Model (TRICAM), will be used to support decision making during the current planning stage of the OCRWM transportation program. 
TRICAM is a constrained optimization code that models the transportation cask handling and storage components of the overall OCRWM waste management system. Each activity (such as cask loading and hauling) is modeled in terms of three variables--radiation dose, costs and constraints. Examples of constraints include the minimum age of the spent nuclear fuel before it would be transported, the quantity of fuel that can be handled annually at the repository, capacities of the transportation casks and pool capabilities. For any given set of radiation doses, costs and constraints, TRICA.I computes the optimum set of 'paths' for getting the spent nuclear fuel from the sources--the waste generator sites--to its ultimate repository destination. These paths include, in addition to transportation, storage in pools and dry casks and fuel consolidation and packaging. 


\section{Notes for Chapter $\mathbf{5 . 0}$}

${ }^{1}$ Nuclear Waste Policy Act of 1982, 42 USC \$10132; $\$ 112$ (b)(E)(iii).

${ }^{2}$ Mission Plan for the Civilian Radioactive Waste Management Program, Volume 1, U.S. Department of Energy, Office of Civilian Radioactive Waste Management, June 1985 [DOE/RW-005], p. 99.

${ }^{3}$ Shipping Container Response to Severe Highway and Railway Accident Conditions, Volume 1, Lawrence Livermore National Laboratory, February 1987 [NUREG/CR-4829], pp. 1-3.

${ }^{4}$ U.S. Nuclear Regulatory Commission, Final Environmental Statement on the Transportation of Radioactive Material by Air and Other Modes, December 1977 [NUREG-0170], p.ix.

${ }^{5}$ Radioactive Material (RAM) Transportation Accident/Incident Analysis, Sandia National Laboratories, March 1986 [SAND85-1016], p. 9.

${ }^{6}$ Ibid., p. 20.

${ }^{7}$ Radioactive Material (RAM Accident/Incident Analysis Program, Sandia National Laboratories, March 1985 [NUREG/CR-361 1], pp. 9-13.

${ }^{8}$ Shipping Container Response, pp. 8-1 to 8-5.

${ }^{9}$ Nuclear Waste Policy Act Environmental Assessment, Yucca Mountain Site, U.S. Department of Energy, Office of Civilian Radioactive Waste Management, May 1986 [DOE/RW-0073], p.xi.

${ }^{10}$ TRANSNET-Access to Advanced Transportation Risk Analysis Techniques, Sandia National Laboratories, n.d. [SAND88-2809C0], n.p.

${ }^{11}$ Telephone conversation between Judith Holm, DOE-Chicago, and Alex Thrower, Southern States Energy Board, November 13, 1990.

${ }^{12}$ Environmental Assessment, p. A-25.

${ }^{13}$ Ibid., p. A-26.

${ }^{14}$ TRANSNET, n.p.

${ }^{15}$ Preliminary Cost and Risk Analysis of Transporting Spent Fuel and High-Level Wastes to Candidate Repository Sites, Sandia National Laboratories, October 1984 [SAND84-1795].

${ }^{16}$ Shipping Container Response to Severe Highway and Railway Accident Conditions, Lawrence Livermore National Laboratory, February 1987 [NUREG/CR-4829], pp. 9-1 to 9-6.

${ }^{17}$ TRANSNET, n.p. 


\section{Chapter 6.0}

\section{Emergency Preparedness and Response}

\subsection{The Regulatory Structure of Emergency Response}

\subsubsection{Introduction}

Emergency preparedness and response in a radioactive materials accident is the collective responsibility of shippers and carriers transporting the materials, the affected state, local and tribal governments and the federal government. ${ }^{1}$ The carrier has the initial responsibility for "onsite" response (at the actual accident scene) to minimize personal injury and property damage from a radioactive release. State and local governments have primary responsibility for emergency response to protect persons, property and the environment within the state from harm from civilian radioactive transportation accidents. Various federal agencies will assist state and local governments upon request in responding to certain non-military radioactive accidents. The federal government has primary responsibility in response to a defense-related radiological accident. ${ }^{2}$

Section 180(c) of the NWPAA requires the secretary of energy to provide technical support and financial assistance to states for the training of local safety officials in areas designated for the transportation of spent fuel and high-level radioactive waste. Under the direction of OCRWM, implementation of $\$ 180$ (c) is designed to build on existing emergency preparedness activities with funding to be provided at least three-to-five years prior to shipment. Training is to commence 18 to 24 months before shipments begin. OCRWM will also coordinate its activities with officials from the Waste Isolation Pilot Plant (WIPP) regarding state, tribal and local emergency preparedness training programs.

In addition, OCRWM employs the expertise and services of various regional groups such as the Southern States Energy Board, the Western Interstate Energy Board and Midwest Council of State Governments to identify emergency preparedness issues. Cooperative agreements between OCRWM and these regional groups provide for the development of reports on mutual aid agreements, state agencies and their responsibilities and implementation of \$180(c). 


\subsubsection{The Federal Role in Emergency Preparedness}

The Federal Emergency Management Agency (FEMA) has prepared a document entitled Guidance for Developing State and Local Radiological Emergency Response Plans and Preparedness for Transportation Accidents, (FEMA-REP-5), to assist state and local governments in preparing and responding to high-level radioactive materials transportation accidents. The federal government's role in emergency response and preparedness is outlined in the document as supporting the state, tribal or local government's lead role. Federal agencies do not become involved at all unless aid is requested by the appropriate state and local authorities. In the event of a defense-related accident, the Department of Energy has the lead response role within designated areas, while state, local or tribal governments have the lead role outside of these areas. ${ }^{3}$

Authority for federal response to radiological emergencies in the United States has evolved from a series of executive order and regulations. Executive Order No. 12148, signed by President Carter on July 20, 1979, is particularly significant. It authorizes the FEMA director to "establish federal policies for, and coordinate, all civil defense and civil emergency planning, management, mitigation and assistance functions of executive agencies." 4 These executive agency responsibilities, as they relate to state and local emergency preparedness, are set forth generally in Title 44 of the Code of Federal Regulations (CFR), which covers emergency management and assistance. 44 CFR 351, entitled "Radiological Emergency Planning and Preparedness," assigns the roles and tasks of federal agencies regarding assistance to state and local governments in their radiological emergency planning and response activities at both fixed nuclear facilities and during and after transportation accidents involving radioactive materials. ${ }^{5}$ The regulation broadly describes the interagency assignments by which nine federal agencies are required to assist one another in performing emergency preparedness activities. These agencies are: Federal Emergency Management Agency (FEMA); Nuclear Regulatory Commission (NRC); Environmental Protection Agency (EPA); Department of Health and Human Services (HHS); Department of Energy (DOE); Department of Transportation (DOT): United States Department of Agriculture (USDA); Department of Defense (DOD); and Department of Commerce (DOC). These agencies are directed to assist FEMA and the states and localities in developing and implementing radiological emergency response plans. ${ }^{6}$ 
The regulation also establishes the Federal Radiological Preparedness Coordinating Committee (FRPCC), chaired by FEMA and consisting of members of the nine federal agencies, discussed herein. FRPCC assists FEMA by providing policy direction for federal assistance to state, tribal and local governments on radiological emergency planning and preparedness activities. The committee is empowered to establish subcommittees to carry out its functions, and has in fact created several subcommittees. One of these subcommittees, the Subcommittee on Federal Response, developed the Federal Radiological Emergency Response Plan (FRERP) to consolidate federal response for the wide range of potential peacetime radiological emergencies, including both incidents at fixed nuclear facilities and transportation accidents.

FRERP outlines the individual authorities and responsibilities for 12 federal agencies with authority and/or resources appropriate to respond to a radiological emergency. Each agency is required to prepare emergency response plans to carry out its role under FRERP. FEMA REP-5 provides implementation guidance for the FRERP. In order for revisions to be made to the FRERP, the FEMA REP-5 must first be revised to correspond to the desired change(s) The FRPCC subcommittee on transportation accidents n.et in Washington. D.C. in July 1990 to discuss various aspects of FEMA REP-5. There has been some discussion concerning revisions to FEMA REP-5 and to the FRERP, but as of November 1990 there has been no revision since August 1988. ${ }^{7}$

The FRERP is primarily concerned with offsite federal response to peacetime radiological emergencies in support of state and local governments. It contains a summary of the emergency response plan for each of the 12 affected agencies outlined by the plan. ${ }^{8}$

While FEMA has the primary federal planning role in radiological emergency response, DOD and DOE are the federal agencies with the most direct operational roles in the response to an accident involving high-level radioactive materials. The Department of Defense has the lead response role for nuclear weapons accidents when the weapons are under DOD's control. The agency will also provide emergency response teams and equipment for incidents involving DOD-controlled hazardous materials other than weapons. ${ }^{9}$

The Department of Energy has the lead response role for emergencies arising from the operation of DOE programs and facilities. ${ }^{10}$ DOE also has primary role in certain nuclear weapons transportation accidents. ${ }^{11}$ The NWPA provides for DOE to be the cognizant federal agency, i.e., lead agency responsible for on-site federal support for certain spent fuel accidents. ${ }^{12}$ The FRERP also requires DOE to assist the states in lesser roles during other types of radiological incidents. ${ }^{13}$ 
In the event of a radiological incident involving a by-product, source, or special nuclear material, including activities at commercial and research nuclear facilities, the Nuclear Regulatory Commission would become the cognizant federal agency. ${ }^{14}$ Numerous federal agencies with emergency response responsibilities have established programs and facilities to meet their obligations. FEMA, DOD and DOE facilities are discussed later in this chapter.

A National Security Emergency Response Policy was established by executive order of President Reagan in November 1988. This order assigns responsibilities for various federal agencies in the event of an occurrence (natural disaster, military attack, technological emergency or other emergency) that seriously degrades or threatens the national security of the United States. This broad language would presumably include a radiological emergency that threatens national security. Primary responsibilities under the order are given to the President, the National Security Council and FEMA. ${ }^{15}$

\subsubsection{State Emergency Preparedness Responsibllities}

Emergency preparedness is generally viewed as a primary responsibility of state, local, and tribal government, with assistance available from the federal government. FEMA REP-5 characterizes state and tribal emergency preparedness and response obligations as follows:

Although the shipper and carrier bear the primary responsibility for assuring that radioactive materials are safely packaged and transported, responsibility for initially responding to a transportation accident generally falls to the state, local or tribal government, as is the case for any other transportation accident or for other types of man-made or natural emergencies. The appropriate agencies should, therefore, be prepared to respond to a transportation accident involving radioactive materials.

a. State and tribal officials have the responsibility to protect persons within the state or tribal jurisdiction from unwarranted radiation exposure and should, therefore:

(1) Develop and distribute to appropriate persons a radiological emergency response plan addressing federal, state, tribal, local and private responsibilities and resources for planning, preparedness and response; 
(2) Designate one or more state and tribal emergency radiological response team and team leader (sic) who have radiological emergency response expertise;

(3) Assure the establishment and operability for a state and tribal communications system to interface with federal and local agencies involved in emergency response;

(4) Negotiate agreements with contiguous states and tribal governments addressing responses to incidents in proximity to a common border; and

(5) Prepare, or assist in preparing, and distribute implementing instructions and procedures to be used by state, tribal, local and/or other emergency response personnel in carrying out their responsibilities. ${ }^{16}$

A study conducted in 1988 by the Transportation Research Center of Indiana University for the Nuclear Regulatory Commission assessed the current levels of emergency response preparedness of the fifty states, the District of Columbia, Puerto Rico and selected indian tribal jurisdictions. The results of this survey were published in May of 1990 in a report entitled Survey of State and Tribal Emergency Response Capabilities for Radiological Transportation Incidents (NUREG/CR-5299). This 1988 survey, hereinafter referred to as the Indiana study, updates a similar survey that was performed in 1980 (NUREG/CR-1620) to assess the capability of states and tribes to respond to transportation incidents involving radioactive materials.

The Indiana study noted the following improvements since 1980: an increased availability of dedicated emergency response vehicles, wider availability of specialized radiation-detection instruments, and higher proportions of police and fire personnel with training in the handling of suspected radiation threats. The study found that most indian tribes still have no capability to evaluate suspected radiation threats. The indian tribes also do not have formal relations with emergency-response personnel in adjacent states. The Indiana study noted, however, that the incidence of suspected radiation threats has declined substantially for the nation as a whole since $1980 .{ }^{17}$ 
The South is generaily well prepared to meet emergencies that may arise. To aid these states in assessing their emergency response capabilities, the Southern States Energy Board, a regional compact established under Public Law 87-503 in 1962, serves as a vehicle for multistate radiological emergency planning. Among the Board's enumerated powers found in Article $\mathrm{V}$ of the compact is the authority for:

$d(2)$ The formulation or administration of measures designed to promote safety in any matter related to the development, use or disposal of nuclear energy, materials, products, installations or wastes.

The Board is further empowered under the compact to enter into supplementary agreements for "the undertaking and continuance" of a specific activity or project. One such agreement is the Southern Mutual Radiation Assistance Plan (SMRAP), created in 1973. The plan states in its preface that it: "is intended to provide the mechanism for cooperation of radiological emergency assistance capabilities between the participating states." SMRAP is authorized by the Southern Agreement for Mutual State Radiological Assistance, and has been signed by the governors of Alabama. Arkansas, Florida, Georgia, Kentucky, Louisiana, Mississippi, Missouri, North Carolina, Oklahoma, South Carolina, Tennessee, Texas and Virginia. ${ }^{18}$

SMRAP is reviewed, revised and administered on a permanent basis by the Southern Emergency Response Council (SERC), established for that purpose under the agreement. SERC consists of the radiological health program directors from each signatory state and the executive director of SSEB. SSEB also serves as staff for the council. ${ }^{19}$

The Interstate Civil Defense and Disaster Compact is designed to provide mutual aid among the states in meeting any emergency or disaster, whether from enemy attack or from any other cause, natural or otherwise. Signatory states in the compact may request aid from the other member states in the form of personnel, supplies, materials and equipment. The compact is not confined to southern states, but has signatories around the country. Eleven southern states are members of the compact. ${ }^{20}$ 


\subsubsection{Local Government Emergency Response}

Local governments share with the state government the duty to respond to emergencies to protect the public from potentially hazardous high-level radioactive waste accidents. Thus, subsequent state and federal emergency response activities will not alter a locality's initial response obligations since local officials are closer to the scene and are able to respond immediately. FEMA REP-5 summarizes the responsibilities of local governments as follows:

b. The local government should ensure that any local emergency response plan is compatible with the state response plan and should specify the respective roles and responsibilities of federal, state, tribal, local [governments] and private organizations in their locality.

The local government, probably its law enforcement or fire safety agency, will most likely be the first governmental responder to an accident and should, therefore, be prepared to take actions usually required in any hazardous material accident as indicated in the DOT Emergency Response Guidebook. These actions include:

(1) Administer emergency measures to save lives and attend to the injured;

(2) Determine if radioactive or other hazardous materials are present in the transportation incident and obtain information about these materials;

(3) Notify appropriate authorities to obtain radiological expertise if radioactive materials are involved; and

(4) Determine the action required to prevent further damage to life or property. ${ }^{21}$ 


\subsubsection{Shipper and Carrier Emergency Preparedness and Response}

Transporters of hazardous materials are required by various federal, state and local laws and regulations to respond to an accident involving the materials. FEMA-REP-5 provides guidance on the responsibilities of shippers and carriers in complying with federal, state, and local regulations as follows:

\section{Shipper}

It is the responsibility of each shipper to know and comply with all applicable federal, state and local regulations pertaining to the shipment of radioactive materials. The responsibility includes:

a. Offering the packages of radioactive materials to the carrier in full compliance with the applicable DOT and NRC packaging requirements because packaging is the primary means of assuring the protection of public health and safety;

b. Supplying shipping papers with the shipment that will provide basic information necessary for the appropriate response actions to be taken in the event of a transportation accident;

c. Providing information to the carrier when a shipment requires any special precautions for safe transportation of the material;

d. Although not always required by federal regulations, it is recommended that shippers provide a list of telephone contacts of persons knowledgeable of shipments that may constitute a significant radiological hazard;

e. Being prepared to supply any additional information that may be required to assist in an emergency response to an accident; and

f. Providing the capability for 24-hour telephone contacts for spent fuel shipments. 


\section{Carrier}

It is the responsibility of each carrier to know and comply with all applicable federal, state and local regulations and other appropriate non-regulatory standards established by such organizations as the American National Standards Institute pertaining to the transportation of radioactive materials including:

a. Ensuring that a prompt and proper response is initiated, including segregating packages and spilled radioactive materials from human contact and ensuring that vehicles, areas or equipment in which radioactive material may have spilled are not used and that vehicles and equipment are not placed in service again until they have been decontaminated and surveyed, equipment and vehicle decontamination should be effected per applicable DOT or state regulatory requirements;

b. Notifying local authorities, DOT, the shipper and the driver's own management at the earliest feasible time after an accident;

c. Maintaining working contact with the responsible governmental authorities until the latter have declared the incident to be satisfactorily resolved and closed;

d. Although not a regulatory requirement, providing appropriate resources for the resolution of the incident, including performing cleanup functions on its own or contracting with others (including perhaps the shipper or consignee) who have the necessary expertise. In those accidents where radioactive material has escaped the confines of the vehicle, there may be a need to repackage and dispose of the primary radioactive materials spilled plus any contaminated material. The carrier's designated person must have appropriate radiological expertise to handle such situations and should be familiar with applicable federal and state regulations. This expertise may be evidenced by the possession of a NRC or NRC Agreement State license to possess and use the radioactive materials released in the accident; 
e. Reimbursing public and private emergency response organizations, as appropriate, per state and local laws or as determined by the actions of the courts;

f. Providing the capability for 24-hour telephone contacts for highway route controlled quantity shipments; and

g. Carriers of any hazardous materials in interstate commerce must have liability insurance of $\$ 1$ million. Carriers of type B highway route controlled quantity and certain other types and quantities of hazardous materials must have liability insurance of $\$ 5$ million. ${ }^{22}$

\subsubsection{Industry Emergency Response}

In addition to complying with government regulations, the transportation incustry is addressing emergency response concerns in the transportation of high-level radioactive materials. The railroad industry, through the Association of American Rallroads (AAR), a rallroad trade organization, issued a nuclear emergency response planning and guidance document for railroad companies in 1984. The project evolved from an AAR and DOE workshop in 1981, which examined ways to respond to nuclear waste accidents involving the nation's railway system. At that meeting, the AAR, DOE, DOT and FEMA agreed to work together to prepare a voluntary model emergency response plan for railroads. ${ }^{23}$

The Nuclear Emergency Response Plan Guidance Document for Railroads provides assistance to the industry by identifying and analyzing factors for consideration in plan development. The document, designed to be compatible with similar documents produced by FEMA, is organized into three major planning areas: preparedness, response and recovery. Within these general areas, 22 specific planning objectives are discussed, and recommendations are provided for each. FEMA REP-5 presents guidance in a similar manner, addressing many of the same objectives. ${ }^{24}$

Railroad companies currently have plans in place for response to hazardous materials incidents in general. The AAR information is intended to supplement these plans to ensure adequate response to nuclear materials accidents. As with FEMA REP-5, the AAR document was developed solely for guidance purposes. 
Compliance with the recommendations, while not mandatory, is strongly urged in order to obtain a common level of preparedness and planning for accidents involving nuclear materials. ${ }^{25}$

While not concerned specifically with the transportation of radioactive materials, the United States chemical industry can provide some assistance with radiological materials accidents through its Chemical Transportation Emergency Center (CHEMTREC). CHEMTREC, established by the Chemical Manufacturers Association, operates a 24-hour hotline that takes calls concerning transportation accidents involving potentially hazardous chemicals, gives advice on immediate safety measures and promptly contacts the shipper. CHEMTREC can provide valuable assistance in case of an accident involving radioactive materials because its hotline, if notified of an accident involving radioactive materials, will in turn alert DOE, which then takes the appropriate action. ${ }^{26}$

\subsection{Emergency Management Institute}

FEMA operates the Emergency Management Institute (EMI) as part of the National Emergency Training Center in Emmitsburg, Maryland. EMI serves as a national focal point for development and delivery of civil defense/emergency management training to enhance emergency management capabilities of federal, state, and local governments and the private sector. ${ }^{27}$ The curriculum consists of a variety of courses, workshops, seminars and conferences on topics including: community preparedness/exercise programs, professional development, executive development/management, natural hazards, radiological hazards, hazardous materials, national emergency preparedness, train-the trainer/instructor training and emergency management computer technologies. ${ }^{28}$

\subsection{U.S. Department of Transportation}

The Department of Transportation is also involved in preparing states and local governments to respond to hazardous materials transportation emergencies. DOT has published and distributed the 1990 Emergency Response Guidebook: Guidebook for Hazardous Materials Incidents, developed under the supervision of DOT's Office of Hazardous Materials Regulation, Materials Transportation Bureau, Research and Special Programs Administration. The book is intended for use by firefighters, police and other emergency services personnel in initially responding to hazardous materials incidents. ${ }^{29}$ 
The book contains an inventory of hazardous materials, including radioactive materials, and a series of 76 one-page guides listing potential hazards and recommended emergency actions. DOT intends for the guidebook to be carried for immediate use by every emergency vehicle (fire, police, first aid, civil defense) in the United States. ${ }^{30}$ 


\section{Notes for Chapter 6.0}

${ }^{1}$ Guidance for Developing State and Local Radiological Emergency Response Plans and Preparedness for Transportation Accidents, Federal Emergency Management Agency, August 1988 (FEMA REP-5, Draft Revision).

${ }^{2}$ Ibid.

${ }^{3}$ Ibid., p. 11.

${ }^{4}$ Exec. Order No. 12148 (1979).

${ }^{5} 44$ C.F.R. 351 (1988).

${ }^{6}$ Ibid.

${ }^{7}$ Various documents and information from the Federal Emergency Management Agency concerning the July 1990 meeting of the FRPCC Subcommittee on Transportation Accidents.

${ }^{8}$ The complete plans are available from the individual agencies.

${ }^{9}$ Federal Radiological Emergency Response Plan, 50 Fed. Reg. 46557 (1985).

${ }^{10}$ Ibid., p. 46559.

${ }^{11}$ FEMA REP-5, p. 2.

${ }^{12} 50$ Fed. Reg. 46543.

${ }^{13}$ Ibid., pp. 46559-60.

${ }^{14}$ Ibid., pp. 46566, 46543.

${ }^{15}$ Exec. Order No. 12656 (1988).

${ }^{16}$ FEMA REP-5, pp. 10-11.

${ }^{17}$ Survey of State and Tribal Emergency Response Capabilities for Radiological Transportation Incidents, NUREG/CR-5399.

${ }^{18}$ Mutual Assistance Agreements for Radiological Emergency Response, Southern States Energy Board, November 1988, p. 3.

${ }^{19}$ Ibid.

${ }^{20}$ Southern States Radiological Emergency Response Laws and Regulations, Southern States Energy Board, May 1989. The eleven states are: Alabama, Arkansas, Georgia, Kentucky, Louisiana, Maryland, Mississippi, South Carolina, Tennessee, Texas and West Virginia. pp. 7-10.

${ }^{21}$ FEMA REP-5, p. 11.

${ }^{22} 49$ CFR 387.9 (1984); (See also, FEMA REP-5, pp. 14-16). 
${ }^{23}$ FEMA REP-5, pp. 14-15.

${ }^{24}$ Ibid.

${ }^{25}$ Ibid., pp. 13-14.

${ }^{26}$ Ibid., p. 37.

${ }^{27}$ Emergency Management Institute Course Catalogue, 1988/89, Federal Emergency Management Agency, pp. 3-7.

${ }^{28}$ Ibid., pp. i-ii.

${ }^{29} 1990$ Emergency Response Guidebook, U.S. Department of Transportation, DOT P 5800.5, (1990). p. ii.

${ }^{30}$ Ibid. 


\section{Chapter 7.0 Transportation Liability}

\subsection{Current Coverage for Nuclear Accidents}

In 1957, Congress devised a system of financial protection for the public in the event of a nuclear power accident to encourage the development of a domestic nuclear power industry which otherwise would have been exposed to liability far in excess of its ability to pay. The Price-Anderson Act ${ }^{1}$ provided insurance and indemnity for personal injury and property damage should a nuclear accident occur in the United States. The act has been renewed approximately every 10 years, and was amented and renewed on August 20, 1988.

Price-Anderson limits the total liability of the nuclear power industry and provides for Congress to fully compensate all members of the public suffering personal injury or property damage as a result of a nuclear accident. Department of Energy contractors, government licensees and non-profit educational institutions are indemniffed, i.e., protected by the federal government, from liability. Compensation for victims of a nuclear accident is based on a form of strict liability imposed by the act.

Prior to the enactment of the 1988 amendments, liability coverage was limited to $\$ 685$ million; the federal government was not obligated to provide compensation if damage from a nuclear accident exceeded that amount. Congress estimated that damage from a nuclear accident could run into billions; therefore, it raised the industry liability limit to over $\$ 7$ billion and provided that the federal government would ensure full compensation for all victims if damages exceeded $\$ 7$ billion.

\subsubsection{Liability Coverage}

The basic liability coverage under the act is a two-pronged system of insurance and indemnity. The insurance is designed to cover large power plants. and the indemnity applies to small utilities, universities, contractors operating Department of Energy facilities and the transportation of nuclear material to and from these facilities. Both systems cover public liability only (worker's compensation claims, acts of war and damage to the facilities themselves are not covered). ${ }^{2}$ Together both cover potential liability for all parties involved in a nuclear accident and liability is limited under both systems. 


\subsubsection{Insurance}

Three types of insurance exist under Price-Anderson: Facility Form, Industry Retrospective Premium and contractor liability insurance. Facility Form Insurance, or Primary Financial Protection, is required of all nuclear power plants with a capacity greater than 100 megawatts (MWe) of electricity. The amount of Facility Form required for such reactors is the maximum amount of insurance commercially available--currently $\$ 200$ million. $^{3}$ Facility Form is issued by hundreds of insurance companies that have created "pools" of insurance. As more insurers enter the pool, coverage increases.

Industry Retrospective Premium insurance is designed to compensate for damages that exceed the coverage provided by Facility Form. If such damages exceed the $\$ 200$ million mark, claims are divided equally among all nuclear power plants required to carry Industry Retrospective Premium insurance, i.e., all power plants with more than 100 MWe capacity. Should a nuclear accident occur at a plant covered by Facility Form, each plant would be assessed up to $\$ 63$ million, with a maximum assessment in any one year of $\$ 10$ million. ${ }^{4}$ With a total of 109 nuclear plants licensed to operate as of November $1988,{ }^{5}$ a total of $\$ 6.867$ billion is available under Industry Retrospective Premium insurance.

Contractor liability insurance is a discretionary type of insurance that the Secretary of the Department of Energy (DOE) may impose upon DOE contractors. ${ }^{6}$ In practice, while the secretary has had this authority under the act, it has never been exercised, primarily because the cost would simply be passed on to the federal government. ${ }^{7}$ For this reason, the secretary will probably not exercise this authority and this type of insurance will probably not be used under the amended act.

\subsubsection{Government Indemnity}

The federal government indemnifies contractors ${ }^{8}$, licensees ${ }^{9}$ and non-profit educational institutions ${ }^{10}$ for certain activities. Federal government indemnification is provided at no cost to these indemnified parties. Licensees are generally allowed to purchase separate insurance. In fact, licensees required to maintain less than $\$ 560$ million in financial protection by the Nuclear Regulatory Commission (NRC) are indemnified for $\$ 500$ million minus the amount by which 
the required protection exceeds $\$ 60$ million. ${ }^{11}$ Universities are indemnified by the NRC for damages from $\$ 250,000$ to $\$ 500$ million and are permitted to purchase Facility Form insurance ${ }^{12}$ since they do not pass on costs directly.

DOE contractors are indemnified under the 1988 amendments for the amount of the two tiers of financial protection required of large power reactors, currently $\$ 7.067$ billion. Should the number of reactors increase, the contractors' indemnification would increase. If on the other hand, the number of reactors should fall below 109 , the amount of indemnity will not decrease. ${ }^{13}$ This amount of indemnification is a substantial increase over the former limit of $\$ 500$ million and it applies retroactively to all contractors with whom the government entered into indemnirication agreements prior to the effective date of the 1988 amendments. ${ }^{14}$

The 1988 amendments specified that nuclear waste activities are to be indemnified to the limits specified for DOE contractors. Such indemnification agreements provide that federal government indemnity for a contractor involved in a nuclear incident occurring during the storage, handling, transportation, treatment or disposal of spent nuclear fuel, high-level nuclear waste or transuranic waste shall be funded by the Nuclear Waste Fund, established by the Nuclear Waste Policy Act of $1982,{ }^{15}$ in an amount up to $\$ 7.067$ billion. In addition, research and development activities on nuclear waste are covered under the amended act. ${ }^{16}$

\subsubsection{Financial Protection Requirements and Overlapping Coverage}

Nuclear reactors, other than those operated by a federal government agency or a non-profit educational institution, are required to maintain financial protection in various amounts, as shown in Table 7-1.

When one or more insurance or indemnity programs apply to an activity covered in the act, the question arises as to which system or policy should pay first. In some cases, insurance policies covering these activities may specify in the policy. In the two-tiered coverage provided for large commercial power plants, Facility Form insurance pays for the first $\$ 160$ million in damages and, if damages exceed that amount, the Industry Retrospective Premium insurance is activated. 
Table 7-1

Financial Protection for Nuclear Reactors

Authorized Capacity

Amount

10 Kilowatts (KW) or less

$\$ 1,000,000^{17}$

$10 \mathrm{KW}$ to $1 \mathrm{MW}$

$\$ 1,500,000^{16}$

$1 \mathrm{MW}$ to $10 \mathrm{MW}$

$\$ 2,500,000^{19}$

$100 \mathrm{MW}$ or greater

$\$ 160,000,000^{20}$

Other reactors

$\$ 4,500,000$ to $\$ 74,000,000^{21}$

Plutonum Processing and Fuel

Fabrication Plant

$\$ 160,000,000^{22}$

Holder of Nuclear Reactor construction

permit with a license to store

special material for later use as

fuel

$\$ 1,000,000^{2}$

Motor carriers of large quantities of

radioactive materials

$\$ 5,000,000^{24}$

Not every area of Price-Anderson coverage is clear. The role of the Motor Carrier Act of 1980 (MCA), ${ }^{25}$ which applies to all motor carriers of radioactive materials, ${ }^{26}$ is far from certain. The Department of Transportation has indicated that the act's insurance requirements meet MCA guidelines ${ }^{27}$ but figures are unavailable on the number of carriers relying on shippers' insurance or insurance of their own outside of the Price-Anderson system. The legislative history of the MCA makes no reference to Price-Anderson and is therefore inconclusive in resolving the issue.

\subsubsection{Carrier Llabillty}

In 49 CFR 387.1 (1989), DOT regulations provide that carriers operating motor vehicles in intrastate, foreign or interstate commerce must maintain minimum levels of coverage to be considered financially responsible. For-hire 
and private carriers transporting highway route-controlled quantities of radioactive materials, as defined under 49 CFR 172.101, must obtain a minimum of $\$ 5$ million in coverage ( 49 CFR 387.9).

Proof of financial responsibility, consisting of an Endorsement for Motor Carrier Policies of Insurance, a motor carrier surety bond or an ICC authorized self-insurance plan, must be maintained at the motor carrier's principal place of business. The policy of insurance or surety bond must be issued by a company authorized to do business in each state in which the carrier operates or in the state where the carrier has its principal place of business.

\subsection{Funding for Damages Exceeding Price-Anderson's Llability Limits}

\subsubsection{Pre-1988 Funding Sources}

Prior to the 1988 Price-Anderson amendments, uncertainty existed as to which party would compensate victims of a nuclear accident if the total damages exceeded the limits of coverage provided by the act. The act required Congress to investigate such accidents and to take whatever action was necessary to protect the public. There was speculation that such increased compensation, if any, would come from various sources, including the nuclear industry, nuclear manufacturers, suppliers, architects or the federal government. If Congress took no action, property owners would bear the costs.

\subsubsection{Current Law}

The 1988 Price-Anderson amendments make significant and substantive changes in awarding compensation for a nuclear accident. Within 90 days after a determination by a court that the public liability from a single nuclear accident may exceed the applicable liability limits, the President is required to submit to Congress a detailed estimate of damages, recommendations for additional funding sources and one or more compensation plans. ${ }^{28}$

The President is required to consider a broad range of possible funding sources in his recommendations to Congress. The compensation plans must, either individually or collectively, provide for full and prompt compensation for all valid claims, and contain recommendations as to the relief to be provided, including any recommendations that funds be allocated or set aside for the 
payment of claims that may arise as a resuit of injuries that may not be discovered until a later date. The President must also include any additional legislative authorities necessary to implement the compensation plan(s). ${ }^{29}$

\subsection{Trends in Federal Law}

The 1988 amendments to the Price-Anderson Act made some $m_{i}$ jor changes in the act in addition to those changes mentioned above. Some of the changes are summarized below.

\subsubsection{Transportation Coverage}

As mentioned previously, the 1988 amendments expressly extended governmental indemnity to nuclear waste activities and gave a sweeping definition of nuclear waste activities, which includes the transportation of nuclear waste. Transportation of nuclear waste is indemnified to $\$ 7.067$ billion. As the number of large commercial reactors increases, the amount of indemnity for transportation incidents will increase, but the amount of indemnity will not fall below the current amount should the number of large nuclear power plants decrease. ${ }^{30}$

\subsubsection{Theft, Sabotage and Diversion}

The Price-Anderson act has never specifically addressed the issues of theft, sabotage or diversion of nuclear materials and the issue is not addressed in the 1988 amendments. The legislative history does contain, however, proposed amendments to extend coverage for illegal diversion during shipment or from its intended place of confinement. ${ }^{31}$ It appears from the legislative history that an unintended diversion may not be covered by the act. ${ }^{32}$

An act of sabotage considered an act of war would fall outside the Price-Anderson framework. ${ }^{33}$ If not an act of war, it would appear that an act of sabotage could be considered a nuclear incident and would therefore be compensable under Price-Anderson. ${ }^{34}$ 


\subsubsection{Precautionary Evacuations}

Immediately following a spent fuel or high-level waste transportation accident, public authorities may decide that the surrounding area should be evacuated to reduce the risk of injury to nearby persons. After further investigation officials may decide that no release of radioactivity occurred and that the evacuation was unnecessary, as happened in the 1979 Three Mile Island incident. There, the insurance pools reimbursed local residents for their costs of evacuating the area. No provision existed, however, for reimbursement for a precautionary evacuation of an indemnified facility.

The 1988 amendments added precautionary evacuations coverage. Any such precautionary evacuation from the area surrounding a nuclear facility, or from an area near a transportation route, is covered under Price-Anderson, even if the evacuation is the result of an event that is not classified as a nuclear incident (i.e, the event does not cause any personal injuries or property damage). The event, however, must pose imminent danger of property damage or personal injury and the evacuation must be initiated by a political official of the affected state or community who is authorized to initiate such an evacuation and who believes the evacuation to be necessary to reasonably protect public health and safety. All additional costs incurred by the state or community in the course of responding to a nuclear incident or precautionary evacuation are compensable as well.

\subsubsection{Changes in the Statute of Limitations}

Prior to the 1988 amendments, the statute of limitations for claimants under the act was 3 years from the date that the claimant knew or reasonably should have known of the injury, but in no event longer than 20 years after the incident. The 1988 act abolished the "within 20 years" language, and instead kept the 3 years within reasonable discovery of the injury requirement. Thus, illnesses that appear more than 20 years after the date of the accident may be recoverable under the present act. $^{35}$

\subsubsection{Other Changes and Trends}

The 1988 amendments include numerous other changes. Some of the most important provisions are as follow: 
A presidential commission on catastrophic nuclear accidents was created to conduct a comprehensive study of how to fully compensate all members of the public in the event a nuclear incident causes damages in excess of present liability limits. Their final report, to be submitted to Congress by August 1990, will, among other things, contain recommendations for changes in laws and rules governing liability and civil procedure necessary for the prompt, equitable and efficient resolution and payment of claims. ${ }^{36}$

Prior to the enactment of the 1988 amendments, the costs of investigating, settling and defending claims was excluded from the liability ceiling. The amendments permit payment of legal costs from financial protection funds except where the court exercising jurisdiction determines that public liability may exceed the liability limits. If costs exceed the liability limits, then the costs can be authorized only if they are reasonable and equitable and the person requesting payment has litigated in good faith, avoided unnecessary duplication of effort with other parties similarly situated, has not made frivolous claims or defenses and has not attempted to unreasonably delay the prompt settlement or adjudication of claims. ${ }^{37}$ Punitive damages will not be permitted against any party indemnified under the Price-Anderson Act. ${ }^{38}$

The NRC is authorized to borrow funds necessary for the payment of claims when awards will exceed the amount of retrospective premium insurance available during the given year. Such funds borrowed are to be repaid by the utilities, along with interest. ${ }^{39}$

The Price-Anderson Act, as amended, is extended for the next 15 years, as opposed to the previous extensions of only 10 years at a time. ${ }^{40}$

A civil penalty of up to $\$ 100,000$ is authorized for each violation of a rule, regulation or order related to nuclear safety issued by DOE or incorporated by reference and issued by DOT. The secretary of DOE has discretion as to the amount of the fine. Certain named universities and research facilities are exempt from this civil penalty. ${ }^{41}$

A criminal penalty of up to $\$ 25,000$ and a jail term of up to two years is permitted for any director, officer or employee of any DOE contractor indemnified under the act for the knowing or willful violation of any safety rule, regulation or order, and if the violation results in, or would have resulted in, a nuclear incident, the maximum penalty is a $\$ 50,000$ fine and five years imprisonment. ${ }^{42}$

The NRC is required to adjust the amount of the standard deferred premium for inflation every 5 years in accordance with the aggregate change in the Consumer Price Index. ${ }^{43}$ 
The chief judge of the court exercising jurisdiction over the claims arising from a nuclear incident is authorized to appoint a case management panel to coorcinate and assign the cases arising from the incident. ${ }^{44}$

\subsection{Possible Changes in State Laws}

\subsubsection{Changes in Statutes of Limitations}

As discussed previously, the statute of limitations under the current act is three years from the date of discovery. If a state statute of limitations is longer, then the state standard controls. The 1988 amendments, eliminating the previous 20-year maximum time on initiating suit, probably has eliminated the need for a longer statute of limitations to cover possible damage from a nuclear accident.

\subsubsection{Proof of Causation}

Under traditional legal standards of proof, the plaintiff must establish that his injuries were caused by the actions of the defendant. It is difficult for people injured by radiation to prove that their illnesses were caused by the radiation since medical research has not fully established the causal connection between radiation and some types of disease. In addition, many diseases have more than one cause.

Neither Price-Anderson nor the FTCA mentions standards of proof; state law thus controls in all cases. Courts in some jurisdictions have established special rules to determine causation, especially in the analogous area of exposure to toxic substances. These rules allow for the admission of statistical evidence concerning the probability of the instance of the disease. This is an area in which, in the future, many states may create their own judicial and legislative rules.

\subsubsection{Sovereign Immunity}

The expansion of the waiver of defenses to all nuclear incidents seems to have eliminated the possibility of a state asserting the defense of sovereign immunity in suits concerning a nuclear accident. The issue, as with the issues of statutes of limitations and standards of liability, probably has been rendered moot by the 1988 Price-Anderson Act amendments. 


\subsubsection{Recovery of Emergency Response Costs}

The 1988 amendments to the Price-Anderson Act again may have an impact on this area of state concern. The act does not specifically mention emergency response costs but it does provide for coverage for the related precautionary evacuation. 


\section{NOTES FOR CHAPTER 7.0}

${ }^{1}$ As amended, at 42 USC $\$ \$ 2014$ and 2210; also referred to as $\$ \$ 11$ and 170 of the Atomic Energy Act.

${ }^{2} 42$ USC $\$ 2014(w)$.

${ }^{3} 42$ USC $\$ 2210(b)$.

${ }^{4}$ Ibid.

${ }^{5}$ Info, U.S. Council of Energy Awareness, Number 234, August 1988, p.1. This estimate of the number of commercial nuclear power reactors licensed to operate in the U.S. may be somewhat conservative. Senate estimates of the number of commercial power generators are 110 or 111 licensed to operate at the time of passage of the Price-Anderson Amendments Act, while House of Representatives estimates are 109 or 110 .

${ }^{6} 42$ USC $\$ 2210(d)(2)$.

${ }^{7}$ Report to House Committee on Energy and Commerce on the Price-Anderson Amendments Act of 1988, p.15.

${ }^{8} 42$ USC $\$ 2210$ (d).

${ }^{9} 42$ USC \$2210(c).

${ }^{10} 42$ USC \$2210(k).

${ }^{11} 42$ USC \$2210(c).

${ }^{12} 42$ USC \$2210(k).

${ }^{13} 42$ USC §2210(d)(3)(B).

${ }^{14} 42$ USC \$2210(d)(3)(C).

${ }^{15} 42$ USC \$2210(d)(1)(B)(II)(ii).

${ }^{16} 42$ USC \$2210(d).

${ }^{17} 10$ CFR $\S 140.11$.

${ }^{18}$ Ibid.

${ }^{19}$ Ibid.

${ }^{20}$ Ibid.

${ }^{21}$ Ibid.

${ }^{22} 10$ CFR \$140.13a.

${ }^{23} 10$ CFR \$140.13.

${ }^{24} 49$ CFR $\S \S 387.7$ and 387.9 , as required by $\S 30$ of the Motor Carrier Act of 1980. 
${ }^{25} 49$ USC $\$ \$ 10101-11902 a$ (various sections).

${ }^{26} 49$ CFR $\S \S 387.7$ and 387.9.

${ }^{27}$ Spent Nuclear Fuel and Figh Level Radioactive Waste Transportation Primer, Western Interstate Energy Board, June 1985, p.5-3.5.

${ }^{28} 4.2$ USC $\$ 2210(i)(2)$.

${ }^{29} 42$ USC $\$ 2210(\mathrm{i})(2)$.

${ }^{30} 42$ USC \$2210(d)(3)(B).

${ }^{31}$ Senate Report No. 100-70, U.S. Code Congressional \& Administrative News, No. 7, October 1988, p.1425.

${ }^{32}$ Ibid.

${ }^{33} 42$ USC $\$ 2014(w)$.

${ }^{34} 42$ USC $\S 2014$ (q).

${ }^{35} 42$ USC $\$ 2210(\mathrm{n})$.

${ }^{36} 42$ USC \$2210(1)(3)(A).

${ }^{37} 42$ USC $\$ 2210(0)(2)$.

${ }^{38} 42$ USC §2210(s).

${ }^{39} 42$ USC \$2210(b)(4)(B).

${ }^{40} 42$ USC $\$ 2210$ note.

${ }^{41} 42$ USC §2282(a).

${ }^{42} 42$ USC \$2273.

${ }^{43} 42$ USC $\$ 2210(t)$.

${ }^{44} 42$ USC $\$ 2210(3)(A)$. 


\section{GLOSSARY OF TIERMS}

activation

ALARA

alpha particle

background radiation

beta particle

biological

halflife

boiling water reactor (BWR)
The process of making a material radioactive by bombardment with neutrons, protons or other nuclear radiation.

"As Low as Reasonably Achievable," a basic concept of radiation protection that specifies that radioactive discharges from nuclear plants and radiation exposure to personnel be kept as far below regulation limits as feasible. The term was originally "As Low as Practicable."

A positively charged particle ejected spontaneously from the nuclei of some radioactive elements. It is identical to a helium nucleus that has a mass number of 4 and an electrostatic charge of +2 . It has low-penetrating power and short range. The most energetic alpha particle will generally fail to penetrate the skin. Alphas are hazardous when an alpha-emitting isotope is introduced into the body.

The radiation in man's natural environment, including cosmic rays and radiation from the naturally radioactive elements, both outside and inside the bodies of humans and animals. It is also called natural radiation. The usually quoted average individual exposure from background radiation is 125 millirem per year.

A charged particle emitted from a nucleus during radioactive decay, with a mass equal to $1 / 1837$ that of a proton. A negatively charged beta particle is identical to an electron. A positively charged beta radiation may cause skin burns, and beta emitters are harmful if they enter the body. Beta particles are easily stopped by a thin sheet of metal or plastic. The time required for a biological system, such as that of a human, to eliminate by natural processes half the amount of a substance (such as a radioactive material) that has entered it.

A reactor is which water, used as both coolant and moderator, is allowed to boil in the core. The resulting steam can be used directly to drive a turbine and electrical generator. 
burnup

BWR

cask

certificate of

compliance

chain reaction

charged particle

cladding

commercial waste

contact-handled

waste

containment

system

contamination

control rod
A measure of how much energy is produced (or fissile material is consumed) during its operation in a reactor.

A boiling water reactor.

A heavily shielded container used to store and/or ship radioactive materials. Lead and steel are common materials used in the manufacture of casks.

An approval of package designs issued upon demonstration that the package designs meet applicable performance standards.

A reaction that stimulates its own repetition. In a fission chain reaction, a fissionable nucleus absorbs a neutron and fissions, releasing additional neutrons. These in turn cail be absorbed by other fissionable nuclei, releasing still more neutrons. A fission chain reaction is self-sustaining when the number of neutrons released in a given time equals or exceeds the number of neutrons lost by absorption in non-fissionable material or by escape from the system.

An ton. An elementary particle carrying a positive or negative electric charge.

The thin-walled metal tube that forms the outer jacket of a nuclear fuel rod. It prevents corrosion of the fuel by the coolant and the release of fission products into the coolant. Aluminum, stainless steel and zirconium alloys are common cladding materials.

Nuclear waste deriving from commercial sources such as power reactors, research laboratories and medical facilities. Waste that does not require shielding other than that provided by its container.

The components of the packaging intended to retain the radioactive contents during transportation.

The deposition of unwanted radioactive material on the surfaces of structures, areas, objects or personnel.

A rod, plate or tube containing a material such as hafnium, boron, etc., used to control the power of a nuclear reactor. By absorbing neutrons, a control rod prevents the neutrons from causing further fission. 
critical mass

criticality

crud

cumulative dose

curie

(Ci)

decay heat

decay, radioactive

decontamination
The smallest mass of fissionable material that will support a self-sustaining chain reaction.

A term used in reactor physics to describe the state when the number of neutrons released by fission is exactly balanced by the neutrons being absorbed (by the fuel and poisons) and escaping the reactor core. A reactor is said to be "critical" when it achieves a self-sustaining nuclear chain reaction.

A colloquial term for corrosion and wear products (rust particles, etc.) that become radioactive under a radiation flux.

The total dose resulting from repeated exposures of radiation to the same region, or to the whole body, over a period of time.

The basic unit used to describe the intensity of radioactivity in a sample of material. The curie is equal to 37 billion disintegrations per second, which is approximately the rate of decay of 1 gram of radium. A curie is also a quantity of any radionuclide that decays at a rate of 37 billion disintegrations per second. Named for Marie and Pierre Curie, who discovered radium in 1898.

The heat produced by the decay of radioactive fission products after the reactor has been shut down.

The decrease in the amount of any radioactive material with the passage of time, due to the spontaneous emission from the atomic nuclei of either alpha or beta particles, often accompanied by gamma radiation. (See halflife).

The reduction or removal of contaminating radioactive material from a structure, area, object or person. Decontamination may be accomplished by (1) treating the surface to remove or decrease the contamination; (2) letting the material stand so that the radioactivity is decreased as a result of natural decay; and (3) covering the contamination to shield or attenuate the radiation emitted. 
defense waste

dose

dose equivalent

dose rate

effective halflife

exposure

external radiation

fissile material
Nuclear waste derived from the manufacture of nuclear weapons and the operation of naval reactors. Associated activities such as the research carried on in weapons laboratories also produce defense waste.

A quantity (total or accumulated) of ionizing radiation received. The term "dose" is often used in the sense of exposure dose, expressed in roentgens, which is a measure of the total amount of ionization that the quantity of radiation could produce in air. This should be distinguished from the absorbed dose, given in rads, that represents the energy absorbed from the radiation in a gram of any material. Furthermore, the biological dose, given in rem, is a measure of the biological damage to living tissue from the radiation exposure.

A term used to express the amount of effective radiation when modifying factors have been considered. The product of absorbed dose multiplied by a quality factor multiplied by a distribution factor. It is expressed numerically in rem.

The radiation dose delivered per unit of time. Measured, for example, in rem per hour.

The time required for the amount of a radioactive element deposited in a living organism to be diminished 50 percent as a result of the combined action of radioactive decay and biological elimination. (See biological halflife).

The absorption of radiation or ingestion of a radionuclide. Acute exposure is generally accepted to be a large exposure received over a short period of time. Chronic exposure is exposure received during a lifetime. (See dose).

Exposure to ionizing radiation when the radiation source is located outside the body.

Although sometimes used as a synonym for fissionable material, this term has acquired a more restricted meaning; namely, any material fissionable by thermal (slow) neutrons. The three primarily fissile materials are uranium-233, uranium-235 and plutonium-239. 
fission

fission gases

fission products

flux

fuel assembly

fuel burnup, exposure

fuel cycle

fuel rod

gamma ray (gamma radiation)
The splitting of a nucleus into at least two other nuclei and the release of a relatively large amount of energy. Two or three neutrons are usually released during this type of transformation.

Those fission products that exist in the gaseous state. Primarily the noble gases (krypton, xenon, radon, etc.).

The nuclei (fission fragments) formed by the fission of heavy elements, plus the nuclides formed by the fission fragments' radioactive decay.

A term applied to the amount of some type of radiation crossing a certain area per unit time. The unit of flux is the number of particles, energy, etc., per square centimeter per second.

A cluster of fuel rods (or plates). Also called a fuel element. Many fuel assemblies make up a reactor core.

Induced nuclear transformation of atoms during reactor operation, expressed as the total energy released per initial unit mass of fuel as a result of irradiation.

The series of steps involved in supplying fuel for nuclear power reactors. It can include mining, milling, isotopic eririchment, fabrication of fuel elements, use in a reactor, chemical reprocessing to recover the fissionable material remaining in the spent fueh reenrichment of the fuel material, refabrication into new fuel elements and waste disposal.

A long, slender tube that holds fissionable material (fuel) for nuclear reactor use. Fuel rods are assembled into bundles called fuel elements or fuel assemblies, which are loaded individually into the reactor core.

High-energy, short wavelength electromagnetic radiation (a packet of energy) emitted from the nucleus. Gamma radiation frequently accompanies alpha and beta emissions and always accompanies fission. Gamma rays are very penetrating and are best stopped or shielded against by defense materials, such as lead or uranium. Gamma rays are similar to $X$-rays, but are usually more energetic. 
gas-conled

reactor

halflife

halflife, biological halflife, effective

health physics

highways routecontrolled quantity ionizing radiation

light-water reactor

man-rem

mill tailings
A nuclear reactor in which gas is the coolant.

The time in which half the atoms of a particular radioactive substance disintegrate to another nuclear form. Measured halfives vary from millionths of a second to billions of years. Also called physical halflife.

The time required for the body to eliminate half of the material taken in by natural biological means.

The time required for a radionuclide contained in a biological system, such as a human or an animal, to reduce its activity by half as a combined result of radioactive decay and biological elimination.

The science concerned with recognition, evaluation and control of health hazards from ionizing radiation.

A quantity within a single package that exceeds 3000 times the $A_{2}$ value of the radionuclides as specified in 49 CFR 173.433 for special form radioactive matirial; 3000 times the $A_{2}$ value of the radionuclides as specified in 49 CFR 173.433 for normal-form radioactive material; or $30,000 \mathrm{Ci}$, whichever is least.

Any radiation capable of displacing electrons from atoms or molecules, thereby producing ions. Exar.ples: alpha, beta, gamma, X-rays, neutrons and ultraviolet light. High doses of ionizing radiation may produce severe skin or tissue damage.

A term used to designate reactors using ordinary water as coolant, including boiling water reactors (BWRs) and pressurized water reactors (PWRs), the most common types used in the United States.

A unit of population dose; the total radiation dose commitment to a given population group; the sum of the individual doses received by a population segment.

Naturally radioactive residue from the processing of uranium ore into yellowcake in a mill. Although the milling process recovers about 93 percent of the uranium, the residues, or tailings, contain several radioactive elements, including uranium, thorium, radium, polonium and radon. 
nuclear fuel

package

packaging

particulates

pellet, fuel

pressurized water reactor (PWR)

primary cask coolant rad

radiation shielding

reactivity

SARP

rem
Material containing fissile nuclides that, when placed in a reactor, enables a self-sustaining nuclear chain reaction to take place.

The shipping container that includes the contents (package equals packaging plus contents).

The shipping container without its contents.

Small solid particles. One form in which radionuclides can be released as the result of a potential accident.

As used in PWRs and BWRs, a pellet is a small cylinder approximately 3/8-inch in diameter and 5/8-inch in length consisting of uranium fuel in a ceramic form--urainum dioxide, $\mathrm{UO}_{2}$. Typical fuel pellet enrichments range from 2 to 3.5 percent uranium-235.

A power reactor in which heat is transferred from the core to a heat exchanger by high-temperature water kept under high pressure in the primary system. Steam is generated in a secondary circuit. Many reactors producing electric power are pressurized water reactors.

The fluid (or liquid or gas) that transfers heat from the fuel assemblies to the inner wall of the cask.

Acronym for radiation absorbed dose. The basic unit of absorbed dose of radiation. A dose of one rad means the absorption of 100 ergs (a small but measurable amount of energy) per gram of absorbing material.

Reduction of radiation by interposing a shield of absorbing material between any radioactive source and a person, work area or radiation-sensitive device.

A parameter giving the deviation from criticality of a nuclear chain-reacting medium such that positive values of correspond to a supercritical state and negative values to a subcritical state.

Safety Analysis for Packaging: a report for submittal to the NRC that describes the technical basis for assuring the agency that a cask meets all regulatory requirements.

Acronym of roentgen equivalent man. The unit of dose of any ionizing radiation that produces the same biological effect as a unit of absorbed dose of ordinary $\mathrm{X}$-rays. 
rod

consolidation spent (depleted)

fuel

spent fuel pool

trunnion

Type A quantity radioactive material

Type A packaging

Type B quantity radioactive material

Type B packaging

waste, radioactive
Disassembly of spent fuel assemblies to obtain a smaller volume of fuel rods.

Nuclear reactor fuel that has been used to the extent that it can no longer effectively sustain a chain reaction.

An underwater storage and cooling facility for fuel elements that have been removed from a reactor.

A structural member attached to the cask and used to lift and rotate the cask and occasionally fasten it to the transporting vehicle.

The quantity of radioactive material, excluding LSA, that may be transported in Type A packaging. This number is based on the radiotoxicity of the radionuclides.

Packaging that is adequate to prevent the loss or dispersal of its radioactive contents if the package it subjected to "normal" conditions of transport tests. No accident resistance is specifically required because of the low risk presented by the contents.

The quantity of radioactive material, except LSA, that must be transported in Type B packaging.

Packaging that is adequate to prevent the loss or dispersal of its radioactive contents if the package is subjected to both "normal" and "hypothetical accident" conditions of transport.

Solid, liquid and gaseous materials from nuclear operations that are radioactive or have become radioactive and for which there is no further use. Wastes are generally classified as high-level (having radioactivity concentrations of hundreds of thousands of curies per gallon or cubic foot), low-level (in the rage of 1 microcurie per gallon or cubic foot) or intermediate level (between these extremes).

Sources: Glossary of Terms, Nuclear Power and Radiation, U.S. Nuclear Regulatory Commission, June 1981. [NUREG-0770].

U.S. Department of Energy, Cask Safety Meeting, Salt Lake City, Utah, February 6-7, 1986. 


\section{SELECTED BIBLIOGRAPHY}

Analysis of Radiation Doses From Operation of Postulated Commercial Spent Fuel Transportation Systems. U.S. Department of Energy, November 1988, [DOE/CH/TPO-001].

Barret, Lake H. "Review and Status of the DOE Cask Acquisition Program." Journal of the Institute of Nuclear Materials M(anagement. XV (April 1987).

"Cooperative Demonstration Projects for Spent Nuclear Fuel." OCRWM Backgrounder. U.S. Department of Energy, Office of Civilian Radioactive Waste Management, April 1987 [DOE/RW-0138].

Dennis, A.W. et al. NNWSI Repository Operational Procedures for Receiving Packaging Emplacing and Retrieving High-Level and Transuranic Waste. Sandia National Laboratories, 1984 [SAND83-1166].

Emergency Management Institute Course Catalogue, 1988/89. Federal Emergency Management Agency.

Environmental Assessment: Deaf Smith County Site, Texas, Volume I. U.S. Department of Energy, Office of Civilian Radioactive Waste Management, May 1986. [DOE/RW-0069].

An Evaluation of Commercial Repository Capacity for the Disposal of Defense High-Level Waste. U.S. Department of Energy, Assistant Secretary for Defense Programs, June 1985. [DOE/DP/0020/1].

Federal Radiological Emergency Response Plan. Federal Emergency Management Agency, Federal Register, November 8, 1985. p.46542.

Final Environmental Statement on the Transportation of Radioactive Material by Air and Other Modes. U.S. Nuclear Regulatory Commission, December 1977. [NUREG-0170].

Final Version Dry Cask Storage Study. U.S. Department of Energy, Office of Civilian Radioactive Waste Management, February 1989. [DOE/RW-0220].

Financial Protection Against Nuclear Hazards: Thirty Years' Experience Under the Price-Anderson Act. New York: Trustees of Columbia University, 1984.

Fore, C.S. et al. Transportation of Radioactive and Hazardous Materials: A Summary of State and Local Legislative Requirements for the Period Ending September 30, 1983. Oak Ridge National Laboratory, June 1984. [ORNL/TM-8860]. 
Guidance for Developing State and Local Radiological Emergency Response Plans and Preparedness for Transportation Accidents. Federal Emergency Management Agency, August 1988. [FEMA REP-5, draft revision].

Guidelines for Selecting Preferred Routes for Large Quantity Shipments of Radioactive Materials. U.S. Department of Transportation, June 1981. [DOT-RSPA/MTB-81].

Have Waste, Will Travel: An Examination of the Implications of High-Level Nuclear Waste Transportation. Natural Hazard Research. The University of Colorado, July 1987. [Working Paper \#59].

High-Level and Transuranic Radioactive Wastes: Background Information Document for Final Rule. U.S. Environmental Protection Ageny, Office of Radiation Program, August 1985. [EPA 520/1-85-023].

HIGHWAY, a Transportation Routing Model: Program Description and Revised User's Manual. Oak Ridge National Laboratory, October 1983. [ORNL/TM-8759].

Hull, Andrew P. and Edward T. Lessard. Risk Comparisons for the Transportation of Spent Fuel From Nuclear Reactors. Brookhaven National Laboratory, Safety and Environmental Protection Division, April 1985. [BNL-36390].

Implementation Plan for Deployment of Federal Interim Storage Facilities for Commercial Spent Nuclear Fuel. Pacific Northwest Laboratory, January 1985. [DOE/RW-0019].

Index to Preemption of State and Local Laws and Regulations under the Hazardous Materials Transportation Act. U.S. Department of Transportation, Research and Special Programs Administration, June 5, 1989.

Integrated Data Base for 1989: Spent Fuel and Radioactive Waste Inventories, Projections, and Characteristics. U.S. Department of Energy, September 1989. [DOE/RW-0006].

INTERLINE, a Railroad Routing Model: Program Description and User's Manual. Oak Ridge National Laboratory, November 1985 [ORNL/TM-8944]. Jordan, Jules, and Barbara Foster. Rail Transport of Spent Fuel and High-Level Waste. Denver, CO: National Conference of State Legislatures, August 1986.

Kunita, R.K., R.W. Lambert and M.L. Smith. "At-Reactor Storage: A Progress Report." Waste Management '85. vol. 1, March 24-28, 1985, pp. 357-361. 
Lambert, R.W. et al., "Waste Management Storage: A Progress Report." Waste Management '86 Proceedings. March 1985.

Lessons Learned by Southern States in Designating Alternative Routes. Southern States Energy Board, September 1990.

Managing the Nation's Commercial High-Level Radioactive Waste. Congress of the United States, Office of Technology Assessment, March 1985. [OTA-O-171].

Managing the Nation's Nuclear Waste: A Guide to OCRWM Transportation Program Responsibilities. U.S. Department of Energy, February 1986. [DOE/RW-0148].

Managing the Nation's Nuclear Waste: The Ilustrated Mechanics of Nuclear Waste Disposal. U.S. Department of Energy, October 1985, [DOE/RW-0054].

Managing the Nation's Nuclear Waste: Implementation of the Nuclear Waste Policy Act of 1982 . U.S. Department of Energy, February 1986. [DOE/RW-0062].

Managing the Nation's Nuclear Waste: Opportunities for Participation in the OCRWM Transportation Program, U.S. Department of Energy, April 1987, [DOE/RW-0171].

Managing the Nation's Nuclear Waste: Overview-Nuclear Waste Policy Act. U.S. Department of Energy, October 1985. [DOE/RW-0053].

McNair, G.W. "Analysis of Potential Effects of an MRS Facility on Spent Fuel Transportation Requirements." Waste Management '85. vol. 1, March 24-28, 1985, pp. 373-374.

Mission Plan for the Civilian Radioactive Management Program, Volume 1. U.S. Department of Energy, Office of Civilian Radioactive Waste Management, June 1985. [DOE/RW-0005].

Mutual Assistance Agreements for Radiological Emergency Response. Southern States Energy Board, November, 1988.

Nuclear Materials Transportation: Safety Concerns, Governmental Regulations and Activities, and Options to Improve Federal Programs. Library of Congress, Congressional Research Service, Report No. 84-45SPR, March 1984.

Nuclear Waste Policy Act (NWPA) of 1982, Pub. L. No. 97-425, 96 Stat. 2201 (1983). 
Nuclear Waste Policy Amendments Act of 1987, Pub. L. 100-203, 101 Stat. 1330-227 (Title 5. Subtitle A. \$5001 et seq., 1987).

Nuclear Waste Policy Act Environmental Assessments, Yucca Mountain Site.

U.S. Department of Energy, Office of Civilian Radioactive Waste Management. May 1986. [DOE/RW-0073].

The Nuclear Waste Primer: A Handbook for Citizens. New York, NY: Nick Lyons Books, 1985.

A Nuclear Waste Primer. 2nd. ed. Washington, D.C.: League of Women Voters of the United States, 1982.

Office of Civilian Radioactive Waste Management: Annual Report to Congress. U.S. Department of Energy, Office of Civilian Radioactive Waste Management, March 1986. [DOE/RW-0004/2].

Office of Civilian Radioactive Waste Management: Annual Report to Congress. U.S. Department of Energy, Office of Civilian Radioactive Waste Management, March 1987. [DOE/RW-0144].

Office of Civilian Radioactive Waste Management: Annual Report to Congress. U.S. Department of Energy. Office of Civilian Radioactive Waste Management, March 1988. [DOE/RW-0189].

Overcast. Thomas D. and Barbara Schuknecht. Federal Preemption of State and Local Nuclear Transportation Regulations. Battelle Human Affairs Research Centers, Science and Government Study Center, January 1985. [SAND85-7180].

Preliminary Analysis of the Cost and Risk of Transporting Nuclear Waste to Potential Candidate Commercial Repository Sites. Sandia National Laboratories, June 1983. [SAND83-0867].

Preliminary Cost and Risk Analysis of Transporting Spent Fuel and High-Level Wastes to Candidate Klepository Sites. Sandia National Laboratories, October 1984. [SAND84-1795].

Public Information Circular for Shipments of Irradiated Reactor Fuel. NRC Office of Nuclear Material Safety and Safeguards, April 1988. [NUREG-0725, rev. 6].

Radioactive Material (RAM Accident/Incident Analysis Program. Sandia National Laboratories, March 1985. [NUREG/CR-3611).

Radioactive Material (RAM) Transportation Accident/Incident Analysis Program. Sandia National Laboratories, March 1986. [SAND85-1016]. 
Radioactive Waste Management: A Summary of State Laws and Administration. EG\&G Idaho, Inc., December 1986. [DOE/LLW-18T, rev. 6].

RADTRAN II Users Guide. Sandia National Laboratories, February 1983. [SANDE,-2681].

Roddy, J.W. et al. Physical and Decay Characteristics of Commercial LWR Spent Fuel. Oak Ridge National Laboratory, January 1986. [ORNL/TM-9591].

Safety Series No. 6: International Atomic Energy Agency Staridards: Regulations for the Safe Transport of Radioactive Materials. International Atomic Energy Agency, Vienna, Austria, 1979.

Sell, Charles E. and Bradford W. Welles. An Assessment of the U.S. Department of Transportation's Radioactive Materials Routing Report. International Energy Associates, January 1986.

"Shipping Cask Analysis System." Energy and Technology Review. June 1989. Shipping Container Response to Severe Highway and Railway Accident Conditions, Volume 1. Lawrence Livermore National Laboratory, February 1987. [NURF,G/CR-4829].

Siting of an MRS Facility: Identification of a Geographic Region that Reduces Transportation Requirements. Pacific Northwest Laboratory, April 1985. [PNL-5424].

Southern States Radiological Emergency Resphnse Laws and Regulations. Southern States Energy Board, May 1989.

Southern States' Routing Agency Report. Southern States Energy Board, February 1989.

Spent Nuclear Fuel and High-Level Radioactive Waste Transportation Primer. Southern States Energy Board, July 1987.

Spent Nuclear Fuel and High-Level Radioactive Waste Transportation Primer. Western Interstate Energy Board, June 1985.

Stahkopf, Karl et al. "Geologic Disposal of Nuclear Waste." EPRI Journal (May 1982).

State Legislative Report: Nuclear Waste Policy Amendments Act of 1987. Denver, CO: National Conference of State Legislatures, May 1988.

"Status of Cask Design Effort." OCRWM Bulletin. August 1988.

"Status of Study on Fuel Burnup Credit," OCRWM Bulletin. March 1989. 
"Storage and Transport Casks Combine to Bring Benefits." Nuclear Engineering International. December 1988.

TRANSNET-Access to Advanced Transportation Risk Analysis Techniques. Sandia National Laboratories, N.d. [SAND88-2809CO].

Transportation Business Plan. U.S. Department of Energy, Office of Civilian Radioactive Waste Management, January 1986. [DOE/RW-0046].

Transportation Impacts of the Commercial Radioactive Waste Management Program. Sandia National Laboratories, April 1986. [SAND85-2715].

Transportation Institutional Plan. U.S. Department of Energy, August 1986. [DOE/RW-0094].

Transportation of Radioactive Materials: A Summary of State and Local Legislative Requirements for the Period Ending December 31, 1985. Oak Ridge National Laboratory, April 1986. [ORNL/TM-9985].

Transporting Spent Fuel. U.S. Nuclear Regulatory Commission, March 1987. [NUREG/BR-0111].

Transporting Spent Nuclear Fuel: An Overview. U.S. Department of Energy, Office of Civilian Radioactive Waste Management, March 1986. [DOE/RW-0065].

Wolff, Theodore A. The Transportation of Nuclear Materials. Sandia National Laboraotories, Transportation Technology Center Development, December 1984. [SAND84-0062]. 


\section{TABLE OF CASES}

City of New York v. U.S. Department of Transportation, 715 F.2d. 732 (2nd Cir. 1983).

National Tank Truck Carriers, Inc. v. Burke, 535 f. Supp. 509 (D.R.I. 1982), affd 698 F.2d. 559 (1st Cir. 1983).

National Tank Truck Carriers, Inc. v. City of New York, 677 F.2d. 270 (1982). 

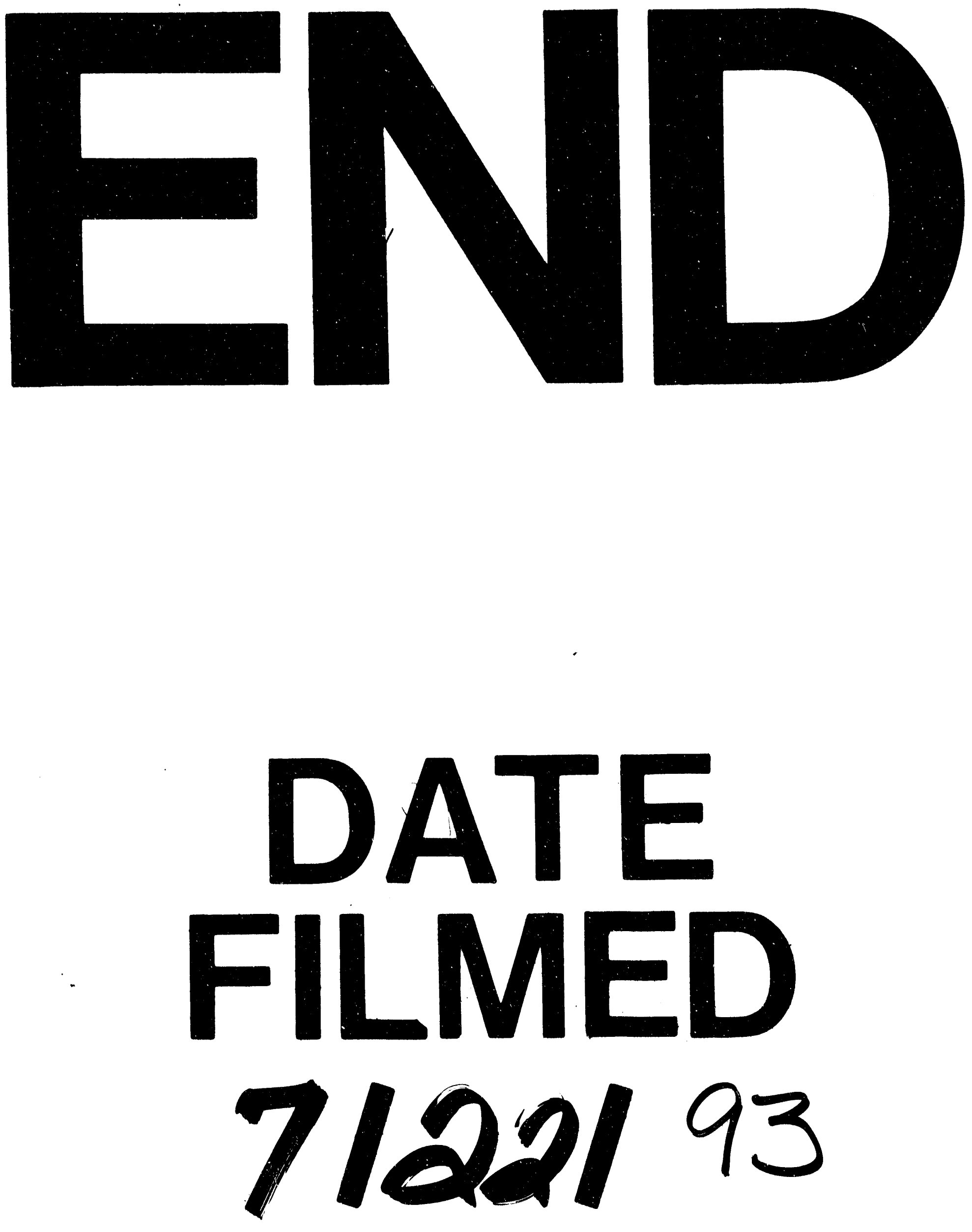
